Aus der Klinik für Kinder und Jugendmedizin, Abteilung Neuropädiatrie (Prof. Dr. med. J. Gärtner) der Medizinischen Fakultät der Universität Göttingen

\title{
Biologische Mechanismen und pharmakologische Induzierbarkeit von translationalem Readthrough
}

\author{
INAUGURAL-DISSERTATION \\ zur Erlangung des Doktorgrades \\ der Medizinischen Fakultät der \\ Georg-August-Universität zu Göttingen
}

vorgelegt von

Lina Karen Werfel

aus

Hannover

Göttingen 2020 
Dekan: Prof. Dr. med. W. Brück

\section{Betreuungsausschuss}

Betreuer/in:

Ko-Betreuer/in:

\section{Prüfungskommission}

Referent/in:

Ko-Referent/in:

Drittreferent/in:

Datum der mündlichen Prüfung:
PD Dr. rer. nat. S. Thoms

Prof. Dr. med. M. Sereda

Prof. Dr. rer. nat. S. Thoms

Prof. Dr. med. M. Sereda

Prof. Dr. hum. biol. M. Schön

09.12.2021 
Hiermit erkläre ich, die Dissertation mit dem Titel "Biologische Mechanismen und pharmakologische Induzierbarkeit von translationalem Readthrough" eigenständig angefertigt und keine anderen als die von mir angegebenen Quellen und Hilfsmittel verwendet zu haben.

Göttingen, den

(Unterschrift) 


\section{Inhaltsverzeichnis}

Abbildungsverzeichnis .................................................................................. III

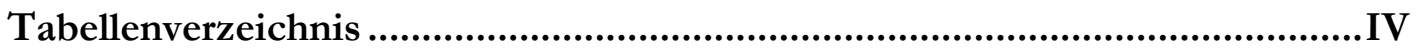

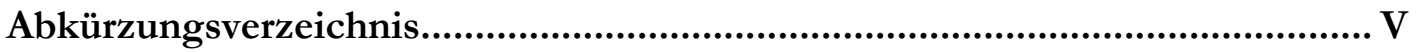

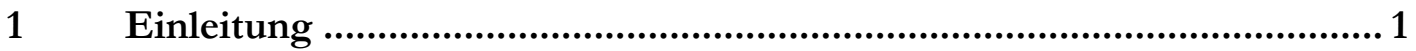

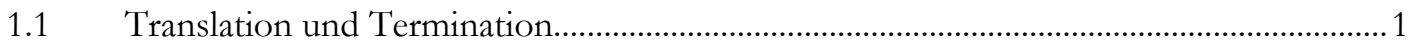

1.2 Endogener translationaler Readthrough und induzierter translationaler Readthrough .. 2

1.3 Die Malatdehydrogenase 1 und die Laktatdehydrogenase B im Peroxisom von Säugetieren und Nichtsäugetieren.......................................................................................

1.3.1 Klinischer Bezug: Peroxisomale Erkrankungen .............................................................

1.4 Einfluss von distalen und proximalen Nukleotiden des Stopcodon-Kontexts auf den endogenen translationalen Readthrough

1.5 Induzierbarkeit von translationalem Readthrough von Nonsense-Mutationen beim

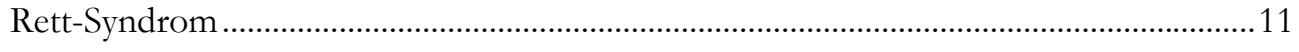

1.6 Fragestellungen der Arbeit.......................................................................................12

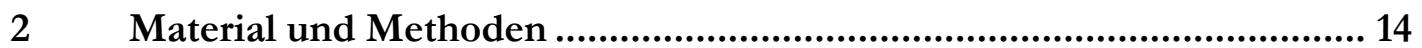

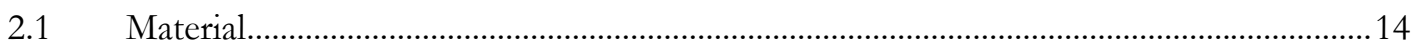

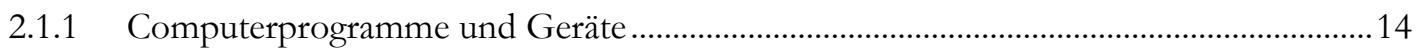

2.1.2 Verbrauchsmaterialien ...........................................................................................16

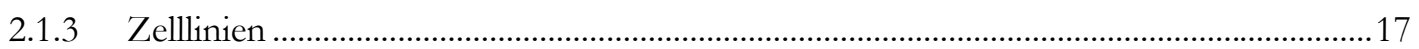

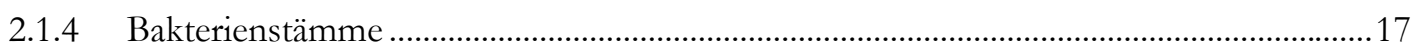

2.1.5 Plasmide und Primer.................................................................................................17

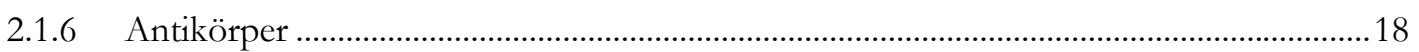

2.1.7 Kits und Chemikalien .............................................................................................. 19

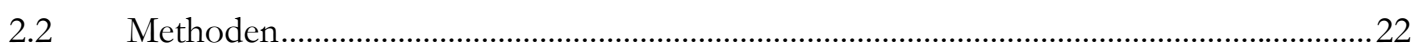

2.2.1 Verwendete Zelllinien und deren Kultivierung .............................................................2 22

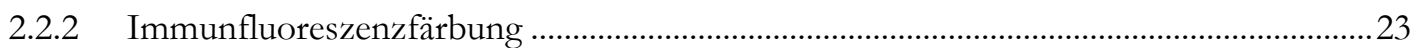

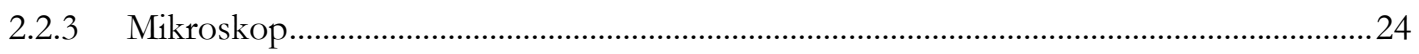

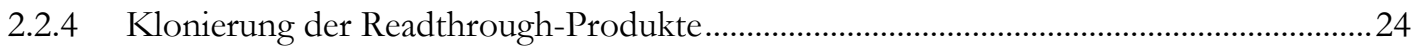

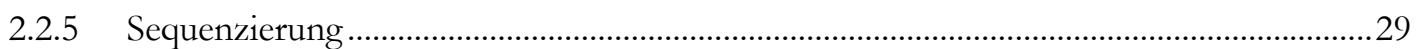

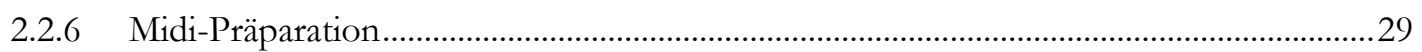

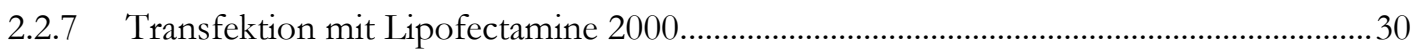

2.2.8 Induktion von Readthrough mit Geneticin ................................................................... 31

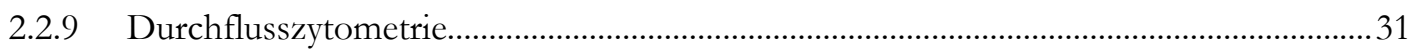

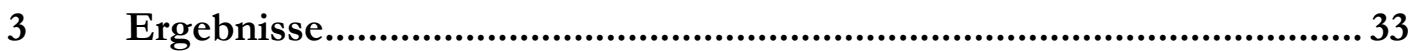

3.1 Durchflusszytometrie zur quantitativen Messung von translationalem Readthrough..33

3.2 Vergleich von translationalem Readthrough in Zellen von Nichtsäugetieren und

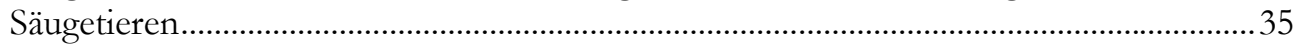

3.2.1 Der Nachweis von LDHB(x) im Peroxisom von Nichtsäugetieren ................................36 
3.2.2 Der translationale Readthrough der MDH1(x) und LDHB(x) in Zellen von Nichtsäugetieren.

3.3 Beitrag von proximalen und distalen mRNA-Elementen zum translationalen

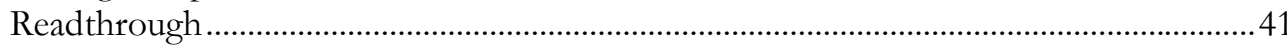

3.3.1 Beitrag von proximalen mRNA-Elementen zum translationalen Readthrough ..............42

3.3.2 Beitrag von distalen mRNA-Elementen zum translationalen Readthrough....................43

3.4 Krankheitsbezogene Untersuchungen zum Readthrough: Evaluation der Induzierbarkeit von translationalem Readthrough bei den häufigsten NonsenseMutationen beim Rett-Syndrom

Diskussion. 


\section{Abbildungsverzeichnis}

Abbildung 1: Schematische Darstellung der Translation. ................................................................. 2

Abbildung 2: Schematische Darstellung der Translation bei Nonsense-Mutationen......................6

Abbildung 3: Schematische Darstellung eines Konstrukts für den dualen Reporter. ...................33

Abbildung 4: Darstellung des Streudiagramms durchflusszytometrischer Messungen des translationalen Readthrough. ............................................................................................. 35

Abbildung 5: Immunfluoreszenzfärbung der LDHB(x) und des Proteins PMP70 in untransfizierten CEF-Zellen.............................................................................................

Abbildung 6: Auswertung der Immunfluoreszenzfärbung der LDHB(x) im Peroxisom in

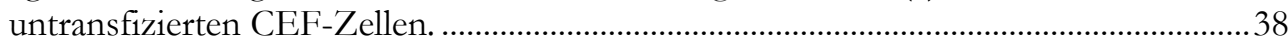

Abbildung 7: Immunfluoreszenzfärbung der MDH1(x) und des Proteins PMP70 in

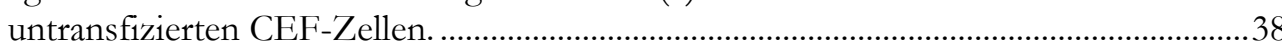

Abbildung 8: Durchflusszytometrische Messungen des translationalen Readthrough des SCC MDH1 (x) in CEF-Zellen......................................................................................... 40

Abbildung 9: Durchflusszytometrische Messungen des translationalen Readthrough des SCC LDHB(x) in CEF-Zellen. .............................................................................................. 40

Abbildung 10: Durchflusszytometrische Messungen des endogenen und induzierten translationalen Readthrough des SCC MDH1(x) und des SCC LDHB(x) in CEFZellen (Induktion mit G418 $(100 \mu \mathrm{g} / \mathrm{ml}))$....................................................................... 41

Abbildung 11: Durchflusszytometrische Messungen des translationalen Readthrough des SCC des Wildtyps der LDHBx und des SCC der mutierten Versionen in transfizierten HeLa-Zellen.

Abbildung 12: Durchflusszytometrische Messungen des translationalen Readthrough des SCC des Wildtyps der MDH1x und des SCC der mutierten Versionen in transfizierten HeLa-Zellen.

Abbildung 13: Schematische Darstellung des Konstrukts Stopcodon und darauffolgende 63 Nukleotide (S63N) für den dualen Reporter.

Abbildung 14: Durchflusszytometrische Messungen des translationalen Readthrough des Konstrukts S63N-VEGF-A(x) in HeLa-Zellen.

Abbildung 15: Darstellung des Streudiagramms durchflusszytometrischer Messungen des mit G418 induzierten translationalen Readthrough der SCC von zwei NonsenseMutationen des Rett-Syndroms in HeLa-Zellen.

Abbildung 16: Durchflusszytometrische Messungen des endogenen und mit G418 induzierten translationalen Readthrough der SCC der häufigsten Nonsense-Mutationen des RettSyndroms in transfizierten HeLa-Zellen.

Abbildung 17: Durchflusszytometrische Messungen des mit G418 induzierten translationalen Readthrough der SCC der häufigsten Nonsense-Mutationen des Rett-Syndroms in transfizierten HeLa-Zellen. 


\section{Tabellenverzeichnis}

Tabelle 1: Computerprogramme und Hersteller ........................................................................ 14

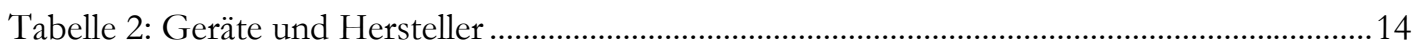

Tabelle 3: Verbrauchsmaterialien und Hersteller .............................................................................16

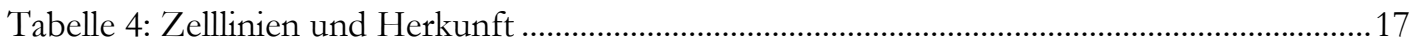

Tabelle 5: Bakterienstämme und Herkunft .................................................................................... 17

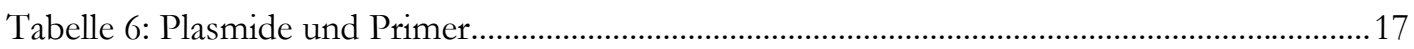

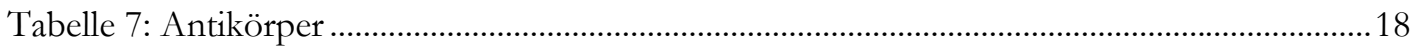

Tabelle 8: Kits/Chemikalien und Hersteller/Zusammensetzung ................................................19

Tabelle 9: Auflistung der klonierten Konstrukte............................................................................22

Tabelle 10: SCC der Vektorkonstrukte für den dual reporter assay in CEF-Zellen........................39

Tabelle 11: Readthrough-Induktionsfaktoren der häufigsten Nonsense-Mutationen des Rett-

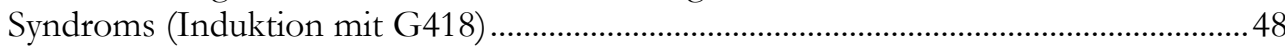




\section{Abkürzungsverzeichnis}

BSA

CEF

CRL

DMEM

DNA

FACS

FCS

FITC

FSC

G418

LB

LDHB

LDHBx

MDH1

MDH1x

PBD

PBS

PE

PFA

PTS

SSC-A

mRNA

tRNA

RTP

SCC

S63N

SRL

TRID

VEGF-A

VASN ds

VASN ds2
Bovine serum albumin, bovines Serumalbumin

Chicken embryo fibroblast, embryonale Huhnfibroblasten

Cysteine - bysine - leucine, Cystein - Lysin - Leucin

Dulbecco's modified eagle medium

Deoxyribonucleic acid, Desoxyribonukleinsäure

Fluorescence-activated cell sorting, Durchflusszytometrie

Fetal calf serum, fötales Kälberserum

Fluorescein isothiocyanate, Fluoreszeinisothiocyanat

Forward scatter, Vorwärtsstreulicht

Geneticin, Geneticin

Lysogeny broth

Lactate debydrogenase B, Laktatdehydrogenase B

Extended lactate dehydrogenase $B$, verlängerte Laktatdehydrogenase B

Malate dehydrogenase 1, Malatdehydrogenase 1

Extended malate debydrogenase 1, verlängerte Malatdehydrogenase 1

Peroxisome biogenesis disorders, Erkrankungen der Biogenese des Peroxisoms

Phosphate-buffered saline, Phosphatgepufferte Salzlösung

Phycoerythrin, Phycoerythrin

Paraformaldehyde, Paraformaldehyd

Premature termination codon, vorzeitiges Stopcodon

Side scatter, Seitwärtsstreulicht

Messenger ribonucleic acid, Boten-Ribonukleinsäure

Transfer ribonucleic acid, Transfer-Ribonukleinsäure

Readthrough propensity, Neigung des Überlesens

Stop codon context, Stopcodon-Kontext

Stop codon and 63 nucleotides downstram, Stopcodon und die 63 darauffolgende Nukleotide

Serine - lysine - leucine, Serin - Lysin - Leucin

Translational readthrough-inducing drug, Medikament, welches Überlesen induziert

$V$ ascular endothelial growth factor A, vaskulärer endothelialer Wachstumsfaktor A

Basensequenz mit zwei Stopcodons direkt hintereinander (Gensequenz: Vasorin)

Basensequenz mit einem Basentriplett zwischen zwei Stopcodons

(Gensequenz: Vasorin)

Extended (in diesem Zusammenhang verlängerte Version des ursprünglichen Proteins) 


\section{$1 \quad$ Einleitung}

\subsection{Translation und Termination}

Bei der Translation als Teilprozess der Proteinbiosynthese werden genetische Informationen der mRNA über Ribosomen und tRNA in eine bestimmte Aminosäuresequenz und somit in Proteine umgeschrieben. Wenn während der Translation die A-Stelle des Ribosoms ein Stopcodon bestehend aus den Basen UGA, UAA oder UAG erreicht, wird die Translation normalerweise beendet. Für ein Stopcodon existiert keine komplementäre tRNA. Stattdessen binden Terminationsfaktoren an das Basentriplett. Durch die Bindung an die mRNA werden die Esterbindungen zwischen der tRNA und der letzten Aminosäure hydrolysiert und das Ribosom dissoziiert. Die Proteinbiosynthese ist damit beendet und das Protein wurde im Regelfall vollständig synthetisiert.

Die Termination ist jedoch nicht zu $100 \%$ effizient. Bindet anstatt der Terminationsfaktoren eine tRNA an das Stopcodon, findet keine Termination statt. Das Terminationssignal der mRNA wird überlesen und die Aminosäuresequenz des Proteins wird bis zum nächsten Stopcodon verlängert. Dieser Prozess wird translationaler Readthrough genannt (Abbildung $1)$.

Die Effizienz der Termination hängt stark von dem Stopcodon und den Nukleotiden um das Stopcodon auf der mRNA ab. Die Nukleotide um das Stopcodon zusammen mit dem Stopcodon werden im Folgenden als Stopcodon-Kontext (stop codon context, SCC) bezeichnet (Bertram et al. 2001; Floquet et al. 2012; Schueren et al. 2014; Hofhuis et al. 2016). 


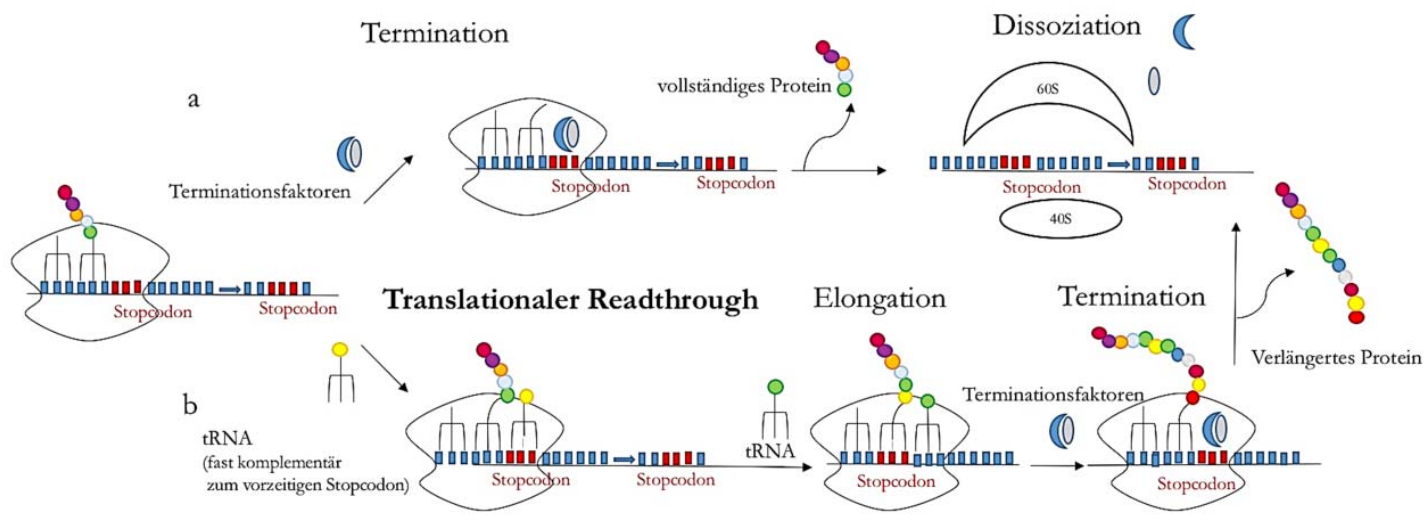

Abbildung 1: Schematische Darstellung der Translation. Die Abbildung zeigt zwei Szenarien: (a) Die Termination der Translation wird durch Terminationsfaktoren, die an das Stopcodon binden, eingeleitet. Die Untereinheiten der Ribosomen dissoziieren. Das Protein ist vollständig translatiert. (b) Statt der Terminationsfaktoren bindet eine tRNA an das Stopcodon, deren Anticodon fast komplementär zum Stopcodon ist. Dies führt zum translationalen Readthrough. Die Bindung der tRNA an das Codon ist zwar weniger optimal, aber die mRNA wird bis zum nächsten Stopcodon translatiert. Es binden Terminationsfaktoren an das nächste Stopcodon und die Proteinuntereinheiten dissoziieren. Das Protein ist verlängert translatiert (nach Bidou et al. 2012).

\subsection{Endogener translationaler Readthrough und induzierter trans- lationaler Readthrough}

Im Gegensatz zum induzierten Readthrough ist der endogene Readthrough ein physiologischer Prozess, der funktionell essenziell sein kann. Endogener translationaler Readthrough führt zur Expression von neuen, verlängerten Isoformen, die sich in ihren biologischen Funktionen von dem ursprünglichen Protein unterscheiden. Diese Isoformen sind die am C-terminalen Ende verlängerten Versionen des ursprünglichen Proteins. Sie werden in diesem Zusammenhang als „extended" mit einem x gekennzeichnet.

Das Readthrough-Phänomen wurde erstmals für Viren und später auch für prokaryotische und eukaryotische Zellen beschrieben (Beier und Grimm 2001; Firth und Brierley 2012). Funktionell erweitert endogener translationaler Readthrough zum einen das Proteom der Organismen. Somit existiert eine höhere Variationsbreite der Merkmale. Endogener translationaler Readthrough kann daher beispielsweise eine Selektion bewirken (Hofstetter et al. 1974; Engelberg-Kulka et al. 1979; Geller und Rich 1980; Yamaguchi et al. 2012). Zum anderen kann endogener translationaler Readthrough die Aktivität und die Lokalisation bestimmter Proteine modulieren (Torabi und Kruglyak 2012). Auf der durch Readthrough verlängerten DNA-Sequenz bestimmter Proteine sind Zielsignale (targeting signals) 
konserviert, die für den Transport in bestimmte Zellorganellen essenziell sind (Freitag et al. 2012). Bezüglich der Genexpression nimmt der Prozess eine bedeutende Rolle ein (Dunn et al. 2013).

Endogener Readthrough ist v. a. in viralen und prokaryotischen, aber auch in einigen eukaryotischen Zellen kein seltenes Phänomen: Bei der Taufliege Drosophila melanogaster sind mehrere hundert Proteine vom endogenen translationalen Readthrough betroffen (Dunn et al. 2013). In Zellen von Säugetieren wurde in den letzten Jahren dagegen nur für wenige Proteine endogener translationaler Readthrough beschrieben. Schueren und Thoms (2016) beschrieben bislang für 50 Proteine Signale, die auf endogenen translationalen Readthrough hinweisen.

Endogener translationaler Readthrough wird von verschiedenen zum Teil noch unbekannten Faktoren reguliert.

In früheren Arbeiten konnte ein Readthrough propensity (RTP) score für den SCC der Proteine des menschlichen Genoms errechnet werden. Dieser zeigt an, wie hoch die Wahrscheinlichkeit für den SCC eines Proteins ist endogenen translationalen Readthrough zuzulassen. Es wurde die mRNA von Proteinen identifiziert, die besonders viel endogenen translationalen Readthrough ermöglicht. Die Malatdehydrogenase 1 (MDH1) hat den bislang höchsten beschriebenen RTP score in eukaryotischen Zellen (Schueren et al. 2014).

Neben dem endogenen translationalen Readthrough gibt es einen durch Medikamente induzierten translationalen Readthrough. Dieser kann bei genetischen Erkrankungen, die durch eine Nonsense-Mutation verursacht werden, eine therapeutische Option darstellen. Nonsense-Mutationen sind Punktmutationen, die zu vorzeitigen Stopcodons (premature termination codon, PTC), also zu der Nukleotidsequenz UAA, UAG oder UGA führen (Abbildung 2). Wenn eine solche Mutation nicht durch einen spezifischen Reparaturmechanismus der mRNA eliminiert wird, endet die Translation am vorzeitigen Stopcodon. Es kommt zu einem Abbruch der Proteinbiosynthese und zur Synthese eines verkürzten und meist nicht funktionsfähigen Proteins (Hentze und Kulozik 1999).

Insgesamt machen Nonsense-Mutationen $10 \%$ aller monogenen Erkrankungen aus (Mort et al. 2008). In den letzten Jahren wurden Behandlungsstrategien für verschiedene durch Nonsense-Mutation verursachte Erkrankungen entwickelt. Neben der ReadthroughInduktion zählen Suppressor-tRNAs und Pseudouridylierung des vorzeitigen Stopcodons zu möglichen therapeutischen Ansätzen (Keeling et al. 2014).

Bei den induzierenden Substanzen, den sogenannten TRIDs (translational readthrough-inducing drugs), handelt es sich meist um Aminoglykoside. TRIDs binden an die kleine Untereinheit 
des Ribosoms, wodurch tRNAs schlechter unterschieden werden. Die Wahrscheinlichkeit, dass anstelle der Terminationsfaktoren eine tRNA, deren Anticodon fast komplementär zum Stopcodon ist, an die mRNA bindet, wird so erhöht (François et al. 2005). AminoglykosidAntibiotika wie Geneticin (G418), Gentamicin oder Paromomycin gehören zu den am längsten bekannten TRIDs. Unter der systemischen Antibiotikatherapie mit Aminoglykosiden können jedoch schwere, unerwünschte Nebenwirkungen wie Nephrotoxizität, Ototoxizität und Retinotoxizität auftreten. Moderne TRIDs wie Derivate der Aminoglykosid-Antibiotika (z. B. Derivate des Paromomycins NB30, NB54, NB84) oder PTC124 zeigen in Studien eine signifikant geringere Toxizität (Goldmann et al. 2012).

Ein aktuelles Beispiel für eine erfolgreiche Behandlung durch Readthrough-Induktion durch die topische Behandlung mit einem Aminoglykosid stellt die Epidermolysis bullosa dystrophica dar. Die Erkrankung gehört zu den blasenbildenden Hauterkrankungen und wird durch eine Nonsense-Mutation auf dem Gen des Kollagen VII verursacht. Kollagen VII wird unter anderem für die Verankerungsfibrillen zwischen der Basalmembran und dem Stratum papillare der Dermis benötigt. Neben Blasenbildungen und daraus resultierenden Wunden und Vernarbungen können Schleimhautläsionen, Wachstumsretardierung sowie Ösophagus- und Analstenosen auftreten. Bisher gibt es keine kurative Therapie. Eine Pilotstudie zeigte, dass topisch und intradermal appliziertes Gentamicin eine Reduktion der Blasenbildung, eine verbesserte epidermal-dermale Adhärenz und eine beschleunigte Wundheilung hervorrufen kann. Durch induzierten translationalen Readthrough bildeten sich funktionsfähiges Kollagen VII und dadurch auch funktionelle Verankerungsfibrillen. Die Expression von funktionsfähigem Kollagen VII hielt drei Monate an. Unter der topischen Gentamicin-Behandlung traten keine unerwünschte Wirkungen auf (Woodley et al. 2017).

Eine wichtige Indikation einer systemischen Readthrough-Behandlung stellt die DuchenneMuskeldystrophie aus dem neuropädiatrischen Bereich dar. Die DuchenneMuskeldystrophie ist eine progressive, neuromuskuläre Erkrankung, bei der es zu Muskelschwäche und Atrophie v. a. der Skelettmuskulatur kommt. Ursächlich ist in $10 \%$ bis $15 \%$ ein durch eine Nonsense-Mutation verursachtes, funktionsloses oder fehlendes Dystrophin-Protein (Leigh et al. 2018). Betroffen sind vor allem Jungen. Das Manifestationsalter liegt meistens zwischen dem dritten und fünften Lebensjahr. Die Patienten versterben größtenteils mit Mitte zwanzig. Aus der Gruppe der Readthroughinduzierenden Medikamente ist das PTC124 Therapeutikum mit dem Handelsnamen Ataluren für die Duchenne-Muskeldystrophie, die durch eine Nonsense-Mutation verusacht 
wurde, bereits zugelassen. Unter der Therapie zeigt sich klinisch eine verlangsamte Progredienz der Erkrankung. In Studien konnte gezeigt werden, dass Patienten, die mit PTC124 therapiert sind, im Vergleich zu Placebogruppen innerhalb von 48 Wochen eine bessere Muskelfunktion in Funktionstests aufweisen und dass der Verlust der Gehfähigkeit der behandelten Patienten hinausgezögert wird (Bushby et al. 2014). Vor allem bei der Patientengruppe, die beim Sechs-Minuten-Gehtest eine Strecke zwischen $300 \mathrm{~m}$ und $400 \mathrm{~m}$ schafft, kann ein Fortschreiten des Krankheitsverlaufs verlangsamt werden. Unter der Therapie mit PTC124 werden keine relevanten Nebenwirkungen beobachtet. Allerdings liegen noch keine Langzeitstudien zur Therapie mit Ataluren vor (McDonald et al. 2017; Ebrahimi-Fakhari et al. 2018; Landfeldt et al. 2019).

Der Einsatz von PTC124 führte in einzelnen Studien auch bei Mukoviszidose zu einem möglichen therapeutischen Effekt, der aktuell allerdings kontrovers diskutiert wird. Mukoviszidose ist in $10 \%$ auf eine Nonsense-Mutation zurückzuführen (Boyle und De Boeck 2013): Bei Patienten mit primärer Manifestation in den Lungen kam es durch den Einsatz von PTC124 zu einer Verbesserung der exspiratorischen Einsekundenkapazität und zu einer Verringerung der Exazerbationsrate. Allerdings funktionierte die Behandlung nicht in Kombination mit dem Antibiotikum Tobramycin (Kerem et al. 2014). Da 60 \% bis $70 \%$ aller Mukoviszidose-Patienten mit Pseudomonas aeruginosa infiziert sind, ist eine Dauertherapie mit Tobramycin zur Aufrechterhaltung der Lungenfunktion die derzeitige Behandlungsstrategie (Mantero et al. 2017). Es wurde diskutiert, dass Tobramycin möglicherweise in Wechselwirkung mit PTC124 die therapeutische Wirkung des Medikaments aufheben könnte. Die Wechselwirkung der beiden Medikamente wurde bei Beginn der PTC124 Studie nicht erwartet (Kerem et al. 2014; Aslam et al. 2017). Aus diesem Grund werden bei Mukoviszidose aktuell kontrollierte, randomisierte Studien mit PTC124 ohne gleichzeitige Tobramycin Behandlung durchgeführt. Erste Ergebnisse deuten darauf hin, dass eine Therapie mit PTC124 bei Patienten mit Mukoviszidose auch dann nicht erfolgreich ist, wenn diese nicht mit Tobramycin behandelt werden. Die Studie ist allerdings noch nicht vollständig veröffentlicht. Mukoviszidose ist ein Beispiel für eine Erkrankung, bei der eine Behandlung mit PTC124 zwar theoretisch wirksam sein könnte, jedoch wahrscheinlich klinisch nicht effizient ist (Zainal Abidin et al. 2017). 


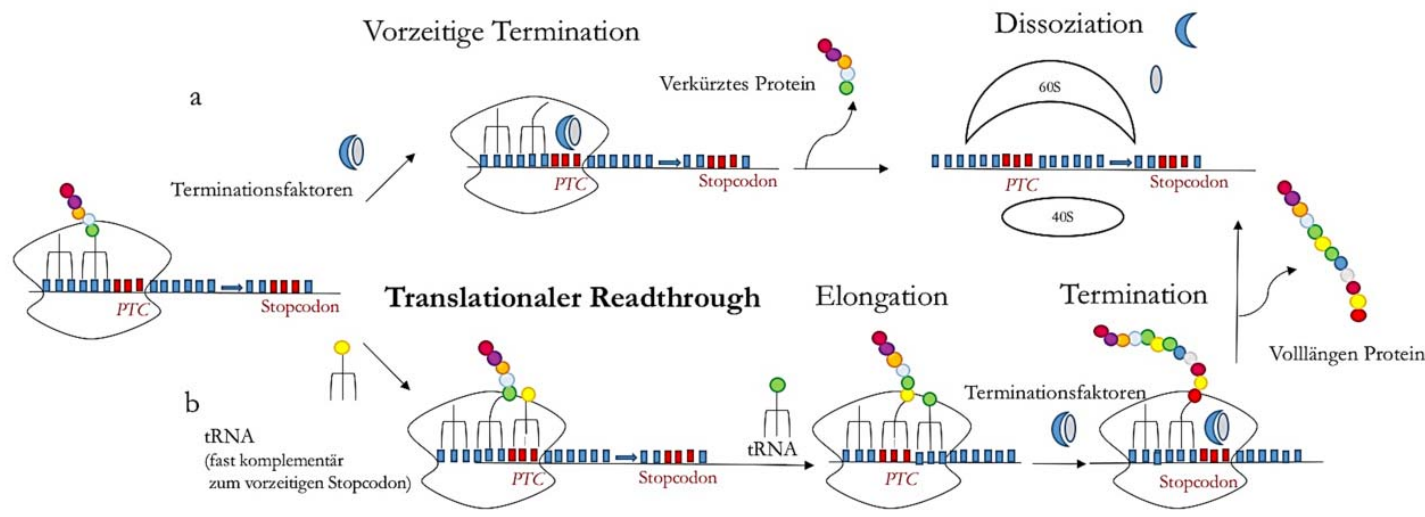

Abbildung 2: Schematische Darstellung der Translation bei Nonsense-Mutationen. Die Abbildung zeigt zwei Szenarien: (a) Die Termination der Translation wird durch Terminationsfaktoren, die an das vorzeitige Stopcodon binden, eingeleitet. Die Untereinheiten der Ribosomen dissoziieren. Das Protein ist unvollständig translatiert. (b) Es bindet eine tRNA an das vorzeitige Stopcodon (premature termination codon, PTC), dessen Anticodon fast komplementär zu dem vorzeitigen Stopcodon ist. Dies führt zum translationalen Readthrough. Die Bindung der tRNA an das Codon ist zwar weniger optimal, aber die mRNA wird bis zum nächsten Stopcodon translatiert. Es binden Terminationsfaktoren an das nächste Stopcodon und die Proteinuntereinheiten dissoziieren. Das Protein ist vollständig translatiert (nach Bidou et al. 2012).

\subsection{Die Malatdehydrogenase 1 und die Laktatdehydrogenase B im Peroxisom von Säugetieren und Nichtsäugetieren}

In dieser Arbeit wurden Readthrough-Phänomene am Beispiel der beiden Enzyme Malatdehydrogenase 1 (MDH1) und Laktatdehydrogenase B (LDHB) u. a. an Zellen von Nichtsäugetieren (Zellen vom Haushuhn) im Vergleich zu humanen Zellen untersucht. Die beiden Moleküle sind deshalb als Modellenzyme interessant, weil es von ihnen in Säugetierzellen verschiedene Isoformen mit unterschiedlichen Funktionen gibt. Dabei sind die längeren Isoformen (LDHBx und $\mathrm{MDH} 1 \mathrm{x}$ ) die ersten Beispiele für funktionellen translationalen Readthrough beim Menschen. Es sollten daher durch vergleichende Untersuchungen Modellzellen charakterisiert werden, die für weitere, vertiefende mechanistische Studien zum Readthrough geeignet sind.

Der funktionelle translationale Readthrough betrifft $u$. a. das Peroxisom. Das Peroxisom ist ein Zellorganell eukaryotischer Zellen, das u. a. an der Lipidverarbeitung und der reaktiven Sauerstoffentgiftung beteiligt ist. Es finden essenzielle Stoffwechselwege wie die $\beta$-Oxidation der überlangkettigen Fettsäuren, Wasserstoffperoxiden und der Abbau von Phytan- und Pristansäure im Peroxisom statt. Zudem spielt das Peroxisom in der Plasmalogenbiosynthese eine Rolle und ist an der Cholesterolbiosythese sowie der Gallensäurensynthese beteiligt. Das Peroxisom ist von einer Lipidmembran umgeben und enthält keine Ribosomen. 
Peroxisomale Enzyme können also nicht im Zellorganell selbst produziert werden und müssen aus dem Zytosol transportiert werden. Werden die Enzyme nicht in das Peroxisom importiert, kann es zu lebensbedrohlichen Erkrankungen kommen. Der Import der Enzyme erfolgt unter anderem über das peroxisomale Zielsignal 1 (peroxisomal targeting signal 1, PTS1) oder das deutlich seltenere peroxisomale Zielsignal 2 (peroxisomal targeting signal 2, PTS2) (Gould et al. 1987). Bei dem PTS1 handelt es sich um die C-terminale Basenabfolge, welche die Aminosäuren Cystein oder Serin, Lysin und Leucin oder eine Variante kodieren. Das PTS1 ist in über $90 \%$ auf der DNA der humanen peroxisomalen Matrixproteine vorhanden (Gould et al. 1989; Farré et al. 2019).

Das PTS der humanen MDH1x liegt versteckt hinter dem Stopcodon in den ReadthroughErweiterungen (Hofhuis et al. 2016). Das PTS1 der MDH1x ist bei allen Vertebraten nachweisbar und funktionsfähig, unterscheidet sich aber in seiner Basenabfolge für Säugetiere bzw. Nichtsäugetiere. Die Basenabfolge des PTS1 der Säugetiere enthält das Tripeptid CRL (Cystein - Lysin - Leucin), während das PTS1 der Nichtsäugetiere das Tripeptid SRL (Serin - Lysin - Leucin) enthält. Dabei ist das PTS1 der Nichtsäugetiere ein effizienteres Zielsignal als das der Säugetiere (Hofhuis et al. 2016).

Die MDH1(x) gehört zu der Gruppe der Oxidoreduktasen. Sie katalysiert Enzymreaktionen, bei denen Reduktionsäquivalente wie $\mathrm{NADH}+\mathrm{H}^{+}$aus $\mathrm{NAD}^{+}$regeneriert werden. Für die peroxisomale $\beta$-Oxidation wird das nicht membrangängige $\mathrm{NAD}^{+}$benötigt. Es ist möglich, dass die Oxidoreduktase MDH1x zu der Regeneration der Redoxäquivalente im Peroxisom beiträgt (van Roermund et al. 1995; Hofhuis et al. 2016). Die LDHB(x) gehört ebenfalls zu der Gruppe der Oxidoreduktasen und ist verglichen mit der MDH1(x) das evolutionär jüngere Enzym (Goward und Nicholls 1994). Sie ähnelt der MDH1(x) nicht nur in der Funktion, sondern auch in der Struktur. Beispielsweise ähnelt die Aminosäuresequenz der MDH1(x) der Haloarchaeen eher der Aminosäuresequenz der LDH(x) als der Sequenz anderer MDH-Isoformen (Cendrin et al. 1993).

In Zellen von Säugetieren ist in der Readthrough-Erweiterung der LDHBx ebenfalls ein verstecktes PTS1 konserviert. Zusätzlich wurde für den Transport der $\mathrm{LDH}(\mathrm{x})$ über die peroxisomale Membran ein Huckepack-Transporter identifiziert. Über den HuckepackTransport kann die durch Readthrough verlängerte Isoform LDHBx gemeinsam mit der anderen LDH-Untereinheit LDHA in das Peroxisom transportiert werden (Schueren et al. 2014; Thoms 2015). In-silico-Analysen zeigen, dass die LDHB(x) die höchste kombinierte Wahrscheinlichkeit für einen hohen RTP score und der gleichzeitigen Expression von PTS1 zeigt. Bei Säugetieren sind ca. 1,6\% der zellulären $\mathrm{LDHB}(\mathrm{x})$ im Peroxisom lokalisiert (Schueren et al. 2014). In Zellen von Nichtsäugetieren (z. B. von Vögeln) wurde für die 
LDHB(x) dagegen kein verstecktes PTS identifiziert. Dieses Phänomen wird als bird gap bezeichnet. Es wird vermutet, dass die $\operatorname{LDHB}(x)$ im Peroxisom bei Nichtsäugetieren nicht vorhanden ist (Hofhuis et al. 2016).

Nichtsäugetiere sind die evolutionär ältere Spezies. Die peroxisomale $\operatorname{LDHB}(\mathrm{x})$ der Säugetiere könnte hypothetisch im Verlauf der Evolution Funktionen der peroxisomalen MDH1(x) übernommen haben. Die gleichen Funktionen, die sich die peroxisomalen $\operatorname{LDHB}(\mathrm{x})$ und $\operatorname{MDH} 1(\mathrm{x})$ der Säugetiere teilen, könnten hypothetisch in Zellen der Nichtsäugetiere von der MDH1(x) alleine übernommen werden. So könnte auch das schwächere PTS1 (CRL) der Säugetiere erklärt werden (Hofhuis et al. 2016). Das PTS der verlängerten Isoform der MDH1x und LDHBx ist ein Beispiel für funktionellen translationalen Readthrough.

\subsubsection{Klinischer Bezug: Peroxisomale Erkrankungen}

In Bezug auf peroxisomale Zielsignale gibt es unabhängig von definierten Funktionen der verlängerten Isoformen der MDH1x und LDHBx einen interessanten klinischen Bezug: Erkrankungen der Biogenese des Peroxisoms (peroxisome biogenesis disorders, PBD) umfassen Pathologien mit Defekten im PEX-Gen (Dranchak et al. 2011). PEX-Gene sind für die Biosynthese des Peroxisoms und die Funktion peroxisomaler Enzyme essentiell. PBD lassen sich in zwei Untergruppen einteilen. $80 \%$ der PBD Patienten sind vom Zellweger-Syndrom betroffen, welches v. a. auf eine Mutation in einem von fünf $P E X-G e n e n$ zurückzuführen ist. Häufig ist das PEX5-Gen betroffen, welches den Rezeptor für das peroxisomale Zielsignal PTS1 kodiert. $15 \%$ der Zellweger-Patienten tragen Nonsense-Mutationen. Bei Patienten des Zellweger-Syndroms akkumulieren langkettige Fettsäuren in verschiedenen Zellsystemen. Betroffene Neugeborene sind hypoton und ernähren sich schlecht. Sie haben ausgeprägte Fazies, degenerative Veränderungen des Gehirns, zum Teil sehr schwere Lebererkrankungen, Nierenzysten, Herzfehler und knöcherne Narben. Säuglinge mit schwerem Zellweger-Syndrom sterben typischerweise im ersten Lebensjahr (Steinberg et al. 1993; Abe et al. 2014).

Die andere Subgruppe umfasst Patienten mit Chondrodysplasia punctata (rhizomeler Typ 1) (RCDP1). Die Erkrankung ist interessant für eine PTC-Therapie, da $60 \%$ der Patienten eine Nonsense-Mutation im PEX7-Gen tragen (Dranchak et al. 2011). Das PEX7-Gen kodiert den Rezeptor für das peroxisomale Zielsignal PTS2 (Di Cara et al. 2019). Das Krankheitsbild der Chondrodysplasia punctata (rhizomeler Typ 1) ist v. a. durch eine peroximale Verkürzung des Humerus, Verkalkungen im Knorpel mit Anomalien der Epiphysen und Metaphysen, 
Katarakten, postnatalen Wachstumsstörungen sowie geistiger Retardierung charakterisiert. Die meisten betroffenen Kinder sterben in der ersten Lebensdekade (Braverman et al. 1993).

Studien zu der Readthrough-Therapie bei Nonsense-Mutationen bestimmter PBD (PEX2, PEX12) zeigten in vitro in humanen Hautfibroblasten und ovariellen Zellen des chinesischen Hamsters Verbesserungen des peroxisomalen Fettsäurekatabolismus und der PlasmalogenBiosynthese als Reaktion auf Geneticin-Behandlungen. Zudem konnte die Biogenese der Peroxisomen in Patientenfibroblasten mit Geneticin verbessert werden. Für PTC124 konnte allerdings in vitro keine Induktion von Readthrough bei PEX7 Nonsense-Mutationen nachgewiesen werden. Insgesamt liegen noch keine In-vivo-Daten einer zugelassenen kausalen Therapie von PBD vor (Dranchak et al. 2011).

\subsection{Einfluss von distalen und proximalen Nukleotiden des Stopcodon- Kontexts auf den endogenen translationalen Readthrough}

Endogener translationaler Readthrough hängt von verschiedenen Faktoren ab. Zum einem wird davon ausgegangen, dass zahlreiche cis-Elemente das Readthrough-Phänomen beeinflussen. Zum anderen werden das Stopcodon selbst und die Nukleotide um das Stopcodon (Stopcodon-Kontext, Stopcodon-context, SCC) als wichtige Einflussfaktoren beschrieben (Firth et al. 2011; Eswarappa et al. 2014). Cis-Elemente sind regulatorische Sequenzabschnitte auf der DNA, die Einfluss auf die Synthese von Proteinen nehmen. Endogener translationaler Readthrough, der von cis-Elementen beeinflusst wird, wird als programmierter translationaler Readthrough beschrieben (Eswarappa et al. 2014). Wichtig ist, dass der programmierte translationale Readthrough von Translationsfehlern abgegrenzt wird. Es ist zwar noch unklar, wie der Prozess am Ribosom genau kontrolliert wird, jedoch wurden erste Faktoren, die mit dem Terminationskomplex interagieren, entdeckt (Eswarappa et al. 2014; Beznosková et al. 2015).

Der vom Stopcodon und SCC abhängige translationale Readthrough wird basaler translationaler Readthrough genannt. Der basale translationale Readthrough hängt im Gegensatz zum programmierten translationalen Readthrough von keinen äußeren Faktoren ab (Schueren et al. 2014). In dieser Arbeit soll hauptsächlich der basale translationale Readthrough bearbeitet werden.

In humanen Zellen stellt das Stopcodon UGA das schwächste Stopcodon dar und erlaubt daher besonders häufig endogenen translationalen Readthrough. UAA dagegen ist das stärkste Stopcodon (Beier und Grimm 2001; Baranov et al. 2002). In einem linearen 
Regressionsmodell konnte die Position des Nukleotids, das den stärksten Einfluss auf den basalen translationalen Readthrough hat, identifiziert werden: Die Position des Nukleotids vier Stellen hinter dem Stopcodon zeigte hier den größten Effekt. Aber auch proximale und distale Nukleotide in der unmittelbaren Nähe des Stopcodons zeigen in In-silicoModellierungen einen signifikanten Einfluss auf den basalen translationalen Readthrough (Floquet et al. 2012; Schueren et al. 2014). In weiteren Untersuchungen ließ sich feststellen, dass die mRNA-Sequenz distal des SCC für den Readthrough nicht erforderlich ist. Es kann aber nicht ausgeschlossen werden, dass Sequenzelemente distal des zweiten Stopcodons zum translationalen Readthrough beitragen (Hofhuis et al. 2016). Andere Studien zeigten jedoch abweichend, dass die Nukleotide distal des Stopcodons in den Verlängerungen den translationalen Readthrough stark beeinflussen (Eswarappa et al. 2014).

In einer Studie zum programmierten translationalen Readthrough des Proteins VEGF-A(x) wurde der translationale Readthrough mit dem firefly luciferase assay gemessen. Für die Messung wurde ein Konstrukt des Proteins VEGF-A(x) generiert, das das Stopcodon und 63 Nukleotide distal des Stopcodons beinhaltete. Eswarappa et al. (2014) schlussfolgerten, dass die 63 Nukleotide distal des Stopcodons den translationalen Readthrough maßgeblich beeinflussen. Der Einfluss der proximalen Nukleotide auf den translationalen Readthrough, von dem in dieser Arbeit ausgegangen wird und der in Arbeiten von Hofhuis et al. (2016) und Schueren et al. (2014) gezeigt wurde, wird somit durch die Ergebnisse von Eswarappa et al. (2014) in Frage gestellt.

Die unterschiedlichen Ergebnisse sind bislang nicht eindeutig erklärbar und sollen in dieser Arbeit weiter untersucht werden. 


\subsection{Induzierbarkeit von translationalem Readthrough von Nonsense- Mutationen beim Rett-Syndrom}

Das Rett-Syndrom gehört zu der Gruppe der schweren neurologischen Entwicklungsstörungen. Es wird x-chromosomal vererbt und führt bei Jungen in der Regel innerhalb von zwei Jahren zu schweren angeborenen Enzephalopathien und zum Tod. Bei Erwachsenen betrifft das Rett-Syndrom daher fast ausschließlich Frauen und ist dann milder ausgeprägt. Das Rett-Syndrom kommt bei einer von 10.000 Lebendgeburten vor (Ip et al. 2018). Initial entwickeln sich die Mädchen normal oder nahezu normal. Nach 8 bis 18 Monaten kommt es zu Rückbildungen der erworbenen kognitiven und motorischen Fähigkeiten. Typisch sind vor allem die Regression der Sprache und der Verlust von Handfunktionen, die durch stereotype Handbewegungen ersetzt werden. Anschließend setzt eine lange Phase des Entwicklungsstillstands ein (Hagberg 1995). In dieser Phase werden häufig Autismus ähnliche Verhaltensweisen beschrieben, weswegen das Rett-Syndrom lange zur Gruppe der Autismus-Spektrum-Störungen zugeordnet wurde. Die Patientinnen zeigen sich im Teenager-Alter aber wieder als sozial interaktiver. Im Verlauf kann es zusätzlich zu einer Ataxie kommen, sodass Patientinnen im Teenager-Alter oft im Rollstuhl sitzen. Der Phänotyp von Patientinnen des Rett-Syndroms variiert allerdings sehr stark. Einige Patientinnen lernen nie zu sprechen oder zu laufen und sind stark von Epilepsien betroffen. Andere zeigen nur sehr geringfügige neurologische Symptome (Huppke et al. 2003).

Das Rett-Syndrom wird zu $90 \%$ bis $95 \%$ durch Mutationen im x-chromosomalen MeCP2Gen verursacht (Amir et al. 1999). Das MeCP2-Gen kodiert das Methyl-CPGBindungsprotein 2, welches zur epigenetischen Kontrolle der Genexpression beiträgt (Chahrour und Zoghbi 2007). Mutationen im MeCP2-Gen treten vorwiegend in Keimzellen der väterlichen Seite auf. Es wurden mehrere hundert verschiedene das Rett-Syndrom verursachende Mutationen identifiziert. Insgesamt tragen $35 \%$ der Patienten des RettSyndroms Nonsense-Mutationen im MeCP2-Gen. Die häufigste Nonsense-Mutation ist die Mutation Rett-pR168X gefolgt von Rett-pR255X und Rett-pR270X (Ip et al. 2018). Aufgrund der Komplexität der Funktion des Methyl-CPG-Bindungsproteins 2 und auch der Symptome des Rett-Syndroms ist die Gentherapie als ein kausaler Behandlungsansatz vermutlich am wirksamsten.

In Tiermodellen konnte gezeigt werden, dass durch die Wiederherstellung der MeCP2Expression Symptome des Rett-Syndroms gelindert werden können (Percy et al. 2007). Die Expression von MeCP2 wird allerdings streng kontrolliert. Eine Überexpression des Proteins kann unter anderem zu einer schweren geistigen Behinderung führen (Van Esch et al. 2005). 
Beim Rett-Syndrom ist nur ein Anteil der MeCP2-Expression gestört. Die Hälfte der Zellen exprimieren ein normales Methyl-CPG-Bindungsprotein 2. Eine Zufuhr des Proteins als Behandlungsansatz würde also in der Hälfte der Zellen zu einer Überdosierung und zu gravierenden Nebenwirkungen führen (Brendel et al. 2009). Dagegen würde eine Readthrough-Therapie nur die mutierten Zellen beeinflussen und wäre somit ein guter Behandlungsansatz. In mehreren Studien konnte gezeigt werden, dass eine Expression des Volllängenproteins des Methyl-CPG-Bindungsproteins 2 durch induzierten translationalen Readthrough grundsätzlich erzeugt werden kann. Die Effizienz der Induktion variierte je nach SCC der Nonsense-Mutation (Brendel et al. 2009; Popescu et al. 2010).

\subsection{Fragestellungen der Arbeit}

In der nachfolgenden Arbeit werden experimentelle Ergebnisse dargestellt, in denen verschiedene Aspekte zum translationen Readthrough bearbeitet werden. Es werden dabei methodische Aspekte bearbeitet, um die künftige Erforschung des Readthrough-Phänomens zu erleichtern: Die Durchflusszytometrie wird hier erstmals zur quantitativen Messung von translationalem endogenem und induziertem Readthrough eingesetzt (Teil eins der Arbeit).

Des weiteren werden Aspekte bearbeitet, die dazu beitragen können, den endogenen translationalen Readthrough und Readthrough-abhängige Prozesse besser zu verstehen. Dazu wird zunächst der funktionelle translationale Readthrough in dem Modell der Nichtsäugetiere bearbeitet. Es soll überprüft werden, ob die LDHB(x) im Peroxisom der Nichtsäugetiere vorhanden ist. Als Beispiel für Zellen von Nichtsäugetieren werden Zellen aus embryonierten Hühnereiern verwendet (CEF-Zellen). Diese und weitere Untersuchungen können Auskunft über die genaue Funktion peroxisomaler Enzyme geben. Da translationaler Readthrough zellspezifisch ist (Hofhuis et al. 2016), wird zusätzlich die endogene Readthrough-Effizienz der $\operatorname{LDHB}(\mathrm{x})$ und $\mathrm{MDH}(\mathrm{x})$ in CEF-Zellen quantitativ gemessen (Teil zwei der Arbeit).

Anschließend wird der Einfluss von Nukleotiden um das Stopcodon auf den endogenen translationalen Readthrough weiter analysiert. Die Arbeit knüpft hier an Vorarbeiten der AG Thoms an, in denen im linearen Regressionsmodell ein signifikanter Einfluss der Nukleotide sechs Positionen proximal des Stopcodons vorhergesagt wurde (Schueren et al. 2014; Hofhuis et al. 2016). Die aus den Regressionsmodellen generierte Hypothese soll hier in vitro überprüft werden. In einem unabhängigen Experiment soll der Effekt der Nukleotide distal und proximal des Stopcodons auf den translationalen Readthrough analysiert werden. Vor allem soll die schon in Vorarbeiten aufgeworfene Frage nach dem Einfluss der proximalen 
Basen für den translationalen Readthrough geklärt werden (Eswarappa et al. 2014; Schueren et al. 2014; Hofhuis et al. 2016) (Teil drei der Arbeit).

Im letzten Teil der Arbeit wird der induzierte translationale Readthrough am Beispiel des Rett-Syndroms bearbeitet. Ziel ist festzustellen, ob Readthrough-induzierende Substrate bei bestimmten Mutationen vom Rett-Syndrom besser beziehungsweise schlechter wirken. Zunächst soll überprüft werden, ob es beim endogenen Readthrough signifikante Unterschiede zwischen den einzelnen Nonsense-Mutationen gibt. Anschließend soll translationaler Readthrough der Nonsense-Mutationen mit dem Aminoglykosid Geneticin induziert werden. Die Effizienz der Readthrough-Induktion der SCC der elf häufigsten Nonsense-Mutationen soll durchflusszytometrisch gemessen und verglichen werden.

Dies könnte klinisch relevant werden, weil so die nebenwirkungsreichen Medikamente zielgerichtet je nach Mutation eingesetzt werden könnten (Teil vier der Arbeit). 


\section{$2 \quad$ Material und Methoden}

\subsection{Material}

\subsubsection{Computerprogramme und Geräte}

Tabelle 1: Computerprogramme und Hersteller

\begin{tabular}{|l|l|}
\hline Computerprogramm & Hersteller \\
\hline Illustrater, Photoshop CS6 & Adobe, San José, USA \\
\hline BD FACS Diva & $\begin{array}{l}\text { BD Biosciences, Frankfurt am Main, } \\
\text { Deutschland }\end{array}$ \\
\hline PRISM & GraphPad, San Diego, USA \\
\hline Microsoft Excel, Microsoft Word, Power Point & Microsoft, Redmont, USA \\
\hline AxioVision 4.8 & Zeiss, Oberkochen, Deutschland \\
\hline
\end{tabular}

Tabelle 2: Geräte und Hersteller

\begin{tabular}{|l|l|}
\hline Gerätename & Hersteller \\
\hline Autoklav & Tecnoma, Fernwald, Gießen, Deutschland \\
\hline Brutschrank (HERAcell 150) & $\begin{array}{l}\text { Thermo Fischer Scientific, Braunschweig, } \\
\text { Deutschland }\end{array}$ \\
\hline Bunsenbrenner (CV 470 Plus) & $\begin{array}{l}\text { CampingAZ, Hungen, } \\
\text { Deutschland }\end{array}$ \\
\hline Eismaschine & $\begin{array}{l}\text { Ziegra Eismaschinen, } \\
\text { Deutschland Isernhagen, }\end{array}$ \\
\hline Elektrophoresekammer & Bio-Rad, München, Deutschland \\
\hline Flow Cytometer BD LSRII (FACS) & $\begin{array}{l}\text { BD Biosciences, Frankfurt am Main, } \\
\text { Deutschland }\end{array}$ \\
\hline Feinwaage & Bio-Rad, München, Deutschland \\
\hline Gefrierschrank & $\begin{array}{l}\text { Liebherr, Bulle, Schweiz } \\
\text { Forma Scientific, Marietta, USA } \\
\text { Panasonic, Kadoma, Japan }\end{array}$ \\
\hline
\end{tabular}




\begin{tabular}{|c|c|}
\hline Gerätename & Hersteller \\
\hline Genetic Analyzer (ABI PRISM 3130) & $\begin{array}{l}\text { Applied Biosystems, Darmstadt, } \\
\text { Deutschland }\end{array}$ \\
\hline Heizblock (TB2 Thermoblock) & Biometra, Göttingen, Deutschland \\
\hline Kühlschrank & Liebherr, Bulle, Schweiz \\
\hline Magnetrührer & $\begin{array}{l}\text { IKA, Staufen, Deutschland } \\
\text { Hanna Instruments, Woonsocket, USA }\end{array}$ \\
\hline $\begin{array}{l}\text { Mikroskop (Zeiss Imager M1 Fluorescence Wide } \\
\text { Field) }\end{array}$ & Zeiss, Oberkochen, Deutschland \\
\hline Photometer & Bio Tek, Bad Friedrichshall, Deutschland \\
\hline Pipetten & Sarstedt, Nümbrecht, Deutschland \\
\hline Pipettierhelfer (Pipetboy acu) & Integra Bioscience, Fernwald, Deutschland \\
\hline Schüttelinkubator & $\begin{array}{l}\text { Infors HT, Bottmingen, Schweiz } \\
\text { Eppendorf, Hamburg, Deutschland }\end{array}$ \\
\hline Schwenktisch (Rocking platform 3013) & $\begin{array}{l}\text { Biometra GmbH, Göttingen, Deutschland } \\
\text { GFL, Burgwedel, Deutschland }\end{array}$ \\
\hline Spektrophotometer (Nanodrop 1000) & $\begin{array}{l}\text { NanoDrop Tachnologies, Wilmington, } \\
\text { USA }\end{array}$ \\
\hline Thermomixer (5436) & Eppendorf, Hamburg, Deutschland \\
\hline Thermozykler (T3000) & Biometra GmbH, Göttingen, Deutschland \\
\hline Vortexmischer & $\begin{array}{l}\text { Heidolph, Schwabach, Deutschland } \\
\text { Velp Scientifica, Usmate, Italien } \\
\text { Bender und Hobein, Bruchsal, Deutschland }\end{array}$ \\
\hline Waage & Sartorius, Göttingen, Deutschland \\
\hline Wärmeinkubator & Bachofer, Reutlingen, Deutschland \\
\hline Wasserbad & Memmert, Schwabach, Deutschland \\
\hline Zellkulturbank (HERA safe, HSPC) & $\begin{array}{l}\text { Heraeus Kendro Laboratory Products, } \\
\text { Hanau, Deutschland }\end{array}$ \\
\hline $\begin{array}{l}\text { Zentrifugen (Universal 320, Rotina, MIKRO } \\
\text { 200R, 5424, GPR Centrifuge, FugeOne } \\
\text { MicroZentrifuge, Sorvall RC5 Superspeed) }\end{array}$ & $\begin{array}{l}\text { Hettich, Tuttlingen, Deutschland } \\
\text { Eppendorf, Hamburg, Deutschland }\end{array}$ \\
\hline
\end{tabular}




\begin{tabular}{|l|l|}
\hline Gerätename & Hersteller \\
\hline & Beckman Coulter, Krefeld, Deutschland \\
& StarLab, Ahrensburg, Deutschland \\
& Thermo Fischer Scientific, Braunschweig, \\
& Deutschland \\
\hline
\end{tabular}

\subsubsection{Verbrauchsmaterialien}

Tabelle 3: Verbrauchsmaterialien und Hersteller

\begin{tabular}{|l|l|}
\hline Verbrauchsmaterial & Hersteller \\
\hline Brutflasche $\left(250 \mathrm{ml}, 75 \mathrm{~cm}^{2}\right)$ & $\begin{array}{l}\text { Greiner Bio-One GmbH, Frickenhausen, } \\
\text { Deutschland }\end{array}$ \\
\hline Deckgläschen & $\begin{array}{l}\text { Thermo Fischer Scientific, Braunschweig, } \\
\text { Deutschland }\end{array}$ \\
\hline $\begin{array}{l}\text { Filter (NucleoBond Xtra Midi plasmid } \\
\text { Purification })\end{array}$ & Macherey Nagel, Düren, Deutschland \\
\hline Mikroreaktionsgefäße $(2,0 \mathrm{ml})$ & Eppendorf, Hamburg, Deutschland \\
\hline Mikrotiterplatte $(12$ well plate $)$ & $\begin{array}{l}\text { Greiner Bio-One GmbH, Frickenhausen, } \\
\text { Deutschland }\end{array}$ \\
\hline Neubauer-Zählkammer & $\begin{array}{l}\text { Thermo Fischer Scientific, Braunschweig, } \\
\text { Deutschland }\end{array}$ \\
\hline Objektträger (Menzel-Gläser) & $\begin{array}{l}\text { Thermo Scientific, } \\
\text { Deutschland }\end{array}$ \\
\hline Pasteurpipetten & Brand, Wertheim, Deutschland \\
\hline Petrischale & Sarstedt, Nümbrecht, Deutschland \\
\hline Pipettenspitzen $(0,5-10 \mu l, 100-1000 \mu l)$ & Sarstedt, Nümbrecht, Deutschland \\
\hline Polystyrol Röhrchen $(14 \mathrm{ml})$ & $\begin{array}{l}\text { Greiner Bio-One GmbH, Frickenhausen, } \\
\text { Deutschland }\end{array}$ \\
\hline Serologische Pipetten $(25 \mathrm{ml}, 10 \mathrm{ml}, 5 \mathrm{ml})$, & Sarstedt, Nümbrech, Deutschlandt \\
\hline Zellsieb (EASYstrainer, $70 \mu \mathrm{m})$ & $\begin{array}{l}\text { Greiner Bio-one, } \\
\text { Deutschland }\end{array}$ \\
\hline
\end{tabular}




\begin{tabular}{|l|l|}
\hline Verbrauchsmaterial & Hersteller \\
\hline $\begin{array}{l}\text { Zentrifugenröhrchen (Falcon tube, } 15 \mathrm{ml}, \\
50 \mathrm{ml})\end{array}$ & Sarstedt, Nümbrecht, Deutschland \\
\hline
\end{tabular}

\subsubsection{Zelllinien}

Tabelle 4: Zelllinien und Herkunft

\begin{tabular}{|l|l|}
\hline Zelllinien & Herkunft \\
\hline CEF (chicken embryo fibroblast)-Zellen & $\begin{array}{l}\text { AG Thoms, verschiedene Zelltypen aus } \\
\text { embryonierten Hühnereiern (Huhnzellen) }\end{array}$ \\
\hline HeLa-Zellen & $\begin{array}{l}\text { AG Thoms, epitheliale menschliche Zellen } \\
\text { aus einem Zervixkarzinom }\end{array}$ \\
\hline
\end{tabular}

\subsubsection{Bakterienstämme}

Tabelle 5: Bakterienstämme und Herkunft

\begin{tabular}{|l|l|}
\hline Bakterienstamm & Herkunft \\
\hline BioBlue ultracompetent cells XL10-Gold & Agilent Technologies, Santa Klara, USA \\
\hline
\end{tabular}

\subsubsection{Plasmide und Primer}

Tabelle 6: Plasmide und Primer

\begin{tabular}{|c|c|}
\hline Plasmide & Primer \\
\hline PST1596_MDH1 & $\begin{array}{l}\text { JH69 for gtcaccgttcctcgectgactagacaatgt } \\
\text { JH70 rev ccggacattgtctagtcaggcagaggaacg }\end{array}$ \\
\hline PST1596_MDH1_Mut-6C & $\begin{array}{l}\text { JH69 for gtcaccgttcccetgcctgactagacaatgt } \\
\text { JH70 rev ccggacattgtctagtcaggcaggggaacg }\end{array}$ \\
\hline PST1596_MDH1_Mut-6G & $\begin{array}{l}\text { JH71 for gtcaccgttccgctgcctgactagacaatgt } \\
\text { JH72 rev ceggacattgtctagtcaggcagcggaacg }\end{array}$ \\
\hline PST1596_MDH1_Mut-6A & $\begin{array}{l}\text { JH73 for gtcaccgttccactgcctgactagacaatgt } \\
\text { JH74 rev ccggacattgctagtcaggcagtggaacg }\end{array}$ \\
\hline PST1596_LDHB & $\begin{array}{l}\text { JH69 for gtcaccgttcegctgcctgactagacaatgt } \\
\text { JH70 rev ccggacattgtctagtcaggcagcggaacg }\end{array}$ \\
\hline
\end{tabular}




\begin{tabular}{|c|c|}
\hline Plasmide & Primer \\
\hline $\begin{array}{l}\text { PST1596_LDHB_Mut-6A } \\
\text { PST1596_LDHB_Mut-6C }\end{array}$ & $\begin{array}{l}\text { JH71 for gtcaccgttccgctgcctgactagacaatgt } \\
\text { JH72 rev ccggacattgtctagtcaggcagcggaacg } \\
\text { h=a,c }\end{array}$ \\
\hline PST1596_LDHB_Mut-6T & $\begin{array}{l}\text { JH259 for gtcaccaaaaaaacctgtgactagtgagctt } \\
\text { JH260 rev ccggaagctcactagtcacaggttttttg } \\
\text { JH261 for gtcaccaaaaacacctgtgactagtgagctt } \\
\text { JH262 rev ccggaagctcactagtcacaggtgtttttg }\end{array}$ \\
\hline PST1596_VEGF-A_TGA & $\begin{array}{l}\text { JH219 for gtcaccggtgagccgggctggaggaaggagcc } \\
\text { tccctcagggtttcgggaaccagacgtctcaccaggaaagacgt } \\
\text { JH220 rev ccgga cgtctttcctggtgagacgtctggttcc } \\
\text { gttcccgaaaccctgagggaggctccttcctccagcceggctcaccg }\end{array}$ \\
\hline PST1596_VEGF-A_TGG & $\begin{array}{l}\text { JH221 for gtcccggtgggccggctggaggaaggagcctccct } \\
\text { cagggtttcgggaaccagacgtctcaccaggaaagacgt } \\
\text { JH222 rev ccggacgtctttcctggtgagacgtctggttcccgaa } \\
\text { ccctgagggaggctccttccctccagcccggcccaccg }\end{array}$ \\
\hline
\end{tabular}

\subsubsection{Antikörper}

Tabelle 7: Antikörper

\begin{tabular}{|l|l|l|}
\hline Antikörper & Beschreibung & Hersteller \\
\hline $\begin{array}{l}\text { Anti- } \alpha \text { LDHB } \\
\text { Abcam ab75167) }\end{array}$ & $\begin{array}{l}\text { Polyklonaler Antikörper aus } \\
\text { dem Kaninchen }\end{array}$ & $\begin{array}{l}\text { Abcam, Cambridge, } \\
\text { Großbritanien }\end{array}$ \\
\hline $\begin{array}{l}\text { Anti-MDH1 (Sigma HPA } \\
\text { 027296) }\end{array}$ & $\begin{array}{l}\text { Polyklonaler Antikörper aus } \\
\text { dem Kaninchen }\end{array}$ & $\begin{array}{l}\text { Sigma-Aldrich, München, } \\
\text { Deutschland }\end{array}$ \\
\hline $\begin{array}{l}\text { Anti-PMP70 (Sigma SAB } \\
\text { 4200181) }\end{array}$ & $\begin{array}{l}\text { Polyklonaler Antikörper aus } \\
\text { der Maus }\end{array}$ & $\begin{array}{l}\text { Sigma-Aldrich, München, } \\
\text { Deutschland }\end{array}$ \\
\hline
\end{tabular}




\begin{tabular}{|c|c|c|}
\hline Antikörper & Beschreibung & Hersteller \\
\hline $\begin{array}{l}\text { Sekundärer Antikörper } \\
\text { (Cy3-Antikörper, rabbit) }\end{array}$ & $\begin{array}{l}\text { Polyklonaler IgG- } \\
\text { Antikörper aus dem Esel, } \\
\text { konjugiert an Cyanine 3, } \\
\text { richtet sich gegen die Fc- } \\
\text { Fragmente der primären } \\
\text { Antikörper der Kaninchen }\end{array}$ & $\begin{array}{l}\text { Jackson Immunoresearch, } \\
\text { Suffolk, USA }\end{array}$ \\
\hline $\begin{array}{l}\text { Sekundärer Antikörper } \\
\text { (Cy3-Antikörper, mouse) }\end{array}$ & $\begin{array}{l}\text { Polyklonaler IgG- } \\
\text { Antikörper aus der Ziege, } \\
\text { konjugiert an Cyanine 3, } \\
\text { richtet sich gegen die Fc- } \\
\text { Fragmente der primären } \\
\text { Antikörper der Maus }\end{array}$ & $\begin{array}{l}\text { Jackson Immunoresearch, } \\
\text { Suffolk, USA }\end{array}$ \\
\hline
\end{tabular}

\subsubsection{Kits und Chemikalien}

Tabelle 8: Kits/Chemikalien und Hersteller/Zusammensetzung

\begin{tabular}{|c|c|}
\hline Kits/Chemikalien & Hersteller/Zusammensetzung \\
\hline ABI PRISM Big Dye Terminator Kit & $\begin{array}{l}\text { Applied Biosystems, Darmstadt, } \\
\text { Deutschland }\end{array}$ \\
\hline Agarose & Bioline, Luckenwalde, Deutschland \\
\hline Agarosegel 1,5\% & $\begin{array}{l}1 \% \text { Agarose, } 0,0006 \% \text { GelRedTM in TAE- } \\
\text { Puffer }\end{array}$ \\
\hline Agarosegel $2 \%$ & $\begin{array}{l}2 \% \text { Agarose, } 0,0009 \% \text { GelRedTM in TAE- } \\
\text { Puffer }\end{array}$ \\
\hline Albumin Fraktion V & $\begin{array}{l}\geq 98 \% \text { BSA, Carl Roth, Karlsruhe, } \\
\text { Deutschland }\end{array}$ \\
\hline Ampicillin & Carl Roth, Karlsruhe, Deutschland \\
\hline Annealing-Puffer & $\begin{array}{l}1 \mathrm{M} \mathrm{NaCl}, 100 \mathrm{mM} \text { Tris-HCL }(\mathrm{pH} 7,5) \text {, } \\
10 \mathrm{mM} \text { EDTA in DEPC } \mathrm{H}_{2} \mathrm{O}\end{array}$ \\
\hline Äthanol & Merck, Darmstadt, Deutschland \\
\hline Auswahl-Agar & Gibco BRL, Karlsruhe, Deutschland \\
\hline Big Dye Sequencing Kit & Thermo Fisher, Osterode, Deutschland \\
\hline Digitonin 5\% & Life Technologies, Carlsbad, Deutschland \\
\hline
\end{tabular}




\begin{tabular}{|c|c|}
\hline Kits/Chemikalien & Hersteller/Zusammensetzung \\
\hline $\begin{array}{l}\text { Dulbecco's Modified Eagle Medium (DMEM) } \\
\text { (hoher Glukoseanteil, 4,5 g/l D-Glukose) }\end{array}$ & PAA Laboratories, Pasching, Österreich \\
\hline $\begin{array}{l}\text { Dulbecco's Modified Eagle Medium (DMEM) } \\
\text { (niedriger Glukoseanteil, } 1,0 \mathrm{~g} / 1 \quad \mathrm{D} \text { - } \\
\text { Glukose) }\end{array}$ & PAA Laboratories, Pasching, Österreich \\
\hline $\begin{array}{l}\text { ELU-Puffer (elution buffer, Elutionspuffer, } \\
\text { NucleoBond Xtra Midi plasmid Purification) }\end{array}$ & Macherey Nagel, Düren, Deutschland \\
\hline $\begin{array}{l}\text { EQU-Puffer (equilibration buffer, } \\
\text { Äquilibrierungspuffer, NucleoBond Xtra Midi } \\
\text { plasmid Purification) }\end{array}$ & Macherey Nagel, Düren, Deutschland \\
\hline Formamid-Lösung & Thermo Fisher, Osterode, Deutschland \\
\hline Fötales Kälberserum & Biowest, Nuaillé, Frankreich \\
\hline GelRedTM & Biotium, Hayward, Kalifornien, USA \\
\hline Geneticindisulfat (G418-Sulfat, $100 \mu \mathrm{g} / \mathrm{ml}$ ) & Roth, Karlsruhe, Deutschland \\
\hline Isopropanol & Merck, Darmstadt, Deutschland \\
\hline L-Glutamin & Merck, Darmstadt, Deutschland \\
\hline Ladepuffer & $\begin{array}{l}0,4 \mathrm{~g} \text { EDTA, } 15 \mathrm{~g} \text { Ficoll-400, } 10 \mathrm{ml} \\
\text { Glycerin, } 1 \text { Spatelspitze Orange } \mathrm{G}\end{array}$ \\
\hline Laminin & Sigma-Aldrich, München, Deutschland \\
\hline Laufpuffer & $\begin{array}{l}3 \mathrm{~g} \text { Tris-Base, } 14,4 \mathrm{~g} \quad \text { Glycin, } 5 \mathrm{ml} \\
20 \% \mathrm{SDS} \text {, auf } 1000 \mathrm{ml} \mathrm{H}_{2} \mathrm{O}\end{array}$ \\
\hline LB (bysogeny broth)-Medium & $\begin{array}{l}5 \mathrm{~g} \text { Trypton ohne Pepton, 2,5 g Hefeextrakt, } \\
5 \mathrm{~g} \mathrm{NaCl} \text { auf } 500 \mathrm{ml} \mathrm{H}_{2} \mathrm{O}\end{array}$ \\
\hline Lipofectamine 2000 & Thermo Fisher, Osterode, Deutschland \\
\hline Lösung 1 (Mini Präparation) & $\begin{array}{l}50 \mathrm{mM} \quad \text { Glukose, } 25 \mathrm{mM} \text { Tris } / \mathrm{HCl} \\
(\mathrm{pH} 8,0), 10 \mathrm{mM} \text { EDTA }(\mathrm{pH} 8,0)\end{array}$ \\
\hline Lösung 2 (Mini Präparation) & $0,2 \mathrm{~N} \mathrm{NaOH}, 1 \% \mathrm{SDS}$ \\
\hline Lösung 3 (Mini Präparation) & $3 \mathrm{M} \mathrm{NaAc} \mathrm{pH} \mathrm{4,8}$ \\
\hline $\begin{array}{l}\text { LYS-Puffer (lysis buffer, Lysepuffer, } \\
\text { NucleoBond Xtra Midi plasmid Purification) }\end{array}$ & Macherey Nagel, Düren, Deutschland \\
\hline
\end{tabular}




\begin{tabular}{|c|c|}
\hline Kits/Chemikalien & Hersteller/Zusammensetzung \\
\hline $\begin{array}{l}\text { NE-Puffer (elution buffer, Elutionspuffer, } \\
\text { NucleoSpin Extract II) }\end{array}$ & $\begin{array}{l}5 \text { MM Tris/HCL, Macherey Nagel, Düren, } \\
\text { Deutschland }\end{array}$ \\
\hline $\begin{array}{lll}\text { NEU-Puffer } \quad \text { (neutralization } & \text { buffer, } \\
\text { Neutralisierungspuffer NucleoBond Xtra } \\
\text { Midi plasmid Purification) }\end{array}$ & Macherey Nagel, Düren, Deutschland \\
\hline $\begin{array}{l}\text { NT-Puffer (binding buffer, Bindepuffer } \\
\text { NucleoSpin Extract II) }\end{array}$ & Macherey Nagel, Düren, Deutschland \\
\hline $\begin{array}{l}\text { NT-Puffer } 3 \text { (wash buffer, Waschpuffer, } \\
\text { NucleoSpin Extract II) }\end{array}$ & Macherey Nagel, Düren, Deutschland \\
\hline NucleoBond Xtra Midi plasmid Purification & Macherey Nagel, Düren, Deutschland \\
\hline NucleoSpin Extract II & Macherey Nagel, Düren, Deutschland \\
\hline NucleoSpin Gel and PCR Clean-up & Macherey Nagel, Düren,Deutschland \\
\hline Paraformaldehyd (4 \% in PBS) & USB, Cleveland, Ohio, USA \\
\hline Penicillin-Streptomycin-Lösung & Biochrom/Merck, Darmstadt, Deutschland \\
\hline Phosphatgepufferte Salzlösung (PBS) & PAA, Pasching, Österreich \\
\hline Primer-T7 (F) & Sigma-Aldrich, München, Deutschland \\
\hline Prolong Gold (mit DAPI) & Life Technologies, Carlsbad, Deutschland \\
\hline $\begin{array}{l}\text { Puffer } 3.1 \text { (NucleoBond Xtra Midi plasmid } \\
\text { Purification) }\end{array}$ & Macherey Nagel, Düren, Deutschland \\
\hline Restriktionsenzym BspEI & Thermo Fisher, Osterode, Deutschland \\
\hline Restriktionsenzym BstEII & Thermo Fisher, Osterode, Deutschland \\
\hline $\begin{array}{l}\text { RES-Puffer (resuspensions buffer, } \\
\text { Resuspensionspuffer, NucleoBond Xtra Midi } \\
\text { plasmid Purification) }\end{array}$ & Macherey Nagel, Düren, Deutschland \\
\hline RNAse A & Fermentas, St. Leon-Rot, Deutschland \\
\hline Sequenzierungsmix BigDye & Thermo Fisher, Osterode, Deutschland \\
\hline T4 Ligase & $\begin{array}{l}\text { New England BioLabs, Frankfurt am Main, } \\
\text { Deutschland }\end{array}$ \\
\hline T4 Puffer & $\begin{array}{l}\text { New England BioLabs, Frankfurt am Main, } \\
\text { Deutschland }\end{array}$ \\
\hline Triton-X 100 & Roth, Karlsruhe, Deutschalnd \\
\hline
\end{tabular}




\begin{tabular}{|l|l|}
\hline Kits/Chemikalien & Hersteller/Zusammensetzung \\
\hline Trypsin-EDTA (0,05\%) & Biochrom/Merck, Darmstadt, Deutschland \\
\hline $\begin{array}{l}\text { WASH-Puffer (Waschpuffer, NucleoBond } \\
\text { Xtra Midi plasmid Purification) }\end{array}$ & Macherey Nagel, Düren, Deutschland \\
\hline
\end{tabular}

\subsection{Methoden}

\subsubsection{Verwendete Zelllinien und deren Kultivierung}

In dieser Arbeit wurden HeLa-Zelllinien und Huhnzellen (chicken embryo fibroblast, CEF) verwendet. Die Suspensionszellen wurden unter sterilen Bedingungen bei $37^{\circ} \mathrm{C}$ kultiviert.

\subsubsection{Kultivierung von HeLa-Zellen}

HeLa-Zellen sind menschliche Epithelzellen, die aus der Biopsie eines Zervixkarzinoms stammen. Die Kultivierung der adhärend wachsenden Zellen erfolgte in $10 \mathrm{ml}$ des Basismediums Dulbecco's Modified Eagle Medium (DMEM) mit niedrigem Glukoseanteil (1,0 g/l). Dieses wurde zuvor mit $10 \%$ fötalem Kälberserum (fetal calf serum, FCS), $1 \%$ Penicillin-Streptomycin-Lösung, sowie mit 1 \% L-Glutamin versetzt.

Je nach Zellwachstum erfolgte alle drei bis fünf Tage ein Mediumwechsel mit Aufteilung der Zellen in einem Verhältnis 1:5. Zunächst wurden die Zellen mit $10 \mathrm{ml}$ phosphatgepufferter Salzlösung (PBS) gewaschen und bei $37^{\circ} \mathrm{C}$ mit $1 \mathrm{ml}$ Trypsin-EDTA $(0,05 \%)$ für 5 min bis zu ihrem Ablösen vom Kulturflaschenboden (evtl. durch vorsichtiges Abklopfen) inkubiert. Zum Inhibieren der Trypsinwirkung wurde die Zellsuspension mit $9 \mathrm{ml}$ Medium versetzt und mit einer Drehzahl von $800 \mathrm{rpm}$ für 5 min zentrifugiert. Es erfolgte ein Absaugen des Mediums. Anschließend wurde ein Fünftel des Zellpellets in $10 \mathrm{ml}$ frischem Medium in einer T75-Zellkulturflasche kultiviert.

\subsubsection{Kultivierung von CEF-Zellen}

CEF-Zellen sind eine Mischung verschiedener Zelltypen aus embryonierten Hühnereiern. Die Zellen wurden von der AG Thoms isoliert.

Für die Kultivierung der CEF-Zellen wurde DMEM mit einem hohen Glukoseanteil (4,5 g/l) verwendet. Das Medium wurde mit 10 \% FCS, 1 \% Penicillin-Streptomycin-Lösung und $1 \%$ L-Glutamin versetzt. Je nach Zellwachstum erfolgte alle fünf bis sieben Tage ein Mediumwechsel mit Aufteilung der Zellen in einem Verhältnis 1:4. Dazu wurden die adhärent wachsenden Zellen mit $1 \mathrm{ml}$ Trypsin-EDTA (0,05 \%) in einer Inkubationszeit von 
8 min bei $37^{\circ} \mathrm{C}$ vom Kulturflaschenboden gelöst, mit $9 \mathrm{ml}$ Medium versetzt und mit einer Drehzahl von 800 rpm für 5 min zentrifugiert. Nach dem Absaugen des Mediums wurde das Zellpellet auf vier Kulturflaschen verteilt und mit jeweils $10 \mathrm{ml}$ Medium versetzt.

Für die Immunfluoreszenzfärbung und die Transfektion wurden die Zellen vor dem Aussähen in einer Neubauer-Zählkammer gezählt. Für jedes Experiment wurden 100.000 Zellen auf zwölf Näpfchen einer Mikrotitierplatte $(12$ well plate) pipettiert. Pro Näpfchen wurde $1 \mathrm{ml}$ Medium hinzugegeben und über Nacht bei $37^{\circ} \mathrm{C}$ inkubiert.

\subsubsection{Immunfluoreszenzfärbung}

Die Lokalisationsbestimmung der Proteine MDH1(x), LDHB(x) und PMP70 in CEF-Zellen erfolgte mittels indirekter Immunfluoreszenzfärbung. Dafür wurden primäre Antikörper, die sich spezifisch gegen die Target-Proteine MDH1(x), LDHB(x) bzw. PMP70 richteten und sekundäre Antikörper, die sich gegen die Fc-Fragmente der primären Antikörper richteten, verwendet. Die Detektion der Antikörper erfolgte mittels Immunfluoreszenzmikroskopie.

Für die Färbung wurden zwölf Deckplättchen mit Laminin beschichtet und in die Näpfchen einer Mikrotiterplatte gelegt. Für jedes Experiment wurden 100.000 Zellen ausgezählt, auf die zwölf Deckplättchen pipettiert und mit frischem Medium (1 ml/Näpfchen) für 24 Stunden bei $37^{\circ} \mathrm{C}$ inkubiert.

Nach gründlichem Waschen mit PBS erfolgte bei den Zellen, bei denen ein Auswaschen des Zytoplasmas erwünscht war, eine Behandlung mit 0,02\%igem Digitonin. Dazu wurde $5 \%$ iges Digitonin für 5 min bei $90^{\circ} \mathrm{C}$ erhitzt und anschließend mit PBS 1:250 verdünnt. Die Zellen, bei denen kein Auswaschen des Zytoplasmas gewünscht war, wurden stattdessen erneut mit PBS behandelt. Nach dem Einwirken des Digitonins wurden alle Zellen mit PBS gewaschen und mit Paraformaldehyd (4\%) für 20 min behandelt und somit fixiert. Es erfolgte ein erneutes Waschen mit PBS. Anschließend wurden die Zellen mit 0,5\%igem Triton X-100 in PBS über 5 min permeabilisiert, mit 10\%igem Rinderalbumin (bovine serum albumine, BSA) blockiert und bei $37^{\circ} \mathrm{C}$ für 20 min inkubiert.

Die Inkubation der fixierten Zellen mit den Antikörpern erfolgte in $30 \mu \mathrm{l}$ 10\%igem BSA bei Raumtemperatur über insgesamt 24 Stunden bei Dunkelheit. Zunächst erfolgte die Färbung mit den primären Antikörpern. Die Verdünnungskonzentrationen der Antikörper in $30 \mu \mathrm{l}$ 10\%igem BSA wurden für die jeweiligen Antikörper einzeln ausgerechnet. Der PMP70Antikörper wurde in einem Verhältnis von 1:500, der MDH1-Antikörper in einem Verhältnis von 1:400 und der LDHB-Antikörper in einem Verhältnis von 1:200 verdünnt. Es erfolgte eine Inkubation mit den Zellen für eine Stunde bei Dunkelheit. Nach dreimaligem Waschen 
mit PBS wurde mit dem sekundären Antikörper gefärbt. Der sekundäre Antikörper wurde in einem Verhältnis von 1:200 in $30 \mu \mathrm{l} 10 \%$ igem BSA verdünnt und mit den Zellen eine Stunde bei Dunkelheit inkubiert. Anschließend wurden die Zellen dreimalig mit PBS gewaschen. Die mit Äthanol gereinigten Objektivträger wurden beschriftet und mit je $30 \mu \mathrm{l}$ Prolong Gold (mit DAPI) betropft. Die an die Deckplättchen fixierten Zellen wurden auf Objektivträger gelegt und 24 Stunden bei Raumtemperatur, Dunkelheit und unter einem Gewicht inkubiert. Nach 24 Stunden wurden die Deckplättchen an den Objektträgern mit Nagellack fixiert.

\subsubsection{Mikroskop}

Die Immunfluoreszenzmikroskopie erfolgte mit einem Fluoreszenzmikroskop der Firma Zeiss (Imager M1 fluorescence wide field) unter Verwendung eines 100x/Öl/1,3 Objektivs und der Software Axiovision 4.8. Pro Einstellung wurden 10-20 Bilder (Z-Stapel) mit der Kamera (Axiocam HRm) in einem Abstand von 0,2 - 0,4 $\mu \mathrm{m}$ hergestellt.

\subsubsection{Klonierung der Readthrough-Produkte}

Die Klonierung erfolgte durch Integration der DNA-Fragmente in Plasmid-Vektoren, die von Bakterien aufgenommen, vervielfältigt und letztendlich aus den Bakterien isoliert wurden. Tabelle 9 zeigt eine Auflistung der klonierten Konstrukte, die für die Arbeit hergestellt wurden.

Tabelle 9: Auflistung der klonierten Konstrukte

\begin{tabular}{|l|l|}
\hline Name des Konstrukts & Inhalt des Konstrukts \\
\hline LDHB-6MutAx & $\begin{array}{l}\text { RFP - SCC LDHB, Mutation an Position -6 (Adenin) - } \\
\text { GFP }\end{array}$ \\
\hline LDHB-6MutCx & RFP - SCC LDHB, Mutation an Position -6 (Cytosin) - \\
\hline MDH1-6MutAx & $\begin{array}{l}\text { RFP - SCC MDH1, Mutation an Position -6 (Adenin) - } \\
\text { GFP }\end{array}$ \\
\hline MDH1-6MutCx & $\begin{array}{l}\text { RFP - SCC MDH1, Mutation an Position -6 (Cytosin) - } \\
\text { RFP - SCC MDH1, Mutation an Position -6 (Thymin) - } \\
\text { GFP }\end{array}$ \\
\hline MDH1-6MutTx &
\end{tabular}




\begin{tabular}{|c|c|}
\hline Name des Konstrukts & Inhalt des Konstrukts \\
\hline VEGF-Ax & $\begin{array}{l}\text { RFP - Stopcodon des Gens VEGF-Ax und den } \\
\text { darauffolgenden } 63 \text { distalen Nukleotiden - GFP }\end{array}$ \\
\hline VEGF-A-TAA & $\begin{array}{l}\text { RFP - Stopcodon des Gens VEGF-Ax und den } \\
\text { darauffolgenden } 63 \text { distalen Nukleotiden, einem weiteren } \\
\text { Stopcodon (TAA) - GFP }\end{array}$ \\
\hline RettpR168X & $\begin{array}{l}\text { RFP - Nonsense-Mutation RettpR168X - GFP } \\
\text { Mutation: c.502C }>\mathrm{T}\end{array}$ \\
\hline RettpR270X & $\begin{array}{l}\text { RFP - Nonsense-Mutation RettpR270X - GFP } \\
\text { Mutation: c. } 808 \mathrm{C}>\mathrm{T}\end{array}$ \\
\hline RettpY141X & $\begin{array}{l}\text { RFP - Nonsense-Mutation RettpY141X - GFP } \\
\text { Mutation: c. } 423 \mathrm{C}>\mathrm{G}\end{array}$ \\
\hline RettpQ170X & $\begin{array}{l}\text { RFP - Nonsense-Mutation RettpQ170X - GFP } \\
\text { Mutation: c.508C > T }\end{array}$ \\
\hline RettpR255X & $\begin{array}{l}\text { RFP - Nonsense-Mutation RettpR255X - GFP } \\
\text { Mutation: c. } 763 \mathrm{C}>\mathrm{T}\end{array}$ \\
\hline RettpS204X & $\begin{array}{l}\text { RFP - Nonsense-Mutation RettpS204X - GFP } \\
\text { Mutation: c. } 611 \mathrm{C}>\mathrm{G}\end{array}$ \\
\hline RettpQ244X & $\begin{array}{l}\text { RFP - Nonsense-Mutation RettpQ244X - GFP } \\
\text { Mutation: c.730C }>\mathrm{T}\end{array}$ \\
\hline RettpK175X & $\begin{array}{l}\text { RFP - Nonsense-Mutation RettpK175X - GFP } \\
\text { Mutation: c.523A }>\text { T }\end{array}$ \\
\hline Rett-pS68X & $\begin{array}{l}\text { RFP - Nonsense-Mutation Rett-pS68X - GFP } \\
\text { Mutation: c. } 203 \mathrm{C}>\mathrm{G}\end{array}$ \\
\hline RettpK177X & $\begin{array}{l}\text { RFP - Nonsense-Mutation RettpK177X - GFP } \\
\text { Mutation: c.529A > T }\end{array}$ \\
\hline
\end{tabular}




\begin{tabular}{|l|l|}
\hline Name des Konstrukts & Inhalt des Konstrukts \\
\hline RettpK363X & RFP - Nonsense-Mutation RettpK363X - GFP \\
& Mutation: c.1087A $>$ T \\
\hline
\end{tabular}

\subsubsection{Vektorverdau}

Zur Herstellung neuer Plasmide wurde die DNA der Vektorplasmide von Restriktionsenzymen an spezifischen Schnittstellen gezielt geschnitten.

Es wurden $4 \mu \mathrm{l}$ DNA eines Vektors, welcher die DNA eines rot fluoreszierenden Proteins (RFP) und grün fluoreszierenden Proteins (GFP) enthielt, verwendet. Die DNA wurde in $4 \mu \mathrm{l}$ Pufferlösung des Puffers 3.1 mit 0,5 $\mu \mathrm{l}$ des Restriktionsenzyms BspEI und 34,5 $\mu \mathrm{l} \mathrm{H}_{2} \mathrm{O}$ bei $37^{\circ} \mathrm{C}$ für zwei Stunden inkubiert. Anschließend wurde das Restriktionsenzym BstEII hinzugegeben und für weitere zwei Stunden bei $60{ }^{\circ} \mathrm{C}$ inkubiert.

\subsubsection{Aufreinigung der DNA}

Die Aufreinigung der DNA erfolgte nach Herstellerprotokoll mit dem NucleoSpin Extract II Kit der Firma Macherey Nagel, Düren. Das DNA-Versuchsvolumen wurde mit $\mathrm{H}_{2} \mathrm{O}$ auf $100 \mu \mathrm{l}$ aufgefüllt, anschließend mit $200 \mu \mathrm{l}$ NT-Puffer (binding buffer, Bindepuffer) gemischt und in eine Säule pipettiert. Nach dem Zentrifugieren (1 min, 11.000 x g, Raumtemperatur) wurde der Überstand verworfen. Die Säule wurde mit $700 \mu$ NT 3-Puffer (wash buffer, Waschpuffer) gewaschen. Nach dem Verwerfen der Waschlösung wurde die aufgereinigte DNA in einem 1,5-ml-Mikroreaktionsgefäß durch Zentrifugation (1 min, $11.000 \mathrm{x} \mathrm{g}$, Raumtemperatur) in $15 \mu \mathrm{l}$ NE-Puffer (elution buffer, Elutionspuffer) eluiert.

\subsubsection{Primerhybridisierung (Primer Annealing)}

Die Primerhybridisierung ist ein Teilprozess der Klonierung, welcher der Zusammenlagerung der Primer dient.

Zur Primerhybridisierung wurde ein Ansatz mit je $2 \mu \mathrm{l}$ des vorwärts und rückwärts andockenden Primers $(100 \mu \mathrm{M}), 2 \mu \mathrm{l}$ Annealing-Puffer und $14 \mu \mathrm{l} \mathrm{H}_{2} \mathrm{O}$ in ein Mikroreaktionsgefäß pipettiert. Zu einer Trennung der eventuell zusammengelagerten Primer wurde der Ansatz im Thermozykler T3000 zunächst für 30 Sekunden auf $95^{\circ} \mathrm{C}$ erhitzt und anschließend langsam für 30 Sekunden auf $40{ }^{\circ} \mathrm{C}$ abgekühlt. So entstanden gute Bedingungen für eine Zusammenlagerung der vorwärts und rückwärts andockenden Primer. Diese wurden anschließend in den geschnittenen Vektor ligiert. 


\subsubsection{Ligation}

Die Ligation dient der Verknüpfung zweier DNA- beziehungsweise RNA-Segmente. In dieser Arbeit wurde die DNA-Sequenz des SCC mittels Ligation in das Vektorplasmid integriert. Das Enzym T4-Ligase diente der Verknüpfung der freien 3'-OH-Enden mit den 5'-PO4-Enden der DNA-Abschnitte.

Es wurden $25 \mathrm{ng}$ des Vektors mit 2,5 ng des Inserts mit $1 \mu \mathrm{l}$ T4-Puffer und 0,5 $\mu \mathrm{l}$ T4-Ligase gemischt und auf $10 \mu \mathrm{l}$ mit $\mathrm{H}_{2} \mathrm{O}$ aufgefüllt. Das Verhältnis zwischen Vektor und Insert wurde 1:10 gewählt, da das Insert 31 Basenpaare und der Vektor 7000 Basenpaare beinhalteten. Das Substanzgemisch wurde eine Stunde bei Raumtemperatur inkubiert.

Die Volumina des Vektors und des Inserts wurden entsprechend der vorhandenen DNAKonzentration errechnet. Beispielsweise ließ sich bei der Klonierung des Plasmids der LDHB(x) (Wildtyp) nach der Primerhybridisierung eine DNA-Konzentration von $830,39 \mathrm{ng} / \mu \mathrm{l}$ messen. Diese wurde mit Wasser 1:100 verdünnt. Das Insert enthielt demnach $8,3039 \mathrm{ng}$ DNA pro $1 \mu \mathrm{l}$. Der Vektor dagegen beinhaltete nach dem Vektorverdau 38,7 ng/ $\mu$ l DNA. 2,5 ng DNA des Inserts entsprachen dementsprechend einem Volumen von 0,3 $\mu$ l. Für 25 ng Vektor wurde ein Volumen von 0,94 $\mu$ l bestimmt. Dem Substanzgemisch aus Insert, Vektor, T4-Puffer, T4-Ligase wurden 7,56 $\mu \mathrm{H}_{2} \mathrm{O}$ hinzugefügt, um auf ein Endvolumen von $10 \mu \mathrm{l} \mathrm{zu} \mathrm{kommen.}$

\subsubsection{Transformation}

Die Transformation dient der Vervielfältigung von Plasmid-DNA in kompetenten Bakterienstämmen, welche die Plasmid-DNA aufnehmen und sich vermehren.

Es wurde $1 \mu \mathrm{l}$ des Ligationsansatzes mit $10 \mu \mathrm{l}$ ultrakompetenten Bakterienzellen (BioBlueZellen) für $20 \mathrm{~min}$ auf Eis inkubiert. Anschließend wurden die Zellen 2 min bei $42{ }^{\circ} \mathrm{C}$ erhitzt und wieder 2 min auf Eis gelagert. Es wurden $400 \mu \mathrm{LB}$ (ysogeny broth)-Medium im Sterilfeld eines Bunsenbrenners hinzugefügt. Der Ansatz wurde bei $37^{\circ} \mathrm{C}$ unter permanentem Schütteln bei $500 \mathrm{rpm} 60$ Minuten inkubiert.

Währenddessen wurden pro Transformation zwei LB-Agarplatten mit Ampicillin bei $37^{\circ} \mathrm{C}$ in einem Inkubator vorgewärmt.

Zur Herstellung der LB-Agarplatten wurden $500 \mathrm{ml} \mathrm{LB}$-Agar autoklaviert, mit $500 \mu \mathrm{l}$ Ampicillin (Verhältnis 1:1000) versehen und im Sterilfeld eines Bunsenbrenners in Petrischalen gegossen. Nach kurzem Trocknen für 5 min bei Raumtemperatur wurden die Platten über Nacht bei $37{ }^{\circ} \mathrm{C}$ inkubiert. 
Für die Transformation wurde die Suspension mit den Bakterien auf die LB-Agarplatten mit Ampicillin ausgestrichen. Aufgrund des Selektivagars wuchsen auf den Platten Kolonien einzelner transformierter Bakterien. Nach 12 bis 18 Stunden wurde mit einer Pipettenspitze eine einzeln stehende Kolonie vorsichtig von dem Agar abgehoben und als Vorkultur in einem sterilen Röhrchen mit 3 ml LB-Medium und $3 \mu$ Ampicillin 18 bis 20 Stunden unter Schütteln inkubiert. $2 \mathrm{ml}$ der Vorkultur wurden dann für die Mini-Präparation verwendet. Aus der verbliebenen Hauptkultur (Volumen $1 \mathrm{ml}$ ) wurde durch eine Midi-Präparation die Plasmid-DNA aus den Bakterien herauspräpariert.

\subsubsection{Mini-Präparation}

Die Durchführung der Mini-Präparation erfolgte basierend auf einer alkalischen Lyse. Durch die Mini-Präparation konnten kleinste Mengen der DNA aus den Bakterien der vorangegangenen Transformation gewonnen und auf Intaktheit geprüft werden.

Es erfolgte die Zentrifugation (1 min, 8000 rpm, Raumtemperatur) von $2 \mathrm{ml}$ der Vorkultur. Nach Verwerfen des Überstandes wurden die Bakterien mit $200 \mu \mathrm{l}$ der Lösung 1 (Tabelle 8) und 1:100 RNAse A $(10 \mu \mathrm{g} / \mu \mathrm{l})$ resuspendiert. Durch Hinzufügen von $200 \mu \mathrm{l}$ der Lösung 2 (Tabelle 8) wurden die chromosomale DNA und die Proteine denaturiert und die Bakterien lysiert. Durch eine pH-Neutralisierung mit $300 \mu \mathrm{l}$ der Lösung 3 (Tabelle 8) wurde die DNA wieder renaturiert. Die Proben wurden zentrifugiert (10 min, 11.000 x g, Raumtemperatur). Der Überstand, in dem sich auch die Plasmid-DNA befand, wurde in ein Reaktionsgefäß überführt. Durch Hinzufügen von $500 \mu$ l Isopropanol (100\%), anschließendem Schütteln mit dem Vortexmischer und einer Zentrifugation (20 min, 14.000 x g, Raumtemperatur) erfolgte die Ausfällung der DNA. Nach dem Verwerfen des Überstandes wurde die DNA mit $400 \mu$ l Äthanol $(70 \%)$ unter kurzem Schütteln mit dem Vortexmischer und mit anschließender Zentrifugation (10 min, 14.000 x g, Raumtemperatur) gewaschen. Das Pellet wurde für $5 \mathrm{~min}$ bei $37^{\circ} \mathrm{C}$ auf einem Heizblock getrocknet. Anschließend wurde es in $100 \mu \mathrm{l}$ $\mathrm{H}_{2} \mathrm{O}$ aufgenommen.

\subsubsection{Bestimmungen der Konzentration und Reinheit der Nukleinsäuren}

Die Bestimmung von Konzentration und Reinheit von Nukleinsäuren erfolgte photometrisch mit dem Spektrophotmeter Nanodrop ND 1000.

Die Konzentrationsbestimmung der DNA wurde nach dem Lambert-Beer'sche-Gesetz anhand der Messung der Absorption bei einer Wellenlänge von $260 \mathrm{~nm}$ (Absorptionsmaximum für Nukleinsäuren) durchgeführt. 
Die Reinheit der DNA-Probe wurde anhand von Wellenlängen-Quotienten überprüft: Das Absorptionsmaximum von Proteinen liegt bei $280 \mathrm{~nm}$. Das Verhältnis der Absorption bei $260 \mathrm{~nm}$ und der Absorption bei $280 \mathrm{~nm}$ sollte deswegen größer als 1,8 sein (OD260 / OD280 > 1,8). Um eine Verunreinigung durch Lösungsmittel zu erkennen, wurde auf das Verhältnis von $260 \mathrm{~nm}$ und $230 \mathrm{~nm}$ geprüft. Es sollte nicht größer als 1,6 sein (OD260 / OD230 > 1,6).

\subsubsection{Sequenzierung}

Die Plasmid-DNA wurde nach der Sanger-Methode sequenziert.

Für die Sequenzierreaktion wurden 300 ng der aufgereinigten DNA mit $1 \mu l$ SequenzierPuffer, 0,5 $\mu$ l Primer (T7 Primer F, der DNA-Sequenz vorwärts andockend) sowie $2 \mu$ l des Sequenzierungsmix BigDye angesetzt und auf $10 \mu \mathrm{l}$ mit $\mathrm{H}_{2} \mathrm{O}$ aufgefüllt. Die Sequenzierreaktion erfolgte im Thermozykler bei einer Annealing-Temperatur von $60^{\circ} \mathrm{C}$.

Für die Aufreinigung der Sequenzierungsprodukte wurden $10 \mu \mathrm{l}$ des Sequenzierungsprodukts mit $120 \mu \mathrm{l} \mathrm{H} \mathrm{H}_{2} \mathrm{O}, 10 \mu \mathrm{l} \mathrm{NaAc}(\mathrm{pH} 4,6)$ und $220 \mu \mathrm{l}$ Äthanol (100\%) versetzt. Nach einer Inkubation von 15 min bei Raumtemperatur und einer Zentrifugation (20 min, $14.000 \mathrm{rpm}$, Raumtemperatur) wurden der Überstand verworfen und die DNA mit $300 \mu \mathrm{l}$ Äthanol (70\%) gewaschen. Das DNA-Pellet wurde bei $37^{\circ} \mathrm{C}$ im Heizblock getrocknet. Abschließend wurde die DNA in $10 \mu \mathrm{l}$ Formamid-Lösung resuspendiert. Die Analyse der Proben wurde mit dem Genetic Analyzer (ABI PRISM 3130) von Dr. rer. nat. Ohlenbusch (AG Thoms) durchgeführt.

\subsubsection{Midi-Präparation}

Die Präparation der transformierten Plasmide aus den kompetenten Bakterienstämmen erfolgte nach Herstellerangaben mit dem NucleoBond Xtra plasmid purification Kit der Firma Macherey Nagel, Düren.

Die restliche Lösung der Hauptkultur, die nicht zur Mini-Präparation verwendet wurde (siehe 2.2.4.5), wurde zentrifugiert (15 min, $5000 \mathrm{xg}, 4{ }^{\circ} \mathrm{C}$ ). Anschließend wurde der Überstand vollständig verworfen. Das Zellpellet wurde mit $8 \mathrm{ml}$ des RES-Puffers (resuspensions buffer, Resuspensionspuffers) und der RNAase durch ständiges Auf- und Abpipettieren resuspendiert. Durch Zugabe von $8 \mathrm{ml}$ LYS-Puffer (bysis buffer, Lysepuffer) wurden die Bakterienzellen lysiert. Die Suspension wurde vorsichtig durch 5-maliges Invertieren des Gefäßes gemischt und für 5 min bei Raumtemperatur inkubiert. 
In dieser Zeit wurde eine NucleoBond Xtra Säule mit einem Filter versehen, der mit $12 \mathrm{ml}$ EQU-Puffer (equilibration buffer, Äquilibrierungspuffer) befeuchtet wurde. Dem Zelllysat wurden $8 \mathrm{ml}$ des NEU-Puffers (neutralization buffer, Neutralisationspuffer) hinzugegeben und durch 15-maliges Invertieren vorsichtig gemischt.

Die Proteine und die genomische DNA fielen aus. Das Zelllysat wurde auf den Filter der Säule geladen. Das Präzipitat aus den Proteinen und der DNA blieben nach dem Durchlaufen im Filter zurück. Der Filter wurde mit $5 \mathrm{ml}$ EQU-Puffer gewaschen und die Lysatreste konnten aus dem Filter entfernt wurden. Der Filter wurde entsorgt und die DNA wurde auf der Säulenmembran mit $8 \mathrm{ml}$ WASH-Puffer (Waschpuffer) gewaschen.

Nun wurde die DNA mit $5 \mathrm{ml}$ ELU-Puffer (elution buffer, Elutionspuffer) von der Membran eluiert und in einem Zentrifugenröhrchen $(50 \mathrm{ml})$ gesammelt. Die DNA wurde anschließend auf fünf Mikrotitiergefäße $(2 \mathrm{ml})$ aufgeteilt. Nach der Zugabe von $700 \mu$ l Isopropanol $(100 \%)$ in jedes der Mikrotitiergefäße und nach Mischen auf einem Vortexmischer erfolgte die Zentrifugation (30 min, $14.000 \mathrm{xg}, 4^{\circ} \mathrm{C}$ ). Der Überstand der DNA wurde abpipettiert und es wurden $400 \mu \mathrm{l}$ Äthanol (70\%) hinzugefügt und zentrifugiert (5 min, $14.000 \mathrm{x} \mathrm{g}$, Raumtemperatur). Das Äthanol (70 \%) wurde abpipettiert und das DNA-Pellet wurde bei Raumtemperatur getrocknet. Nun konnte die DNA in $60 \mu \mathrm{l}$ sterilen $\mathrm{H}_{2} \mathrm{O}$ durch Schütteln bei Raumtemperatur für 15 min resuspendiert werden.

Im Anschluss erfolgte eine Bestimmung der DNA-Konzentration und des Reinheitsgrades (2.2.4.7).

\subsubsection{Transfektion mit Lipofectamine 2000}

Die Transfektion ist ein Prozess, bei dem fremde DNA bzw. RNA in Zellen eingebracht wird.

Die Transfektion wurde mit Lipofectamine 2000 durchgeführt. Durch eine Komplexbildung der negativ geladenen Phophatgruppe der DNA und der kationischen Lipide kommt es zu einer endozytischen Aufnahme der Komplexe in das Zytoplasma. Im Zellinneren wird die endosomale Membran destabilisiert, sodass die fremde DNA ins Zellinnere freigesetzt wird.

Die Transfektion erfolgte unter sterilen Bedingungen in der Zellkultur. Pro Probe wurden $100 \mu \mathrm{l}$ DMEM (1,0 g/1 D-Glucose) mit 1 \% Penicillin-Streptomycin-Lösung und $1 \%$ LGlutamin mit 7,5 $\mu$ Lipofectamine in einem Reaktionsgefäß (A) gemischt. In ein zweites Reaktionsgefäß (B) wurden $125 \mu$ des gleichen Mediums und 1,7 $\mu$ l Plasmid-DNA gegeben. Anschließend wurden je $100 \mu$ laus den Reaktionsgefäßen A und B in das Reaktionsgefäß C 
pipettiert und invertiert. Nach einer Inkubationszeit von 5 min bei Raumtemperatur wurden $150 \mu \mathrm{l}$ des Reaktionsgemisches (C) auf die ausgesäten Zellen der Mikrotiterplatte pipettiert (siehe 2.2.1). Die Zellen konnten nach einer Inkubationszeit von 24 Stunden bei $37^{\circ} \mathrm{C}$ für die Durchflusszytometrie beziehungsweise für die Kontrollen der Immunfluoreszenzmikroskopie verwendet werden.

\subsubsection{Induktion von Readthrough mit Geneticin}

Geneticin (G418) ist ein Aminoglykosid, welches ab einer bestimmten Konzentration Readthrough induziert. Für die Readthrough-Induktion wurde unter sterilen Bedingungen vor der Transfektion 0,4 $\mu \mathrm{g}$ Geneticin (4 $\mu \mathrm{l}$; Stocklösung $100 \mu \mathrm{g} / \mathrm{ml}$ ) mit $700 \mu \mathrm{l}$ Medium gemischt und auf die ausgesäten Zellen gegeben. Nach einer Inkubationszeit von zwei Stunden wurde mit der Transfektion begonnen.

\subsubsection{Durchflusszytometrie}

Die Durchflusszytometrie ist eine Methode zur Messung markierter Zellen. Es können Zellen aufgrund ihrer Eigenschaften (Form, Struktur, Markierung) gezählt und analysiert werden.

\subsubsection{Aufbereitung der Zellen für die Durchflusszytometrie}

Die Zellen wurden nach der Transfektion für 24 Stunden bei $37^{\circ} \mathrm{C}$ inkubiert. Das Medium wurde abgesaugt und die Zellen wurden mit PBS gewaschen. Anschließend wurden die adhärenten Zellen bei $37^{\circ} \mathrm{C}$ für 5 min mit drei Tropfen Trypsin-EDTA (0,05\%) inkubiert und somit gelöst. Die abgelösten Zellen wurden in $1 \mathrm{ml}$ Medium aufgenommen, durchmischt und in ein Zentrifugenröhrchen umgefüllt. Die Zellen wurden abzentrifugiert. Das Zellpellet wurde anschließend mit $700 \mu \mathrm{l}$ PBS und $10 \%$ FCS resuspendiert und durch ein Zellsieb in ein Polystyrol Röhrchen gegeben. Die durchflusszytometrische Messung fand innerhalb der nächsten halben Stunde statt.

\subsubsection{Durchflusszytometrie mit dem Gerät Flow Cytometer BD LSRII}

15 min vor der Messung wurden die Laser CUBE (404 nm, $100 \mathrm{~mW}$, blau) und COMPASS (561 nm, $50 \mathrm{~mW}$, gelb) zum Aufwärmen angeschaltet. Das Hauptgerät der Maschine Flow Cytometer BD LSRII wurde gestartet. Während des Hochfahrens wurde die Software BD FACS Diva auf dem Computer gestartet und die Namen der Proben eingelesen. Die Proben wurden nun nacheinander auf dem Vortexmischer geschüttelt und gemessen. 
Das Ausschalten des Durchflusszytometers erfolgte mit den Programmen CLEAN (5 min), RINSE (5 min) und MILLIQ WATERQ (5 min).

Bei der gesamten Messung wurde darauf geachtet, dass so wenig Luft wie möglich eingesaugt wurde.

Die Daten des Experiments wurden zunächst im Format flow cytometry standard (fcs) gespeichert. Später wurden die Daten in das Format xls umgewandelt und mit Microsoft Excel ausgewertet. 


\title{
3 Ergebnisse
}

\subsection{Durchflusszytometrie zur quantitativen Messung von translationalem Readthrough}

Für die exakte Messung des translationalen Readthrough ist ein verlässliches und genaues Messprinzip erforderlich. In der vorliegenden Arbeit wurde daher das Prinzip der Durchflusszytometrie zur Messung des translationalen Readthrough etabliert. So konnte der translationale Readthrough einer Zellpopulation in jeder Zelle einzeln quantifiziert werden.

Humane HeLa-Zellen und CEF-Zellen wurden kultiviert und mit fluoreszierenden Vektorkonstrukten transfiziert. Anschließend wurden die Signale durchflusszytometrisch gemessen. Am 5'-Ende des Vektorkonstrukts befand sich die DNA des rot fluoreszierenden Proteins (RFP) und am 3'-Ende die DNA des grün fluoreszierenden Proteins (GFP). Zwischen der DNA der fluoreszierenden Proteine wurde der Stopcodon-Kontext (Stopcodoncontext, SCC) der DNA eines Proteins integriert. Der SCC beinhaltete die spezifische Basenabfolge von zehn Nukleotiden vor und zehn Nukleotiden nach dem Stopcodon (Abbildung 3).

a

$\mathrm{b}$

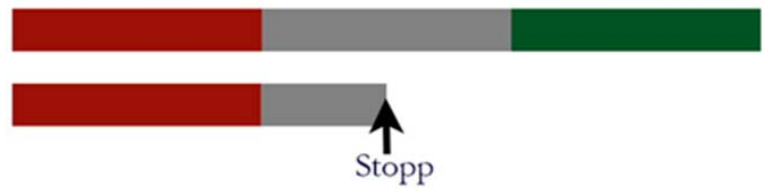

- RFP

- SCC

- GFP

\begin{abstract}
Abbildung 3: Schematische Darstellung eines Konstrukts für den dualen Reporter. Rot fluoreszierendes Protein (RFP), Stopcodon-Kontext (Stopcodon-context, SCC) und grün fluoreszierendes Protein (GFP). RFP stellt die Kontrolle der Enzymsynthese dar. Der Stopcodon-Kontext beinhaltet das Stopcodon einschließlich der zehn Nukleotide upstream und downstream des jeweiligen Enzyms. GFP signalisiert translationalen Readthrough. Mit einer Normierung zum 100 \% Vektor konnte der prozentuale Anteil des translationalen Readthrough analysiert werden. (a) Translationaler Readthrough: RFP wird exprimiert, SCC wird exprimiert, GFP wird exprimiert-rotes und grünes Signal im dualen Reporter. (b) Kein translationaler Readthrough: RFP wird exprimiert, SCC wird bis zum Stopcodon exprimiert - rotes Signal im dualen Reporter.
\end{abstract}

RFP diente der internen Expressionskontrolle. GFP war der Indikator für translationalen Readthrough. Als positive Kontrollen wurden Vektoren ohne den SCC bzw. mit einem SCC, 
bei dem anstelle des TGA-Stopcodons das Tryptophan-kodierende TGG verwendet wurde, eingesetzt.

Die zu messende Zellpopulation wurde in Abhängigkeit von der Zellgröße und Zellgranularität durch die Messung des Vorwärtsstreulichts und des Seitwärtsstreulichts des jeweiligen Zelltyps festgelegt. Anschließend konnte der translationale Readthrough über Fluoreszenzmessungen analysiert werden. Für die Untersuchungen wurden verschiedenfarbige Laser (CUBE (404 nm, $100 \mathrm{~mW}$, blau), COMPASS (561 nm, $50 \mathrm{~mW}$, gelb)) eingesetzt. Die Rotfluoreszenz (Phycoerythrin-A, PE-A) wurde mit der Grünfluoreszenz (Fluoresceinisothiocyanat-A, FITC-A) verglichen. Die Zellen, in denen translationaler Readthrough stattfand, exprimierten das RFP und das GFP. Sie zeigten eine rote und grüne Fluoreszenz. Die Zellen, in denen kein translationaler Readthrough stattfand, exprimierten das RFP und den SCC bis zum Stopcodon. Die Translation wurde also vor der Basensequenz des GFP beendet. Die Zellen gaben lediglich ein rotes Signal. Über das Verhältnis des GFP zum RFP und mit einer Normierung zum $100 \%$ Vektor konnte der prozentuale Anteil des translationalen Readthrough analysiert werden (Abbildung 4). 
a
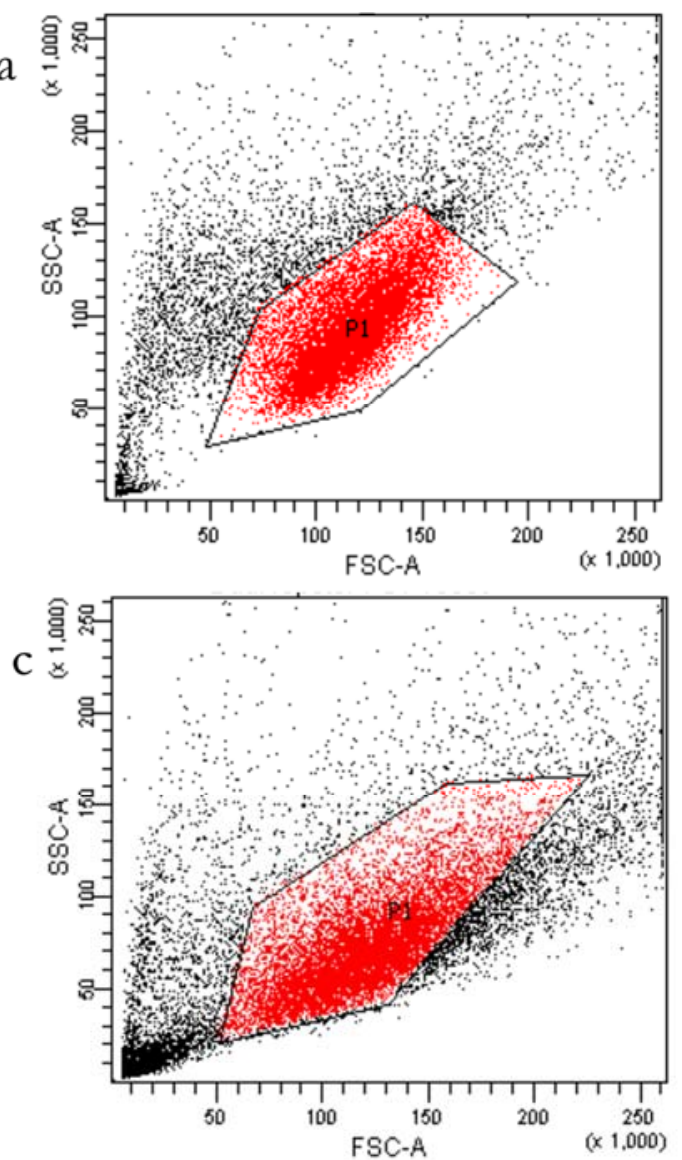

$\mathrm{b}$
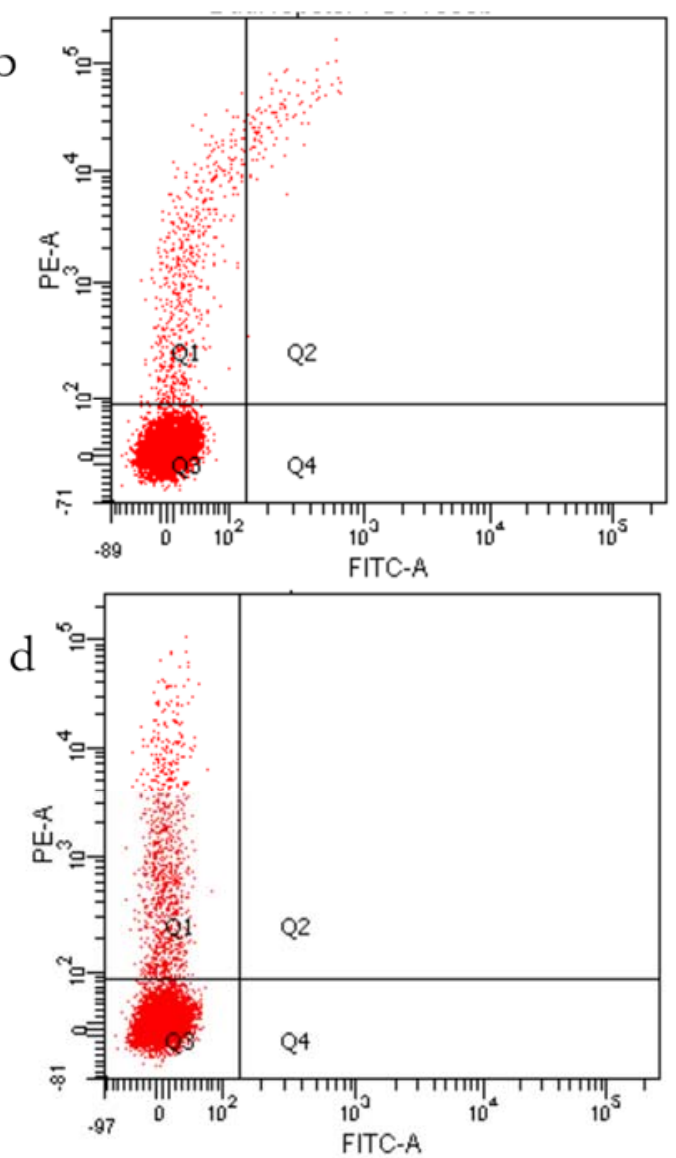

Abbildung 4: Darstellung des Streudiagramms durchflusszytometrischer Messungen des translationalen Readthrough. (a, b) Messung des Vektors des SCC der MDHx in CEF-Zellen. (c, d) Kontrollmessung eines Vektorkonstrukts aus RFP und Basen in CEF-Zellen. (a, c) Dargestellt ist die Zellgröße (forward scatter, Vorwärtsstreulicht, FSC-A) in Abhängigkeit von der Zellgranularität (side scatter, Seitwärtstreulicht, SSC-A). In dem Bereich, in dem sich die meisten Zellen befinden, wird die zu messende Zellpopulation ausgewählt. Der rot gefärbte Bereich zeigt die Zellpopulation, bei welcher translationaler Readthrough quantitativ gemessen wird. (b, d) Der translationale Readthrough wird durch Messungen der PEA (rote Fluoreszenz) gegen FITC-A (grüne Fluoreszenz) analysiert. Zellen, in denen translationaler Readthrough stattfindet, zeigen rote und grüne Fluoreszenzen und sind im oberen Quadranten rechts dargestellt (Q2). Zellen in Q1 sind mit dem Vektor transfiziert (rotes Signal), zeigen aber keinen translationalen Readthrough (kein grünes Signal).

\subsection{Vergleich von translationalem Readthrough in Zellen von Nichtsäugetieren und Säugetieren}

Um die Grundlagen des Readthrough-Phänomens besser zu verstehen, wurden in der vorliegenden Arbeit zellspezifische Unterschiede Readthrough-abhängiger Prozesse herausgearbeitet. Der Begriff Nichtsäugetiere beschreibt im Folgenden alle Vertebraten, die keine Säugetiere sind (mit Ausnahme der Amphibien). 


\subsubsection{Der Nachweis von LDHB(x) im Peroxisom von Nichtsäugetieren}

Translationaler Readthrough ist essentiell für den Transport der MDH1x und LDHBx in das Peroxisom. Durch translationalen Readthrough werden versteckte peroxisomale Zielsignale (peroxisomal targeting signals, PTS) translatiert, die den peroxisomalen Import erst möglich machen. Interessanterweise sind PTS in den Genen der MDH1 und LDHB aller Säugetiere vorhanden, während bei allen anderen Vertebraten (Nichtsäugetiere) das PTS nur in dem Gen der MDH1 konserviert ist (Hofhuis et al. 2016). Daher wurde in der vorliegenden Arbeit die Frage bearbeitet, ob die sich aus dem Sequenzvergleich getroffene Aussage auch im tatsächlichen Readthrough und in der Lokalisierung der Proteine im Peroxisom bzw. im Zytosol in Nichtsäugetierzellen widerspiegelt. Die Lokalisierung der MDH1(x) und der LDHB(x) wurde mit Hilfe einer Kofärbung der Peroxisomen in Zellen von Nichtsäugetieren bestimmt. Exemplarisch für Nichtsäugetierzellen wurden embryonale Huhnfibroblasten (chicken embryo fibroblasts, CEF-Zellen) verwendet.

Für die Immunfluoreszenzfärbungen wurden zunächst CEF-Zellen kultiviert und anschließend mit fluoreszierenden Antikörpern markiert. In Vorversuchen wurden drei Antikörper, die sich gegen Proteine im Peroxisom richteten, miteinander verglichen. Dabei erwies sich der Antikörper PMP70 zur Darstellung vom Peroxisom in CEF-Zellen als besonders spezifisch. Für die Darstellung der LDHB(x) wurden ebenfalls in Vorversuchen Antikörper miteinander verglichen. Hier erwies sich der $\alpha$ LDHB-Antikörper in CEF-Zellen als besonders sensitiv und spezifisch. Anschließend wurde die Lokalisation der $\operatorname{LDHB}(\mathrm{x})$ fluoreszenzmikroskopisch analysiert. In der überwiegenden Zahl von 60 untersuchten Zellen war keine Kolokalisation der LDHB(x) im Peroxisom sichtbar (Abbildung 5, Abbildung 6). Zusätzlich wurde das Zytoplasma in unabhängigen Ansätzen mit Digitonin aus den Zellen herausgewaschen und die Zellen wurden anschließend gefärbt. Die nachweisbaren Proteine konnten demnach nur noch in den verbliebenen Zellorganellen lokalisiert sein, die wiederum mikroskopisch dargestellt wurden. Die $\operatorname{LDHB}(\mathrm{x})$ befand sich nach dem Auswaschen des Zellplasmas in über $80 \%$ der Zellen nicht im Peroxisom (Abbildung 5, Abbildung 6).

Als Kontrolle wurden die MDH1(x) und das Peroxisom unter gleichen Bedingungen mittels Immunfluoreszenzfärbung dargestellt. Hier wurde ohne bzw. nach Auswaschen des Zytoplasmas mit Digitonin eine deutliche Kolokalisation festgestellt (Abbildung 7). Das bedeutet, dass die MDH1(x) in CEF-Zellen im Peroxisom lokalisiert ist.

Zusammenfassend lässt sich festhalten, dass in CEF-Zellen als Beispiel von Zellen der Nichtsäugetiere die $\operatorname{LDHB}(\mathrm{x})$ überwiegend nicht im Peroxisom lokalisiert ist. 
Anti-LDHB

a

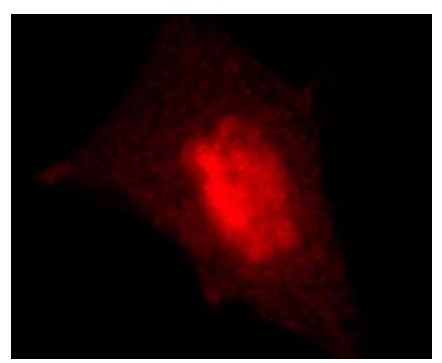

$\mathrm{b}$

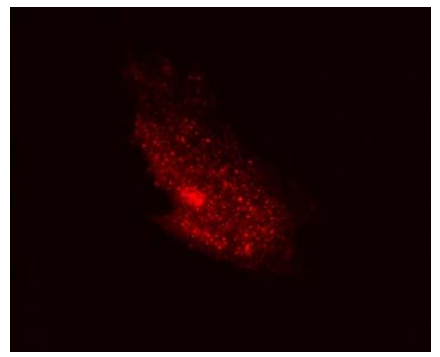

c

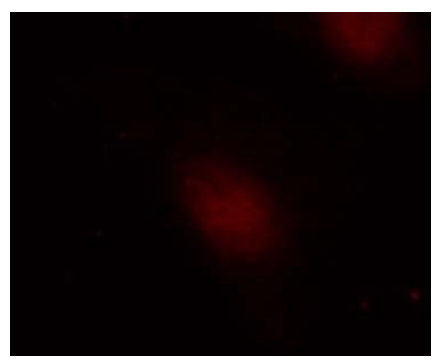

$\mathrm{d}$

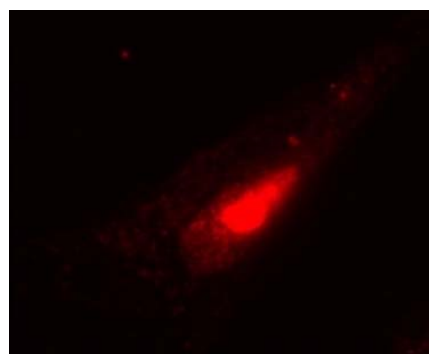

Anti-PMP70
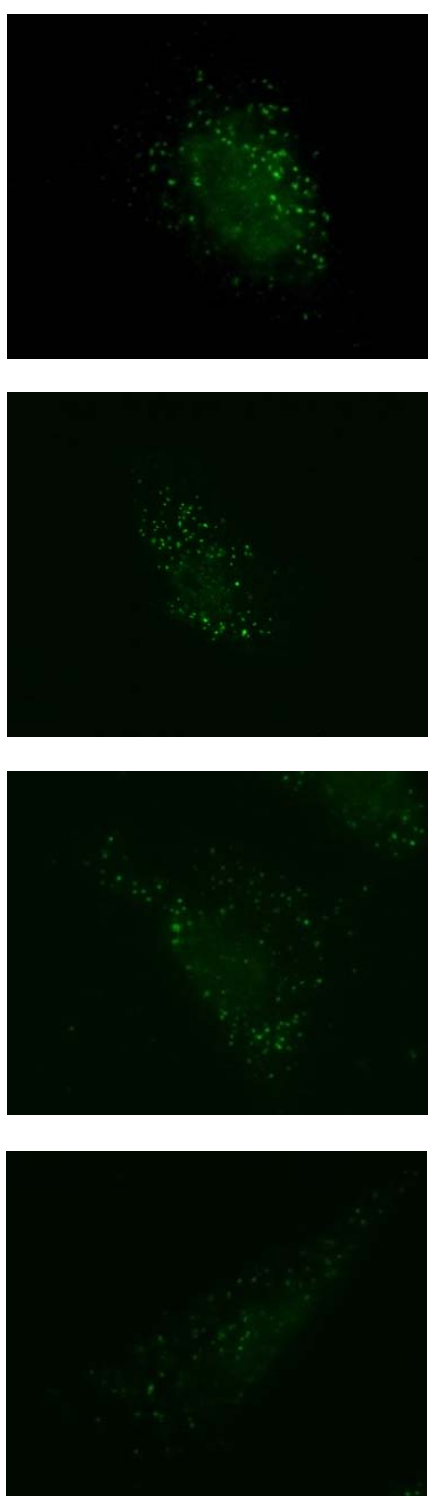

Anti-LDHB, Anti-PMP70
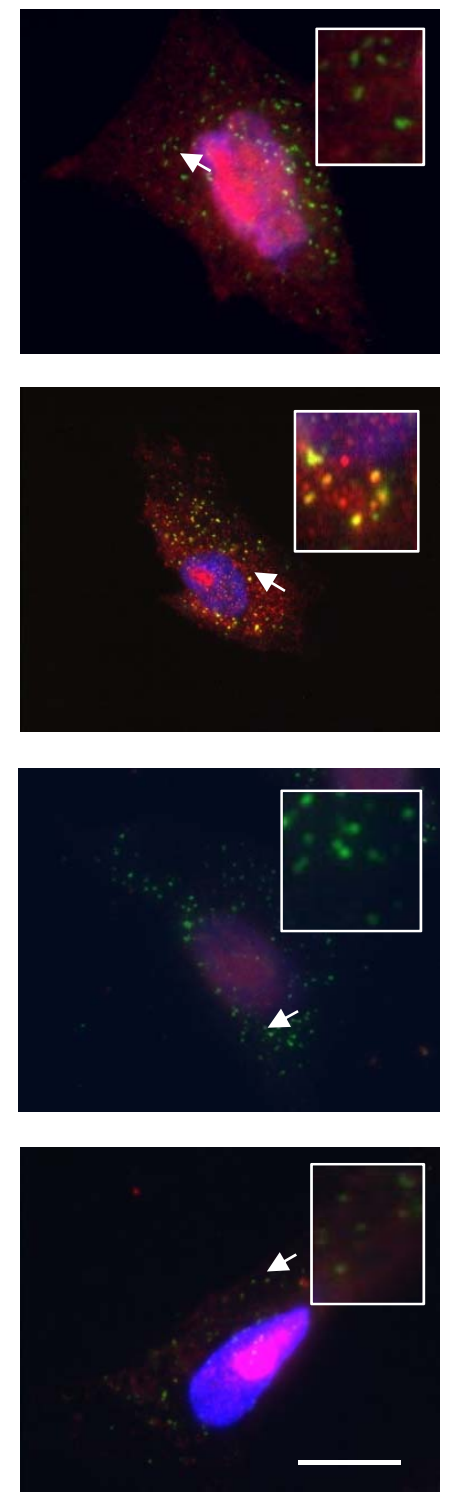

Abbildung 5: Immunfluoreszenzfärbung der $\operatorname{LDHB}(\mathrm{x})$ und des Proteins PMP70 in untransfizierten CEF-Zellen. LDHB(x)-Antikörper: rot, PMP70-Antikörper: grün, Kolokalisation: gelb. Der Pfeil zeigt auf das Areal, welches im Kästchen vergrößert dargestellt ist. (a, b) Exemplarische Darstellung für eine Zelle ohne Behandlung mit Digitonin: (a) Keine Kolokalisation der LDHB(x) im Peroxisom, (b) Kolokalisation der LDHB(x) im Peroxisom. (c, d) Unabhängiger Ansatz, exemplarische Darstellung für eine Zelle nach Behandlung mit Digitonin: (c) Keine Kolokalisation der LDHB(x) im Peroxisom, (d) Kolokalisation der LDHB(x) im Peroxisom. Maßstab: $10 \mu \mathrm{m}$ 
Immunfluoreszenzfärbung ohne Digitonin

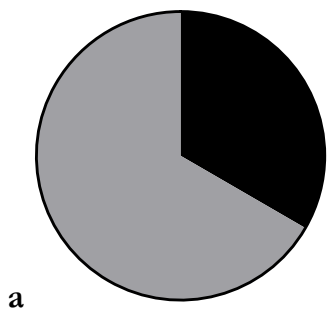

Immunfluoreszenzfärbung mit Digitonin

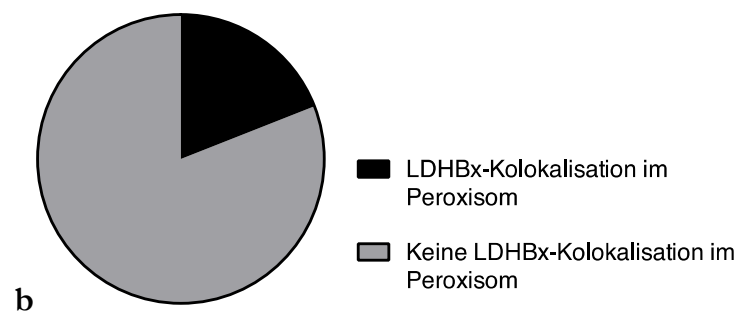

Abbildung 6: Auswertung der Immunfluoreszenzfärbung der LDHB(x) im Peroxisom in untransfizierten CEF-Zellen. (a) Von 60 Zellen (ohne Behandlung mit Digitonin) zeigten 20 Zellen eine LDHBx-Kolokalisation im Peroxisom. In 40 Zellen wurde keine Kolokalisation nachgewiesen. (b) In 21 unabhängigen Ansätzen wurde das Zellplasma mit Digitonin vor den Färbungen ausgewaschen. In vier Fällen konnte eine Kolokalisation der $\operatorname{LDHB}(\mathrm{x})$ im Peroxisom detektiert werden. In 17 Fällen konnte eine Kolokalisation ausgeschlossen werden.

Anti-MDH1

a

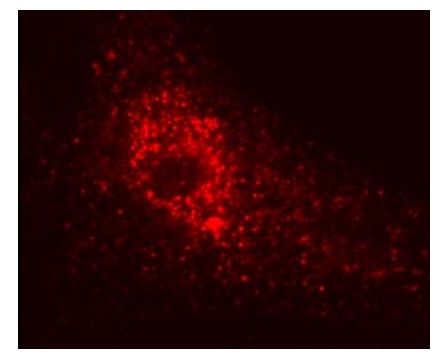

$\mathrm{b}$

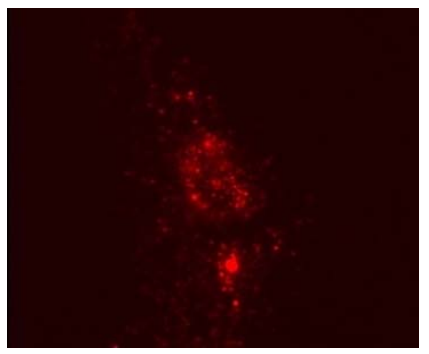

Anti-PMP70
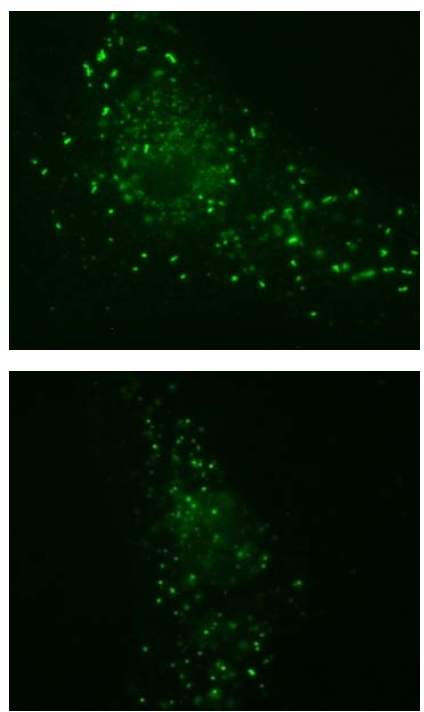

Anti-MDH1, Anti-PMP70
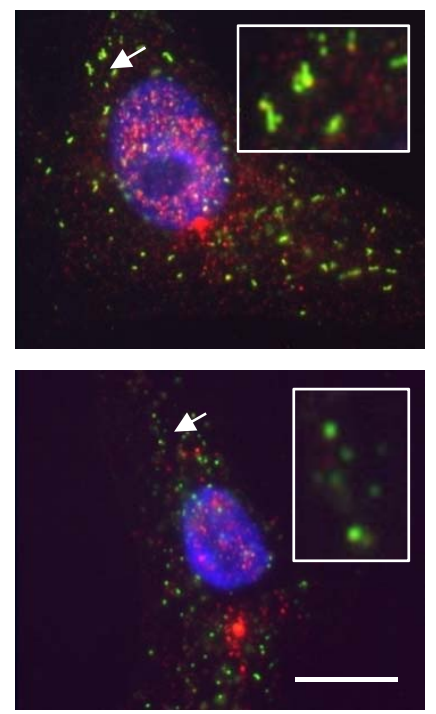

Abbildung 7: Immunfluoreszenzfärbung der MDH1(x) und des Proteins PMP70 in untransfizierten CEF-Zellen. MDH1(x)-Antikörper: rot, PMP70-Antikörper: grün. Kolokalisation: gelb. Der Pfeil zeigt auf das Areal, welches im Kästchen vergrößert dargestellt ist. (a) Exemplarische Darstellung für eine Zelle ohne Behandlung mit Digitonin: Lokalisation der MDH1(x) im Peroxisom, im Zytosol und in anderen Zellorganellen. (b) Unabhängiger Ansatz, Exemplarische Darstellung für eine Zelle nach Behandlung mit Digitonin: Lokalisation der MDH1(x) im Peroxisom, im Zytosol und in anderen Zellorganellen. Maßstab: $10 \mu \mathrm{m}$ 


\subsubsection{Der translationale Readthrough der MDH1(x) und LDHB(x) in Zellen von Nichtsäugetieren}

Der Readthrough der LDHB(x) und der MDH1(x) ist zellspezifisch. Die LDHB(x) und die MDH1(x) zeigen den höchsten translationalen Readthrough in Glioblastomzellen (U118Zellen) (Hofhuis et al. 2016). In den folgenden Versuchen wurde der quantitative Unterschied vom translationalen Readthrough der MDH1(x) und der LDHB(x) in Nichtsäugetieren (am Beispiel von CEF-Zellen) bearbeitet.

Der endogene translationale Readthrough in Zellen von Nichtsäugetieren wurde durchflusszytometrisch gemessen. Es wurden Vektorkonstrukte kloniert (Tabelle 10, Abbildung 3) und in kultivierte CEF-Zellen transfiziert. Die Vektorkonstrukte VASN ds und VASN ds2, bestehend aus der Basensequenz mit zwei Stopcodons direkt hintereinander, fungierten in jedem Experiment als Negativkontrolle.

Der SCC der MDH(x) zeigte einen deutlich höheren Anteil an translationalem Readthrough in CEF-Zellen als der SCC der LDHB(x) (Abbildung 8, Abbildung 9).

Tabelle 10: SCC der Vektorkonstrukte für den dual reporter assay in CEF-Zellen

\begin{tabular}{|l|l|}
\hline Vektorkonstrukt & Weitere Informationen zum SCC \\
\hline RFP - LDHBx - GFP & LDHBx Wildtyp \\
\hline RFP - LDHBx-TAA - GFP & LDHBx mit Stopcodon TAA \\
\hline RFP - MDH1x - GFP & MDH1x Wildtyp \\
\hline RFP - MDH1x-TAA - GFP & MDH1x mit Stopcodon TAA \\
\hline RFP - VASN ds - GFP & $\begin{array}{l}\text { Basensequenz mit 2 Stopcodons direkt } \\
\text { hintereinander }\end{array}$ \\
\hline RFP - VASN ds2 - GFP & $\begin{array}{l}\text { Basensequenz mit einem Basentriplett } \\
\text { zwischen 2 Stopcodons }\end{array}$ \\
\hline RFP - Basensequenz - GFP & Basensequenz ohne Stopcodon \\
\hline
\end{tabular}




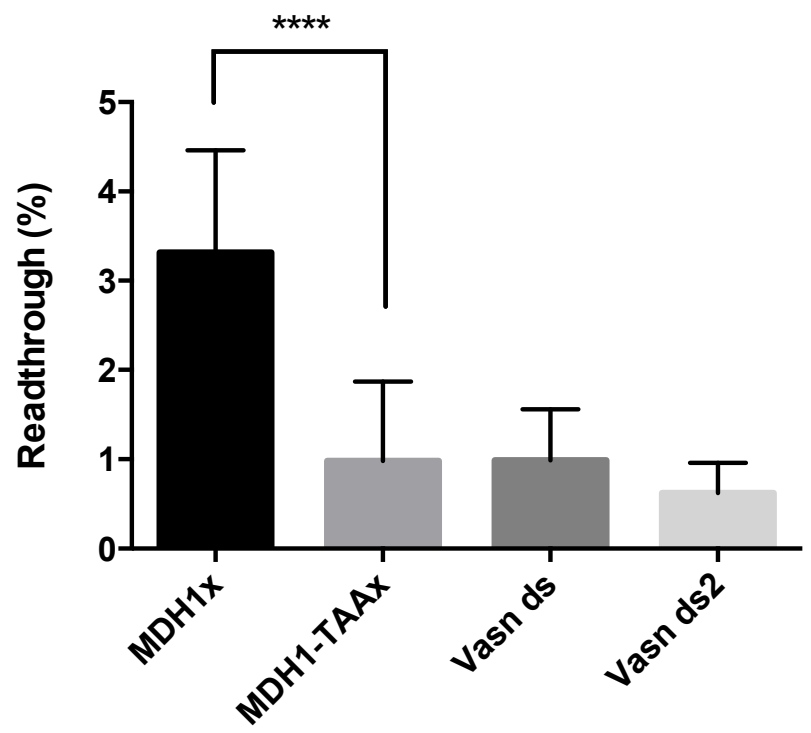

Abbildung 8: Durchflusszytometrische Messungen des translationalen Readthrough des SCC MDH1(x) in CEF-Zellen. Student's t-test: ${ }^{* * * *} \mathrm{p}<0,001$, Mittelwerte und Standardabweichungen, $\mathrm{n}=10$

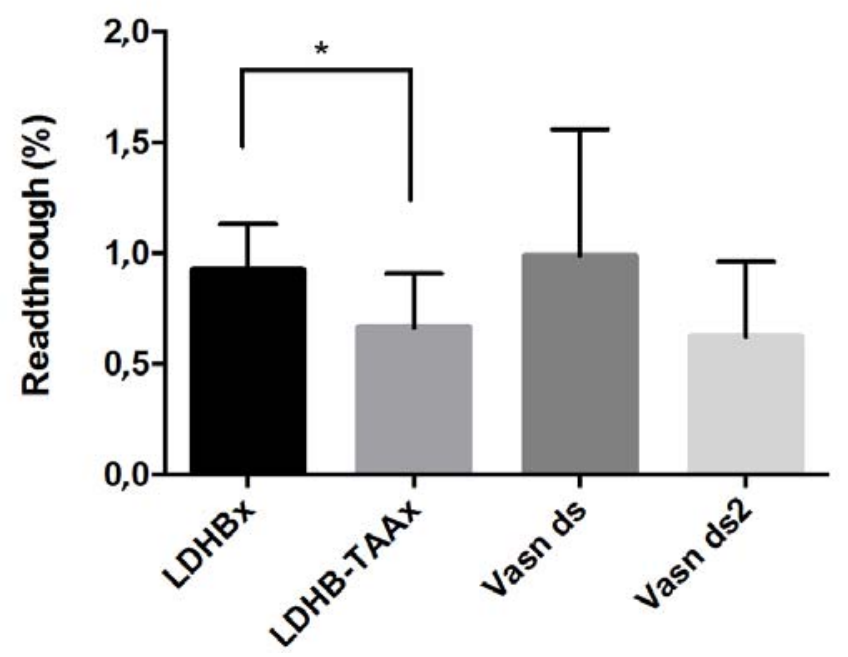

Abbildung 9: Durchflusszytometrische Messungen des translationalen Readthrough des SCC LDHB(x) in CEF-Zellen. Student's t-test: ${ }^{*} \mathrm{p}<0,05$, Mittelwerte und Standardabweichungen, $\mathrm{n}=11$

Der translationale Readthrough des SCC der LDHB(x) und des SCC der MDH1(x) wurden mit dem Aminoglykosid Geneticin (G418) induziert. Durch die Bindung von Aminoglykosiden an die ribosomale RNA kann es vermehrt zu Fehlpaarungen der Basen zwischen Codon der mRNA und Anticodon der tRNA kommen. Es binden tRNAs, die nur ein fast passendes Anticodon enthalten, an das Stopcodon der mRNA und lösen somit translationalen Readthrough aus (Kellermayer 2006). 
Mit Geneticin (G418) ließ sich der translationale Readthrough des SCC der MDH1(x) stärker induzieren als der SCC der LDHB(x): Der Readthrough-Induktionsfaktor für den SCC der MDH1(x) lag bei 3,92. Für den SCC der LDHB(x) konnte ein Induktionsfaktor von 3,47 gemessen werden.

Zusammenfassend erzielte der SCC der MDH1(x) in CEF-Zellen einen höheren Anteil an endogenem und an induziertem translationalen Readthrough als der SCC der LDHB(x) (Abbildung 15).

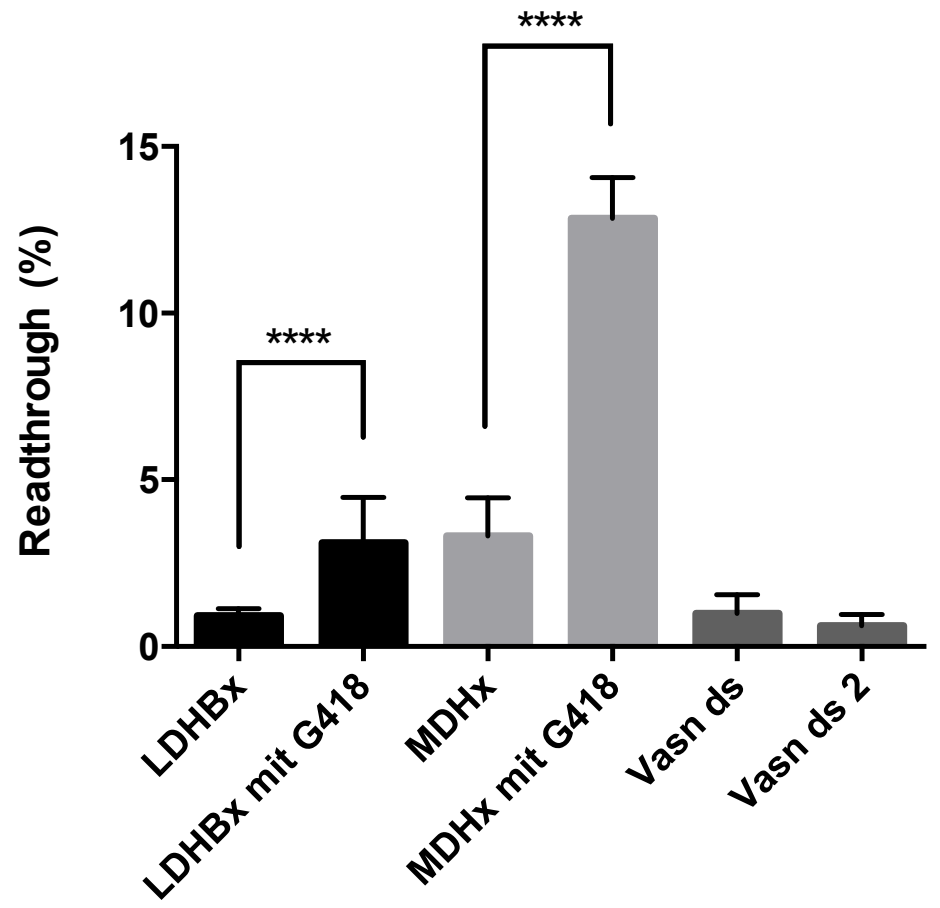

Abbildung 10: Durchflusszytometrische Messungen des endogenen und induzierten translationalen Readthrough des SCC MDH1(x) und des SCC LDHB(x) in CEF-Zellen (Induktion mit G418 $(100 \mu \mathrm{g} / \mathrm{ml}))$. Student's t-test. ${ }^{* * * *} \mathrm{p}<0,0001$, Mittelwerte und Standardabweichungen, $\mathrm{MDH}(\mathrm{x}): \mathrm{n}=10$, $\operatorname{MDH}(\mathrm{x})+\mathrm{G} 418: \mathrm{n}=5, \operatorname{LDHB}(\mathrm{x}): \mathrm{n}=11, \operatorname{LDHB}(\mathrm{x})+\mathrm{G} 418: \mathrm{n}=4$

\subsection{Beitrag von proximalen und distalen mRNA-Elementen zum translationalen Readthrough}

In der vorliegenden Arbeit wurde aufgrund von publizierten Ergebnissen davon ausgegangen, dass das Stopcodon selbst und die Nukleotide proximal und distal des Stopcodons Einfluss auf den translationalen Readthrough haben (Schueren et al. 2014; Hofhuis et al. 2017). Um translationalen Readthrough im Detail zu verstehen, sollte hier der mögliche Einfluss der Nukleotide um das Stopcodon analysiert werden. 


\subsubsection{Beitrag von proximalen mRNA-Elementen zum translationalen Readthrough}

In-silico-Modellierungen legten nahe, dass Nukleotide unmittelbar proximal und distal des Stopcodons Einfluss auf die Effizienz des translationalen Readthrough haben. Vor allem die Nukleotidsequenzen vier, fünf und sechs Positionen distal sowie fünf und sechs Positionen proximal des Stopcodons zeigen in silico einen großen Einfluss (Schueren et al. 2014). Um den Einfluss proximaler mRNA-Elemente auf den translationalen Readthrough zu analysieren, wurde die Base sechs Positionen proximal des Stopcodons der DNA der LDHB(x) und der MDH1(x) mutiert. Der mutierte SCC wurde mit der DNA des RFP und des GFP in ein Vektorkonstrukt integriert und kloniert (siehe 3.1). Anschließend wurde das Konstrukt in kultivierte HeLa-Zellen transfiziert und durchflusszytometrisch nachgewiesen. Für die Messungen wurden bewusst die genannten Proteine ausgewählt, da diese bekanntlich endogenen translationalen Readthrough erlauben.

Es zeigten sich signifikante quantitative Unterschiede im translationalen Readthrough zwischen den Wildtypen und ihren mutierten Versionen. Für den SCC der Wildtypen war ein höherer Anteil an translationalem Readthrough messbar als für die mutierten SCCVersionen (Abbildung 11, Abbildung 12).

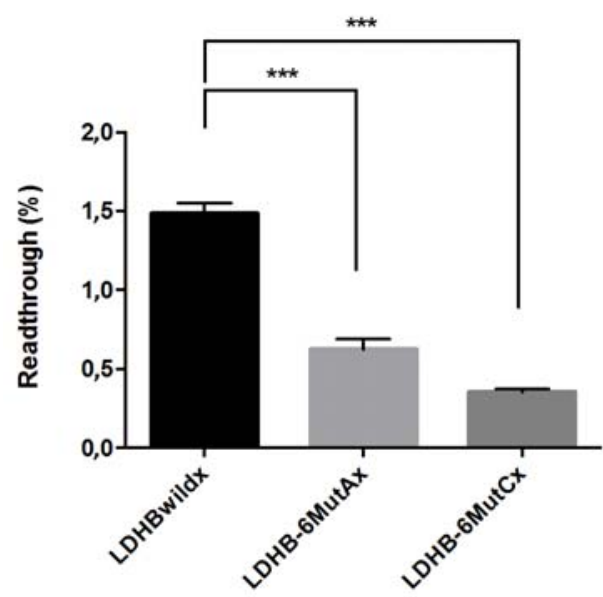

Abbildung 11: Durchflusszytometrische Messungen des translationalen Readthrough des SCC des Wildtyps der LDHBx und des SCC der mutierten Versionen in transfizierten HeLa-Zellen. Mutation: LDHB-6MutAx: Einbau von Adenin sechs Positionen proximal des Stopcodons, LDHB-6MutCx: Einbau von Cytosin sechs Positionen proximal des Stopcodons. Student's t-test. ${ }^{* * *} \mathrm{p}<0,001$, Mittelwerte und Standardabweichungen, LDHBwildx: $\mathrm{n}=3$, LDHB-6MutAx: $\mathrm{n}=3$, LDHB-6MutCx: $\mathrm{n}=3$ 


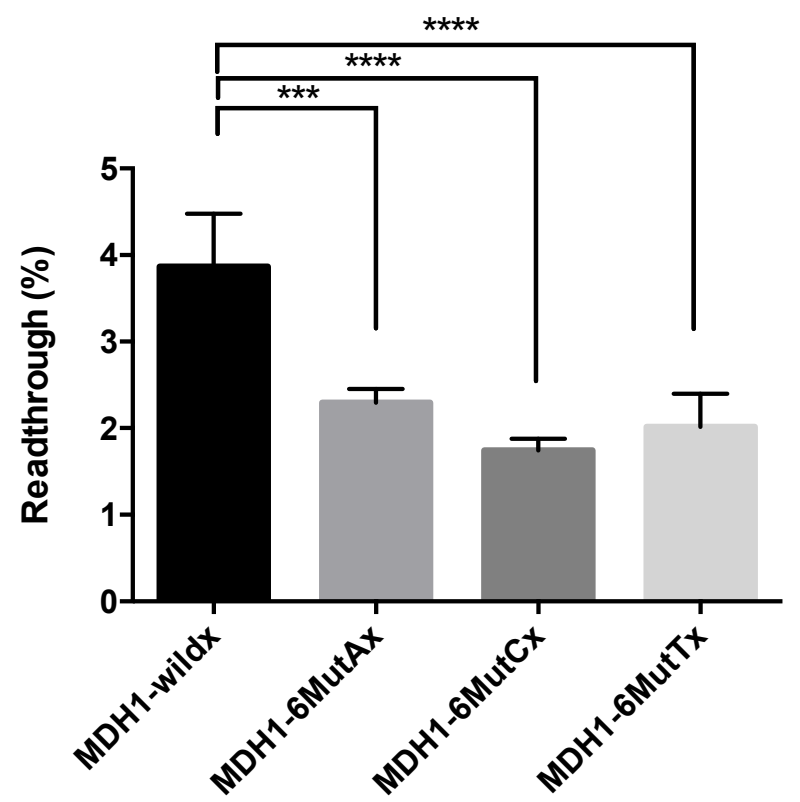

Abbildung 12: Durchflusszytometrische Messungen des translationalen Readthrough des SCC des Wildtyps der MDH1x und des SCC der mutierten Versionen in transfizierten HeLa-Zellen. Mutation: MDH1-6MutAx: Einbau von Adenin sechs Positionen proximal des Stopcodons, MDH1-6MutCx: Einbau von Cytosin sechs Positionen proximal des Stopcodons, MDH1-6 MutTx: Einbau von Thymin sechs Positionen proximal des Stopcodons. Student's t-test: ${ }^{* * *} \mathrm{p}<0,001,{ }^{* * * *} \mathrm{p}<0,0001$, Mittelwerte und Standardabweichungen, MDH1-wild: $\mathrm{n}=2$, MDH1-6MutAx: $\mathrm{n}=5$, MDH1-6MutCx: $\mathrm{n}=5$, MDH16MutTx: $\mathrm{n}=5$

\subsubsection{Beitrag von distalen mRNA-Elementen zum translationalen Readthrough}

Bei den bisherigen Versuchsreihen beinhaltete der SCC zehn Nukleotide vor und zehn Nukleotide nach dem Stopcodon (Abbildung 3). Zuvor wurde jedoch publiziert, dass das Stopcodon und die 63 Nukleotide distal des Stopcodons ausschlaggebend für den Readthrough sein können (Eswarappa et al. 2014).

Für die Analyse des Einflusses distaler mRNA-Elemente auf den translationalen Readthrough wurde daher hier exemplarisch der translationale Readthrough eines Konstrukts, bestehend aus dem Stopcodon der DNA des Proteins VEGF-Ax und den darauffolgenden 63 distalen Nukleotiden, gemessen (im Folgenden abgekürzt als Stopcodon und 63 Nukleotide, S63N). Der Inhalt von S63N unterschied sich also vom SCC der vorherigen Versuchsreihen dadurch, dass proximal keine Nukleotide eingebaut waren. Für die durchflusszytometrische Messung wurde am 5'-Ende von S63N die DNA eines rot fluoreszierenden Proteins (RFP) und am 3'-Ende die DNA eines grün fluoreszierenden Proteins (GFP) in den Vektor integriert (Abbildung 13). Die Vektoren wurden in kultivierte 
HeLa-Zellen transfiziert und der translationale Readthrough wurde, wie in 3.1 beschrieben, durchflusszytometrisch gemessen.

Als Negativkontrolle wurde der translationale Readthrough des Konstrukts VEGF-A-TAA gemessen. Das Konstrukt VEGF-A-TAA bestand aus der DNA des RFP, dem Stopcodon des Gens VEGF-Ax, den darauffolgenden 63 distalen Nukleotiden, einem weiteren Stopcodon (TAA) und der DNA des GFP. Das Stopcodon TAA wurde statt des Stopcodons TGA integriert. Das Stopcodon TAA gilt als stärker und lässt weniger Readtrough zu (Beier und Grimm 2001; Baranov et al. 2002).

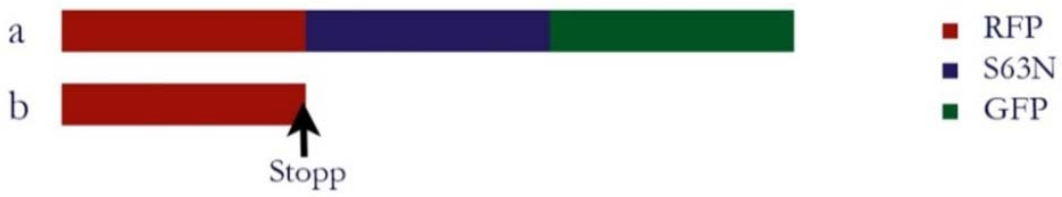

Abbildung 13: Schematische Darstellung des Konstrukts Stopcodon und darauffolgende 63 Nukleotide (S63N) für den dualen Reporter. Rot fluoreszierendes Protein (RFP), Stopcodon und 63 Nukleotide (S63N) und grün fluoreszierendes Protein (GFP). RFP stellt die Kontrolle der Enzymsynthese dar, während GFP translationalen Readthrough signalisiert. S63N beinhaltet die DNA des Stopcodons einschließlich der 63 Nukleotide downstream des Gens VEGF-Ax. Die Ratio von GFP/RFP kann über einen $100 \%$ Vektor normiert werden. (a) Translationaler Readthrough: RFP wird exprimiert, S63N wird exprimiert, GFP wird exprimiert - rotes und grünes Signal im dualen Reporter. (b) Kein translationaler Readthrough: RFP wird exprimiert. Durch das direkt angrenzende Stopcodon wird S63N nicht exprimiert rotes Signal im dualen Reporter.

Es wurde kein signifikanter Unterschied im endogenen translationalen Readthrough zwischen dem Konstrukt S63N-VEGF-A(x) und dem Kontrollkonstrukt S63N-VEGF-ATAA festgestellt (Abbildung 14). Entweder findet durch die Abwesenheit der proximalen Basen kein translationaler Readthrough statt oder das Protein VEGF-A(x) erlaubt keinen translationalen Readthrough.

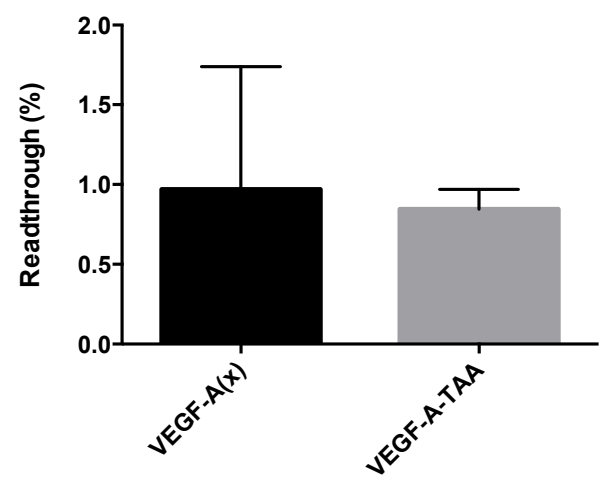

Abbildung 14: Durchflusszytometrische Messungen des translationalen Readthrough des Konstrukts S63N-VEGF-A(x) in HeLa-Zellen. Student's t-test. $\mathrm{p}>0$,5, Mittelwerte und Standardabweichungen, $\mathrm{n}=11$ 


\subsection{Krankheitsbezogene Untersuchungen zum Readthrough: Evaluation der Induzierbarkeit von translationalem Readthrough bei den häufigsten Nonsense-Mutationen beim Rett-Syndrom}

Das Rett-Syndrom ist eine monogene Erkrankung, die ca. zu einem Drittel durch eine Nonsense-Mutation im MeCP2-Gen verursacht wird. Nonsense-Mutationen können prinzipiell mit Readthrough-induzierenden Substanzen behandelt werden. Hier wurden der endogene sowie der induzierte translationale Readthrough der häufigsten NonsenseMutationen des Rett-Syndroms quantitativ gemessen (RettpR168X, RettpR270X, RettpY141X, RettpQ170X, RettpR255X, RettpS204X, RettpQ244X, RettpK175X, RettpS68X, RettpK177X, RettpK363X). Die häufigste auftretende Nonsense-Mutation des MeCP2-Gens ist die Mutation RettpR168X.

Zunächst wurde der endogene translationale Readthrough der elf häufigsten Mutationen untersucht. Für die Messungen wurden Plasmide aus GFP-SCC-RFP hergestellt (siehe 3.1). Die Plasmide wurden anschließend in kultivierte HeLa-Zellen transfiziert und der translationale Readthrough wurde durchflusszytometrisch gemessen (Abbildung 15). Es zeigten sich keine signifikanten Unterschiede zwischen den einzelnen Mutationen bezüglich des endogenen translationalen Readthrough (Abbildung 16).

In einem unabhängigen Ansatz wurden die transfizierten Zellen mit dem Readthroughinduzierenden Aminoglykosid Geneticin (G418) behandelt. Der induzierte translationale Readthrough wurde anschließend durchflusszytometrisch bestimmt. Es konnten signifikante Unterschiede bezüglich der Effizienz der Readthrough-Induktion mit G418 zwischen den einzelnen Mutationen festgestellt werden (Abbildung 16). Von den gemessenen Mutationen konnte der translationale Readthrough des SCC der Mutation RettpR270X am besten induziert werden. Die Substanz G418 erhöhte hier den translationalen Readthrough um den Faktor 35,4. Der niedrigste Induktionsfaktor ließ sich für den SCC der Mutation RettpR168X mit 0,96 messen (Tabelle 11). Insgesamt konnte der translationale Readthrough der Mutationen Rett-pR270X, Rett-pS68X, Rett-pS204X，Rett-pR255X，Rett-pQ170X，RettpQ244X, und Rett-pK177X mit G418 signifikant induziert werden. Die Reihenfolge der genannten Mutationen entspricht dem Ausmaß des induzierten translationalen Readthrough. Die Mutationen Rett-pR168X, Rett-pY141X, Rett-pK175X, Rett-pK363X zeigten keine signifikanten Veränderungen zwischen induziertem und endogenem translationalen Readthrough (Abbildung 16). In der Varianzanalyse konnten signifikante Unterschiede zwischen der Readthrough-Induzierbarkeit der mit G418 behandelten Nonsense-Mutationen errechnet werden (Ordinary One-Way Anova, Abbildung 17). 
a

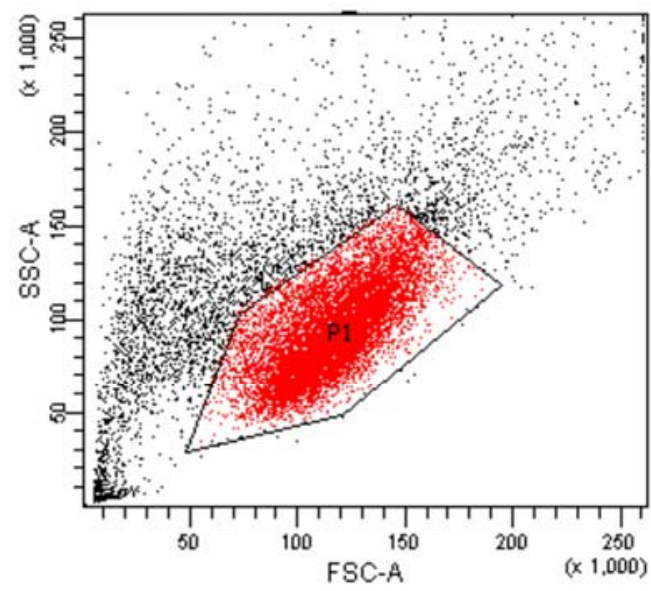

c

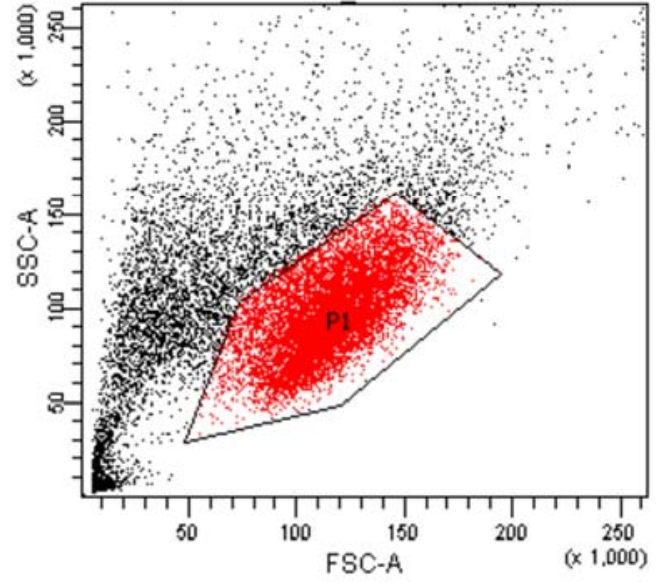

$\mathrm{b}$

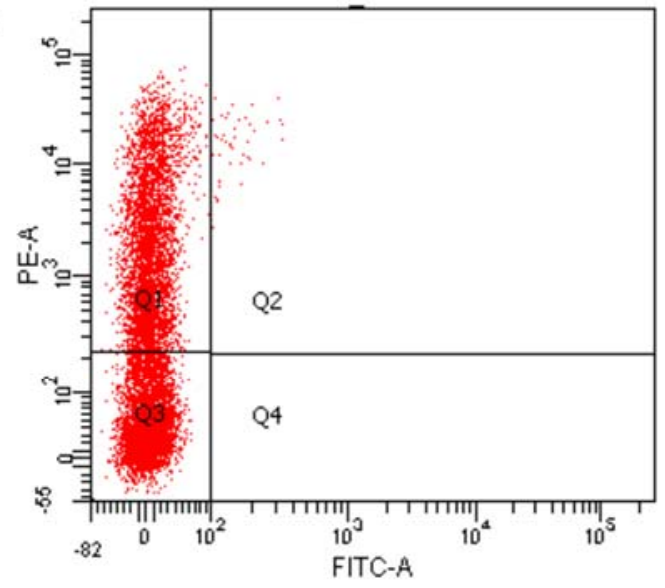

d

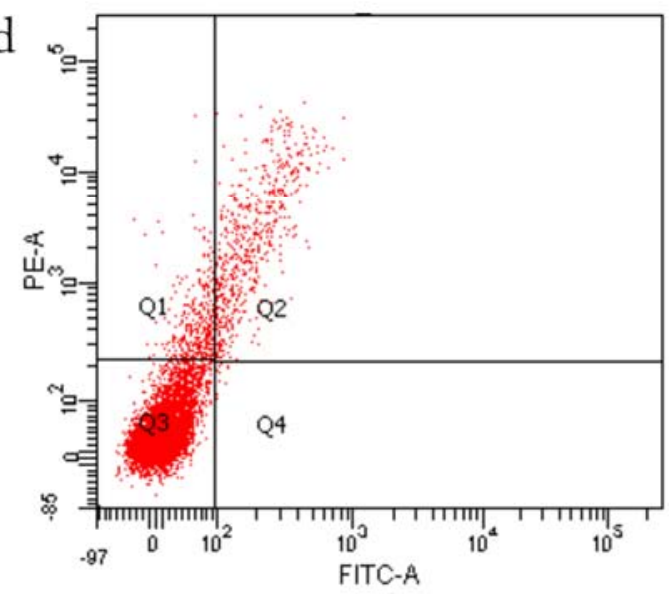

Abbildung 15: Darstellung des Streudiagramms durchflusszytometrischer Messungen des mit G418 induzierten translationalen Readthrough der SCC von zwei Nonsense-Mutationen des Rett-Syndroms in HeLa-Zellen. ( $a, b)$ Messungen des induzierten translationalen Readthrough des SCC der Mutation RettpR168X, welche die häufigste Nonsense-Mutation des Rett-Syndroms in Deutschland darstellt. (c, d) Messungen des induzierten translationalen Readthrough des SCC der Mutation RettpR270X, welche sich mit der höchsten Effizienz induzieren ließ. (a, c) Dargestellt ist die Zellgröße (FSC-A) in Abhängigkeit von der Zellgranularität (SSC-A). Der rot gefärbte Bereich zeigt die Zellpopulation, bei welcher translationaler Readthrough quantitativ gemessen wird. (b, d) Der translationale Readthrough wird durch Messungen der PEA (rote Fluoreszenz) gegen FITC-A (grüne Fluoreszenz) analysiert. Zellen, die mit dem Vektor transfiziert sind, zeigen rote Fluoreszenzen (Q1). Zellen, in denen translationaler Readthrough stattfindet, zeigen rote und grüne Fluoreszenzen (Q2). 


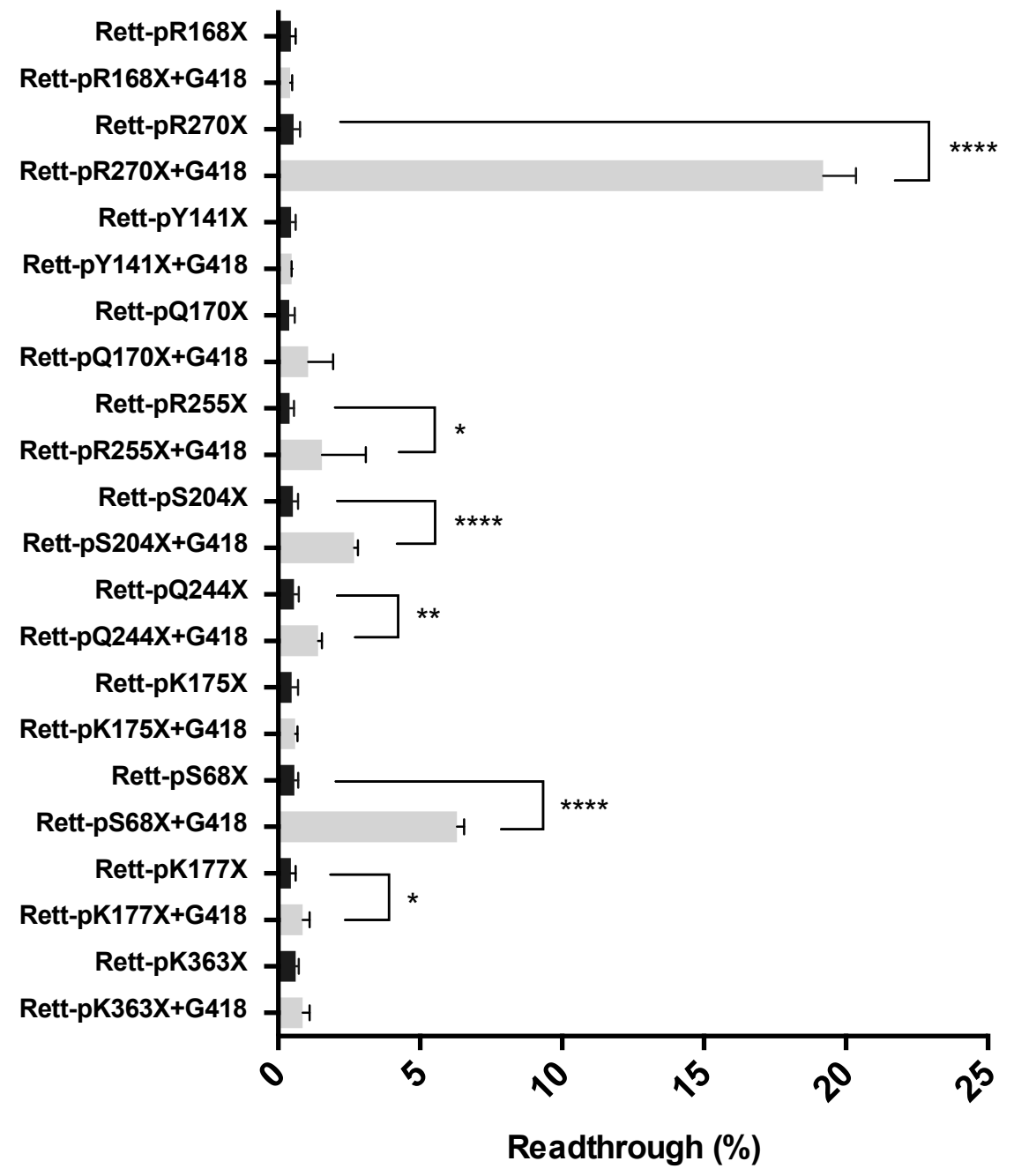

Abbildung 16: Durchflusszytometrische Messungen des endogenen und mit G418 induzierten translationalen Readthrough der SCC der häufigsten Nonsense-Mutationen des Rett-Syndroms in transfizierten HeLa-Zellen. Darstellung des endogenen translationalen Readthrough in schwarz und des induzierten translationalen Readthrough in grau. Untersucht wurden die elf häufigsten Nonsense-Mutationen des Rett-Syndroms. Die Reihenfolge gibt die Häufigkeit der Mutationen in Deutschland wieder. Der induzierte translationale Readthrough zeigt in sieben von elf Mutationen einen signifikanten Unterschied zum translationalen endogenen Readthrough. Student's t-test. ${ }^{*} \mathrm{p}<0,05,{ }^{*} \mathrm{p}<0,005,{ }^{*} * * * \mathrm{p}<0,0001$, Mittelwerte und Standardabweichungen, Rett-pR168X n=7, Rett-pR168X + G418 n = 3, Rett-pR270X n = 6, Rett$\mathrm{pR} 270 X+$ G418 $\mathrm{n}=3$, Rett-pY141X $\mathrm{n}=6$, Rett-pY141X + G418 $\mathrm{n}=3$, Rett-pQ170X $\mathrm{n}=7$, Rett$\mathrm{pQ} 170 \mathrm{X}+\mathrm{G} 418 \mathrm{n}=3$, Rett-pR255X $\mathrm{n}=7$, Rett-pR255X + G418 $\mathrm{n}=3$, Rett-pS204X $\mathrm{n}=6$, Rett$\mathrm{pS} 204 \mathrm{X}+\mathrm{G} 418 \mathrm{n}=3$, Rett-pQ244X $\mathrm{n}=3$, Rett-pQ244X + G418 $\mathrm{n}=3$, Rett-pK175X $\mathrm{n}=7$, Rett$\mathrm{pK} 175 \mathrm{X}+\mathrm{G} 418 \mathrm{n}=3$, Rett-pS68X $\mathrm{n}=7$, Rett-pS68X +G418 $\mathrm{n}=3$, Rett-pK177X $\mathrm{n}=7$, Rett$\mathrm{pK} 177 \mathrm{X}+\mathrm{G} 418 \mathrm{n}=3$, Rett-pK363X n = 6, Rett-pK363X + G418 n = 3 
Tabelle 11: Readthrough-Induktionsfaktoren der häufigsten Nonsense-Mutationen des RettSyndroms (Induktion mit G418)

\begin{tabular}{|l|l|}
\hline Nonsense-Mutation & Readthrough-Induktionsfaktor \\
\hline RettpR168X & 0,96 \\
\hline RettpR270X & 35,37 \\
\hline RettpY141X & 1,01 \\
\hline RettpQ170X & 2,69 \\
\hline RettpR255X & 3,78 \\
\hline RettpS204X & 5,16 \\
\hline RettpQ244X & 2,48 \\
\hline RettpK175X & 1,24 \\
\hline RettpS68X & 10,91 \\
\hline RettpK177X & 2,21 \\
\hline RettpK363X & 2,28 \\
\hline
\end{tabular}

Nach induziertem translationalen Readthrough erhöhte sich der Readthrough quantitativ um den rechts dargestellten Faktor.

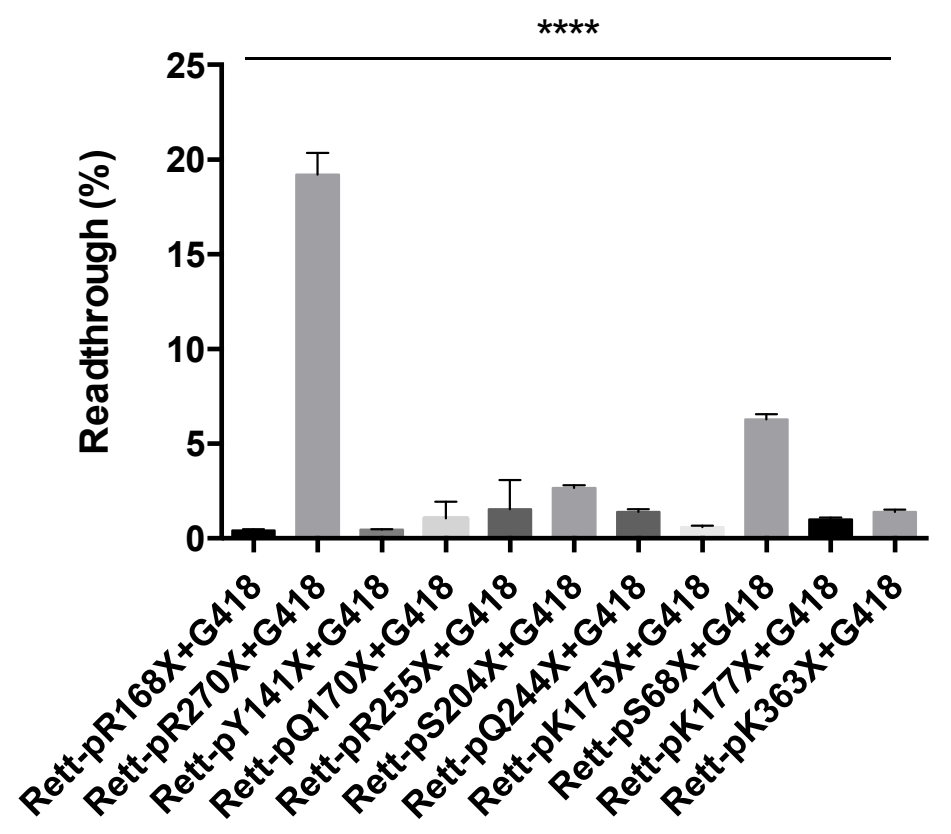

Abbildung 17: Durchflusszytometrische Messungen des mit G418 induzierten translationalen Readthrough der SCC der häufigsten Nonsense-Mutationen des Rett-Syndroms in transfizierten HeLa-Zellen. Student's t-test. ${ }^{* * * *} \mathrm{p}<0,0001$, Mittelwerte und Standardabweichungen, Ordinary One-Way Anova, $\mathrm{n}=3$ 


\section{Diskussion}

Ziel der Arbeit war es, neue Erkenntnisse zum Readthrough-Phänomen zu gewinnen. Ein besseres Verständnis der molekularen Grundlagen ist notwendig, um gezielte Therapien für durch Nonsense-Mutationen verursachte Erkrankungen zu entwickeln bzw. zu optimieren. Weiterhin wurden in der Arbeit peroxisomale Enzyme, die einen besonders hohen endogenen translationalen Readthrough-Anteil zeigen, in Modellzellen aus Säugetieren (Mensch) und Nichtsäugetieren (Huhn) näher charakterisiert. Dies sollte zum Verständnis der Grundlagen des Readthrough-Phänomens und Readthrough-abhängiger Prozesse beitragen. Zudem könnte dieser Teil der Arbeit klinisch relevant werden, um peroxisomale Erkrankungen, wie beispielsweise das Zellweger-Syndrom, besser zu verstehen.

Für die verschiedenen experimentellen Ansätze wurde zunächst die Methode der Durchflusszytometrie zur quantitativen Messung des endogenen sowie des induzierten translationalen Readthrough erfolgreich etabliert.

Dabei wurden humane HeLa-Zellen und embryonale Huhnfibroblasten (cbicken embryo fibroblasts, CEF) mit Vektorkonstrukten transfiziert. Die Vektoren enthielten die Nukleotidsequenzen des rot fluoreszierenden Proteins (RFP), des Stopcondon-Kontexts (SCC) und des grün fluoreszierenden Proteins (GFP). Der SCC bestand aus der DNA des Stopcodons sowie der spezifischen Basenabfolgen zehn Nukleotide vor und zehn Nukleotide nach dem Stopcodon des jeweiligen Enzyms. RFP stellte die Kontrolle der Enzymsynthese dar, während GFP den translationalen Readthrough anzeigte. Die Signale wurden durchflusszytometrisch gemessen.

Die hier etablierte durchflusszytometrische Bestimmung, bei der das transfizierte Genprodukt (GFP) fluoresziert und durchflusszytometrisch direkt nachgewiesen werden kann, ist vergleichsweise einfach und hat den Vorteil, dass die Signale auf Einzelzellebene quantifiziert werden können. Interessant könnte die Durchflusszytometrie bei der Suche nach Readthrough-induzierenden Substanzen für die Therapie von durch NonsenseMutationen verursachten Erkrankungen in Modellzellen sein. In dieser Arbeit wurden ausschließlich HeLa- und CEF-Zelllinen als Modellzellen verwendet. Grundsätzlich ist in künftigen Experimenten der Einsatz einer gemischten Zellpopulation, welche sich aufgrund physikalischer Eigenschaften oder im Phänotyp unterscheidet, denkbar. Die differenzierte Auswertung könnte basierend auf gezielter Doppelmarkierung mit Antikörpern erfolgen.

Im Ergebnis erwies sich die Methode der Durchflusszytometrie als effizient und als gute Alternative zu anderen quantitativen Messungen des translationalen Readthrough. Der 
firefly luciferase assay stellt z. B. eine Alternative dar. Nach Ko-Transfektion des FireflyLuciferase-Gens wird hier die Enzymaktivität der Luciferase als Marker für das Ausmaß des translationalen Readthrough bestimmt (Eswarappa et al. 2014).

Eine weitere Methode, mit der Readthrough-Phänomene prinzipiell indirekt zu erfassen sind, ist der Western Blot. Hier werden Proteine, d. h. die Produkte nach der Translation, mit spezifischen Antikörpern nachgewiesen und über ihr Molekulargewicht charakterisiert. Der Vorteil des Western Blots besteht somit darin, dass die Molekülgröße der verlängerten Isoform eines Proteins dargestellt und ins Verhältnis zum ursprünglichen Protein gesetzt werden kann. Ein Nachteil gegenüber der hier eingesetzten Durchflusszytometrie ist jedoch z. B. die geringere Sensitivität bei der Quantifizierung des Proteinnachweises, welche z. B. durch die Denaturierung der Proteine vor der Polyacrylamid-Gelelektrophorese und Übertragung auf Nitrozellulose oder andere Proteinträger bedingt sein kann. Außerdem existieren verschiedene Störgrößen wie z. B. die mögliche Denaturierung von Epitopen unter den Bedingungen der Polyacrylamid-Gelelektrophorese. Die Epitope sind dann für die spezifischen Antikörper nicht mehr zugänglich. Zudem ist es unmöglich mittels Western Blot die Proteinexpression gemischter Zellpopulationen bestimmten Zellen zuzuordnen.

In dieser Arbeit konnte gezeigt werden, dass sich die Methode der Durchflusszytometrie für Messungen des endogenen und induzierten translationalen Readthrough von peroxisomalen Enzymen in CEF-Zellen eignet. Außerdem konnte zum ersten Mal in vitro bestätigt werden, dass die Base sechs Positionen proximal des Stopcodons in humanen HeLa-Zellen den translationalen Readthrough signifikant beeinflusst. Dies war zuvor in In-silico-Messungen vorhergesagt worden (Schueren et al. 2014). Zudem konnten erfolgreich durchflusszytometrische Messungen des endogenen und induzierten translationalen Readthrough verschiedener Nonsense-Mutationen des Rett-Syndroms in humanen HeLaZellen erfolgen.

Die Durchflusszytometrie wurde zeitgleich zu den hier dargestellten Experimenten in der Göttinger neuropädiatrischen Arbeitsgruppe an verschiedenen humanen Zelllinien für die MDH1x erprobt. Auch hier konnten die In-silico-Daten von Schueren et al. (2014) bestätigt werden: Die MDH1x zeigte in vivo den vorhergesagten prozentualen Anteil an endogenen Readthrough. In Kontrolluntersuchungen wurde die MDH1x in voller Länge einschließlich 57 Nukleotide nach dem Stopcodon exprimiert. Der translationale Readthrough wurde mittels Western Blot analysiert. Der gemessene Anteil des translationalen Readthrough des Vollängenproteins entsprach dem durchflusszytometrisch gemessenen Anteil des translationalen Readthrough des SCC (Hofhuis et al. 2016). Western Blot, In-silico-Analysen 
und durchflusszytmetrische Messungen zeigten das gleiche Ergebnis. Es scheint keine relevanten Störgrößen in dem verwendeten dual reporter assay zu geben.

Dem Readthrough-Phänomen liegt vermutlich eine evolutionäre Entwicklung zugrunde, welche hier anhand des Zellorganells Peroxisom analysiert wurde. Das Peroxisom hat wichtige Funktionen in der Sauerstoffentgiftung, im Lipidstoffwechsel und in weiteren essentiellen Stoffwechselwegen. Peroxisomale Enzyme können nicht vom Peroxisom produziert werden und werden meist über ein peroxisomales Zielsignal (peroxisomal targeting signal, PTS) aus dem Zytosol in das Peroxisom transportiert (Gould et al. 1989). Das PTS besteht aus einer Abfolge von drei C-terminalen Aminosäuren, die an die peroxisomalen Rezeptoren binden (Farré et al. 2019). Im Zusammenhang dieser Rezeptoren sind bislang zwei durch Nonsense-Mutation verursachte Erkrankungen bekannt (Zellweger-Syndrom, Chondrodysplasia punctata), die möglicherweise durch Readthrough-Induktion behandelt werden könnten (Dranchak et al. 2011).

Untersucht wurde hier der evolutionsbedingte Entwicklungsprozess der Readthroughabhängigen peroxisomalen Enzyme LDHBx und MDH1x anhand eines Vergleichs zwischen Säugetieren und den evolutionär älteren Nichtsäugetieren. Als Beispiel für die Nichtsäugetiere wurden Vogelzellen gewählt. Als Beispiel für Säugetiere wurden humane Zellen verwendet.

Die Oxidoreduktasen MDH1x und LDHBx ähneln sich in Funktion und Struktur (Cendrin et al. 1993). Die MDH1(x) ist dabei das evolutionär ältere Enzym (Goward und Nicholls 1994). In Zellen von Säugetieren ist auf der DNA beider Enzyme hinter dem Stopcodon das PTS1 (LDHB: Aminosäuresequenz SRL, MDH1: Aminosäuresequenz CRL) konserviert. Das PTS1 wird von den durch Readthrough verlängerten Isoformen exprimiert. So sind die LDHBx wie auch die MDH1x anteilig in Zellen der Säugetiere lokalisiert (Hofhuis et al. 2016). In Zellen von Nichtsäugetieren zeigt die MDH1x in ihrer Extension ein PTS1, welches effizienter als das der Säugetiere ist. Auf der DNA der LDHBx der Nichtsäugetiere ist in der Extension kein bekanntes PTS konserviert. Es wird diesbezüglich eine bird gap beschrieben (Hofhuis et al. 2016).

In der vorliegenden Arbeit wurde die Lokalisation der LDHBx in CEF-Zellen mittels Immunfluoreszenzfärbung analysiert. Es wurde speziell untersucht, ob eine Kolokalisation zwischen der LDHBx und dem Peroxisom besteht. Zusammenfassend konnte festgestellt werden, dass sich die LDHBx in $20 \%$ bis $33,3 \%$ im Peroxisom der untersuchten Zellen befand. 
Die Tatsache, dass nur eine Untergruppe der Zellen die LDHBx enthielt, spricht für eine Regulation der Anwesenheit der LDHBx im Peroxisom. In einer anderen Studie konnte bezüglich der Anwesenheit der MDH1x im Peroxisom eine Dynamik festgestellt werden. Die durch Readthrough verlängerte Isoform MDH1x ließ sich in verschiedenen Zelltypen einer Spezies in unterschiedlichen Mengen im Peroxisom nachweisen (Hofhuis et al. 2016).

Falls das Vorhandensein der peroxisomalen LDHBx dem Bedarf der einzelnen Zelle angepasst wäre und die LDHBx nur in bestimmten Zellen im Peroxisom konserviert wäre, müsste für die peroxisomale LDHBx der Vögel ein noch nicht bekanntes PTS existieren.

Da sich die $\mathrm{LDHB}(\mathrm{x})$ in nur $20 \%$ bis $33,3 \%$ im Peroxisom und somit hauptsächlich nicht im Peroxisom der Nichtsäugetiere befand, kann man Folgendes über die Funktion der peroxisomalen MDH1(x) ableiten: In den aus evolutionärer Sicht älteren Zellen (hier CEFZellen) könnte die MDH1(x) in der Mehrzahl der Zellen möglicherweise als alleinige NADabhängige Oxidoreduktase im Peroxisom Funktionen übernehmen, die in Zellen der Säugetiere von der $\operatorname{LDHB}(\mathrm{x})$ und der MDH1(x) gemeinsam übernommen werden. Im Peroxisom finden NAD-abhängige Reaktionen wie die $\beta$-Oxidation statt. Da die Membran des Peroxisoms für $\mathrm{NAD}^{+}$und $\mathrm{NADH}$ undurchlässig ist, liegt die Funktion der Enzyme vermutlich in der Beteiligung der Regeneration der Reduktionsäquivalente im Peroxisom (van Roermund et al. 1995; Hofhuis et al. 2016). Die MDH1(x) katalysiert reversibel die NAD-abhängige Reaktion von Malat zu Oxalacetat, während die LDHB(x) reversibel die NAD-abhängige Reaktion von Laktat zu Pyruvat katalysiert. Die MDH-Substratspezifität kann jedoch durch einen Aminosäurewechsel von Oxalacetat zu Pyruvat geändert werden (Cendrin et al. 1993). Vermutlich sind die Oxidoreduktasen zusätzlich am Laktat-PyruvatShuttle und Malat-Aspartat-Shuttle und somit am Export-Import der Redoxäquivalente zwischen Peroxisom und Zytosol beteiligt.

Die Bereitstellung der Redoxäquivalente wird in Zellen der Säugetiere von der MDH1 und der LDHB übernommen. Durch die Anwesenheit der zusätzlichen Oxidoreduktase LDHBx im Peroxisom der Säugetiere wird weniger MDH1x als im Peroxisom der Nichtsäugetiere benötigt. Möglicherweise ist so die von Hofhuis et. al (2016) beschriebene abgeschwächte Effizienz des PTS1 (CRL) der MDH1x der Säugetiere erklärbar.

Translationaler Readthrough zeigte sich in Vorgängerarbeiten als zellspezifisch. Zum Beispiel zeigt der SCC der LDHBx und der MDHx in Glioblastomzellen (U118-Zellen) einen höheren Anteil an endogenem Readthrough als in humanen HeLa-Zellen, Cos-7-Zellen oder HEK-Zellen (Hofhuis et al. 2016). In der AG Thoms konnte für den SCC der MDH1x ein Readthrough-Wert von 4,3 $\pm 0,82 \%$ gemessen werden. In der vorliegenden Arbeit wurde 
der quantitative endogene und induzierte Readthrough des SCC der MDH1(x) und der LDHB(x) unter gleichen Bedingungen wie in Hofhuis et al. (2016) in CEF-Zellen durchflusszytometrisch untersucht. Für den SCC der MDH1x in CEF-Zellen war ein Readthrough-Anteil von 3,27 \pm 1,14\% messbar. Der Unterschied war nicht signifikant. Auch die Readthrough-Induzierbarkeit ergab bezüglich der beiden Zelllinien keine signifikanten Unterschiede. In HeLa-Zellen konnte für den SCC der MDH1 nach der Behandlung mit G418 translationaler Readthrough von 13,1 \pm 1,17\% gemessen werden (Hofhuis et al. 2016). In CEF-Zellen ließ sich für das gleiche Konstrukt unter gleichen Bedingungen ein Readthrough-Anteil von 12,84 \pm 1,22\% messen. CEF-Zellen zeigen für die MDH1 einen ähnlichen Anteil an translationalen Readthrough wie HeLa-Zellen. Warum translationaler Readthrough teilweise zellspezifisch und teilweise nicht zellspezifisch ist, bleibt ungeklärt.

Insgesamt konnte für den SCC der MDH1x ein höherer Anteil an translationalem Readthrough als für den SCC der LDHBx gemessen werden (Abbildung 10). Auffällig war, dass die LDHBx und die Negativkontrolle VASN ds keine signifikant unterschiedlichen Anteile an translationalem Readthrough zeigten (Abbildung 9). VASN ds ist ein Vektorkonstrukt bestehend aus einer Basensequenz zwei direkt hintereinanderliegender Stopcodons. Vermutlich liegen die ähnlichen Readthrough-Werte der beiden Konstrukte an einer Ungenauigkeit der durchflusszytometrischen Messungen in niedrigen ReadthroughBereichen.

Dem endogenen translationalen Readthrough werden verschiedene Einflussfaktoren zugeschrieben. Es wird zwischen dem programmierten translationalen Readthrough, bei dem cis-Elemente bzw. trans-wirkende Aktivatoren die Readthrough-Effizienz beeinflussen, und dem basalen translationalen Readthrough unterschieden. Beim basalen translationalen Readthrough werden das Stopcodon und der SCC als Einflussfaktoren beschrieben (siehe 1.4).

In dieser Arbeit wurden Mechanismen des basalen translationalen Readthrough im Hinblick auf den Einfluss der Nukleotide proximal und distal des Stopcodons im Detail untersucht. In-silico-Modellierungen sahen bereits einen signifikanten Einfluss des Nukleotids sechs Positionen proximal des Stopcodons voraus (Schueren et al. 2014). Die Frage nach dem Einfluss der proximalen Nukleotide auf den translationalen Readthrough wurde hier aufgegriffen. Der dual reporter assay ermöglichte es, Readthrough-Werte der DNA-Sequenzen zwei verschiedener Proteine mit Mutationen zwei Trinukleotidsequenzen proximal des 
Stopcodons (Position minus sechs) zu vergleichen. Die Mutationen sechs Positionen proximal des Stopcodons reduzierte den endogenen translationalen Readthrough signifikant. In dieser Arbeit konnte erstmals in vitro der Einfluss der Base sechs Positionen proximal des Stopcodons bestätigt werden. Zusätzlich konnte gezeigt werden, welche Base für welches Enzym besonders viel oder wenig translationalen Readthrough auslöst.

Der signifikante Einfluss der Base sechs Positionen proximal des Stopcodons bestätigt den relevanten Einfluss des SCC auf den endogenen translationalen Readthrough.

Im Anschluss der hier beschriebenen Experimente fanden ähnliche Versuchsreihen in der Göttinger neuropädiatrischen Arbeitsgruppe statt. In den weiterführenden Experimenten wurde der Einfluss der Basen distal des Stopcodons auf den translationalen Readthrough untersucht: Alle getesteten Veränderungen der Nukleotide des SCC (Mutationen vier und sechs Positionen distal des Stopcodons) führten zu einer signifikanten Abnahme des translationalen endogenen Readthrough (Hofhuis et al. 2016).

Aktuell gibt es noch keinen allgemeinen Konsens, ob translationaler Readthrough hauptsächlich vom SCC beeinflusst wird oder ob primär cis-wirkende mRNA-Elemente distal des Stopcodons bzw. trans-wirkende Aktivatoren den translationalen Readthrough fördern. So kamen Eswarappa et al. (2014) aufgrund ihrer Experimente zum Schluss, dass die 63 Nukleotide distal des Stopcodons den translationalen Readthrough maßgeblich beeinflussen. Es war ein Konstrukt des Gens VEGF-Ax, welches das Stopcodon sowie 63 Nukleotide hinter dem Stopcodon beinhaltete, in einem quantitativen firefly luciferase assay untersucht worden. Der Anteil des endogenen translationalen Readthrough des Konstrukts lag bei 9\%. Weitergehende Experimente der Arbeit zeigten, dass eine Sequenz für eine Bindungsstelle (A2RE) für einen trans-wirkenden Verstärker (hnRNA A2/B1) in dem Bereich der 63 Nukleotide hinter dem Stopcodon, welche den translationalen Readthrough reguliert, liegt (Eswarappa et al. 2014).

Da die Ergebnisse von Eswarappa et al. (2014) den Einfluss der proximalen Nukleotide für den translationalen Readthrough, der in dieser sowie in der Arbeit von Hofhuis et al. (2016) gezeigt wird, in Frage stellen, wurde der translationale Readthrough einer neu definierten Basenabfolge des Gens VEGF-Ax zum Vergleich gemessen. Das neue Konstrukt beinhaltete das Stopcodon sowie die 63 distal des Stopcodons liegenden Nukleotide und wurde S63N genannt. Es wurde ein Vektorkonstrukt, welches die DNA vom RFP - S63N - GFP enthielt, mit dem hier etablierten dual reporter assay gemessen. 
Es konnte kein signifikanter endogener translationaler Readthrough festgestellt werden. Dies weist auf eine Abhängigkeit des endogenen translationalen Readthrough von dem gesamten SCC (einschließlich proximaler und distaler Basen) hin. Es wäre interessant in Folgearbeiten direkte Vergleichsmessungen zwischen dem SCC (Stopcodon, zehn Nukleotide vor und zehn Nukleotide nach dem Stopcodon) und dem S63N (Stopcodon, 63 Nukleotide nach dem Stopcodon) des VEGF-Ax-Gens in dem dual reporter assay durchzuführen. So könnte der direkte Einfluss der Extension des VEGD-Ax-Gens auf den translationalen Readthrough nachgewiesen werden.

Die Experimente von Eswarappa et al. (2014) und dieser Arbeit unterscheiden sich grundsätzlich in der Methode. In der vorliegenden Arbeit wurde der translationale Readthrough mittels GFP, RFP und dem Konstrukt, beginnend mit dem Stopcodon des VEGF-Ax-Gens durchflusszytometrisch gemessen, während in der Versuchsreihe Eswarappa et al. (2014) der translationale Readthrough des Konstrukts des kompletten VEGF-Ax-Gens in Kombination mit dem Firefly-Luciferase-Gen mittels einem dual reporter assay indirekt gemessen wurde.

Möglicherweise sind die hohen Readthrough-Werte von Eswarappa et al. (2014) auf das Vorhandensein der Extension (x) des VEGF- $A x$-Gens mit den Bindungsstellen für den trans-wirkenden Verstärker, in Kombination mit dem kompletten SCC, d. h. auch der letzten zehn Nukleotide vor dem Stopcodon, zurückzuführen. Die zehn Nukleotide vor dem Stopcodon fehlten in dem Konstrukt dieser Arbeit. Möglich wären auch Störungen der Readthrough-Messungen durch den firefly luciferase assay, die eventuell eine fälschlich hohe Readthrough-Aktivität vorgetäuscht hatten. Derartige Störungen durch den firefly luciferase assay wurden im Schrifttum wie folgt diskutiert (Auld et al. 2009; Auld et al. 2010): Der firefly luciferase assay beruht auf einem ATP-abhängigem Reporterenzym und wird z. B. bei der Untersuchung von neuen Medikamenten eingesetzt. Beispielsweise wurde die Substanz PTC124 durch den Einsatz des firefly luciferase assays entdeckt. PTC124 förderte dabei die Aktivität des Firefly-Luciferase-Reportergens in Säugetierzellen. In der maßgeblichen Studie wurde die erhöhte Aktivität der Luciferase auf den translationalen Readthrough eines konstruierten Stopcodons zurückgeführt (Welch et al. 2007). In späteren Studien konnte in Kontrollassays mittels renilla reniformis luciferase durch PTC124 interessanterweise kein translationaler Readthrough ausgelöst werden (Auld et al. 2009). In einer anderen Studie wurde die Readthrough-induzierende Aktivität von PTC124 mit verschiedenen Untersuchungsmethoden in vitro mit der Readthrough-induzierenden Aktivität von G418 verglichen. PTC124 löste verglichen mit G418 ebenfalls kaum translationalen Readthrough 
aus (McElroy et al. 2013). Vermutlich hat PTC124 unabhängig vom Einfluss auf den translationalen Readthrough eine direkte Wirkung auf den firefly luciferase assay. Dies kann zu einer Überschätzung des Ausmaßes des Readthrough geführt haben, wenn dieser ausschließlich durch den firefly luciferase assay bestimmt wurde (Auld et al. 2010).

In In-vivo-Modellen von Krankheiten und in klinischen Studien gibt es jedoch Daten, die dafürsprechen, dass die Substanz PTC124 wirkt. Beispielsweise verzögert die Substanz bei Patienten mit der Muskeldystrophie Duchenne die Krankheitsprogression wie den Verlust der Gehfähigkeit (siehe 1.2). Die Hersteller PTC Therapeutics gehen dabei von einer Wirkung über induzierten translationalen Readthrough aus (PTC Therapeutics Herstellerangaben). Da die oben genannten Publikationen jedoch gegen eine Wirkung über translationalen Readthrough sprechen und auch in dieser Arbeit Hinweise gefunden wurden, die dafürsprechen, dass der firefly luciferase assay die Messungen von translationalen Readthrough stört, wäre es notwendig den Wirkmechanismus von PTC124 in weiteren Arbeiten zu erforschen.

Zusammenfassend lässt sich aufgrund der eigenen Ergebnisse ein deutlicher Einfluss proximaler Nukleotide (der Position minus sechs) auf den translationalen Readthrough erkennen. Der Einfluss der 63 Nukleotiden nach dem Stopcodon, der nach Eswarappa et al. (2014) für den Readthrough des VEGF-A(x)-Gens entscheidend sein soll, konnte hier dagegen nicht bestätigt werden.

Eine weitere Erkrankung, für die eine Therapie mit einer translational readthrough-inducing drug (TRID) einen attraktiven Behandlungsansatz darstellen könnte, ist das Rett-Syndrom. Das Rett-Syndrom wird in $35 \%$ durch Nonsense-Mutationen im x-chromosomalen MeCP2-Gen verursacht (Ip et al. 2018). Das MeCP2-Gen kodiert für das Methyl-CPG-Bindungsprotein 2 und spielt bei der epigenetischen Kontrolle der Genexpression eine entscheidende Rolle (Chahrour und Zoghbi 2007). Dies erklärt die Vielfalt der Symptome des Rett-Syndroms (siehe 1.5).

Es konnte bereits in Studien gezeigt werden, dass sich die Nonsense-Mutationen des RettSyndroms in vitro prinzipiell mit G418, Gentamicin und Derivaten des Paramycins (z. B. NB54 und NB84) überlesen lassen. Die Effektivität der Readthrough-Induktion der Nonsense-Mutationen des MeCP2-Gens war vergleichbar mit der Effektivität der Readthrough-Induktion von Nonsense-Mutationen anderer Erkrankungen. In diesem Zusammenhang wurden für die häufigsten Nonsense-Mutationen des Rett-Syndroms Effektivitäten der Readthrough-Induktion zwischen $10 \%$ und 21,8 \% in HeLa-Zellen gemessen (Brendel et al. 2009). In Fibroblasten aus Mäuseohren, die die Mutation 
RettpR168X-Mutation im MeCP2-Gen exprimierten, konnte ebenfalls translationaler Readthrough induziert werden. Die Effizienz der Readthrough-Induktion fiel jedoch etwas niedriger aus (Brendel et al. 2011). Es konnte so ein weiteres Mal bestätigt werden, dass die Effizienz des induzierten translationalen Readthrough in eukaryotischen Zellen vom SCC abhängt (Howard et al. 2000).

In dieser Arbeit wurde die Effektivität der Readthrough-Induktion für die elf häufigsten Nonsense-Mutationen (RettpR168X, RettpR270X, RettpY141X, RettpQ170X, RettpR255X, RettpS204X, RettpQ244X, RettpK175X, Rett-pS68X, RettpK177X, RettpK363X) des Rett-Syndroms vergleichend evaluiert. Zunächst wurde der endogene translationale Readthrough der frühzeitigen Stopcodons durchflusszytometrisch gemessen. Es zeigte sich in allen Fällen kaum endogener translationaler Readthrough. Es konnten keine signifikanten Unterschiede zwischen dem Readthrough der SCC der untersuchten Mutationen festgestellt werden.

Anschließend wurde der translationale Readthrough der gleichen Mutationen mit dem Aminoglykosid G418 induziert. Aminoglykoside binden in hoher Konzentration an die ribosomale RNA und induzieren eine Konformationsänderung. Die Qualität des Korrekturlesens wird somit vermindert und es kommt zu vermehrten Fehlpaarungen der Basen zwischen Codon und Anticodon. Dadurch binden häufiger tRNAs, die ein fast passendes Anticodon enthalten, an die durch die Nonsense-Mutation verursachten vorzeitigen Stopcodons der mRNA. Aminoglykoside induzieren somit translationalen Readthrough von Nonsense-Mutationen (Kellermayer 2006).

Es ließen sich signifikante Unterschiede in der Effizienz der Induzierbarkeit zwischen den verschiedenen Nonsense-Mutationen feststellen. Die Effizienz der Readthrough-Induktion variierte zwischen keiner signifikanten Readthrough-Induktion und einer Induktion des translationen Readthrough um den Faktor 35. Der höchste Anteil an induzierten Readthrough konnte für die Mutation RettpR270X gemessen werden. Dagegen ließ sich bei der in Deutschland häufigsten Nonsense-Mutation des Rett-Syndroms RettpR168X kein translationaler Readthrough mit G418 induzieren.

Es existieren weltweit regionale Unterschiede bezüglich der Prävalenz der gemessenen Mutationen. Beispielsweise ist die Mutation RettpR270X, bei welcher Readthrough mit der höchsten Effizienz induzierbar war, in China kaum nachzuweisen. In Frankreich hingegen tragen ungefähr 10,3 \% aller Rett-Patienten die Mutation RettpR270X (Percy et al. 2007). Hier erscheint ein möglicher Therapieerfolg bei der Readthrough-Therapie mit Aminoglykosiden aufgrund der vorgelegten Ergebnisse wahrscheinlicher. 
Für eine mögliche Therapie mit Readthrough-induzierenden Aminoglykosiden sollte bedacht werden, dass diese die Bluthirnschranke nur in hoher Konzentration überwinden können. Aminoglykoside haben insbesondere bei höheren Dosierungen signifikante Nebenwirkungen, was die Anwendung bei einer systemische Readthrough-Therapie möglicherweise limitiert (Brendel et al. 2011). Zu den gravierenden Nebenwirkungen zählen die Nephrotoxizität und die Ototoxizität. Um die systemische Toxizität zu umgehen, könnte eine mögliche intrathekale Applikation diskutiert werden.

Im Hinblick auf die Nebenwirkungen wäre es in jedem Fall wichtig, Readthroughinduzierende Medikamente nur dann einzusetzen, wenn von einem wahrscheinlichen Therapieerfolg ausgegangen werden könnte. In dieser Arbeit wurden die NonsenseMutationen, die sich sehr gut beziehungsweise kaum überlesen lassen, für das Rett-Syndrom bestimmt. Readthrough-induzierende Medikamente könnten somit zielgerichtet je nach Mutation eingesetzt werden.

Bei der Entwicklung einer klinischen Therapie mit Readthrough-induzierenden Substanzen beim Rett-Syndrom sollte berücksichtigt werden, dass es bislang keine Daten dazu gibt, wie hoch die Effizienz der Readthrough-Induktion sein muss, um die Symptome und den Krankheitsfortschritt zu verhindern.

Zudem ist bislang unklar, ob das durch induzierten Readthrough in voller Länge exprimierte Protein biologisch aktiv ist (Brendel et al. 2009). In den durch Readthrough-verlängerten Isoformen wird eine zufällige tRNA, meist für die Aminosäure Tryptophan kodierend, an die Position des Stopcodons eingebaut (Hofhuis et al. 2016). In den Wildtypen der Proteine ist jedoch an der betreffenden Stelle oft eine andere Aminosäure exprimiert, was Auswirkungen auf die biologische Funktion des Proteins haben könnte. Beispielsweise ist im MeCP2-Gen meist das Basentriplett der Aminosäure Arginin mutiert (gilt für RettpR168X, RettpR270X, RettpR255X) (Brendel et al. 2009). Würde hier anstatt der Aminosäure Arginin Tryptophan in das Protein eingebaut werden, könnte dies gegebenenfalls funktionelle Auswirkungen auf das Methyl-CPG-Bindungsprotein 2 haben. Die biologische Aktivität der nach medikamentösen Readthrough exprimierten Proteine sollte also in funktioneller Hinsicht im Detail untersucht werden.

Die hier für das Rett-Syndrom beschriebenen Werte für die Readthrough-Induzierbarkeit beziehen sich auf Experimente mit dem Aminoglykosid G418. Das Substrat G418 gilt als besonders effektiver Induktor von Readthrough, weswegen es hier exemplarisch eingesetzt wurde. G418 wird allerdings auch wegen seiner Hemmung der Proteinbiosynthese in humanen Zellen in der Forschung zur Selektion genetisch veränderter Zellen verwendet. Vor 
allem die Derivate des Aminoglykosids Paromomycin NB54 und NB84 scheinen hohe Erfolgsaussichten bezüglich einer Readthrough-Therapie des Rett-Syndroms zu haben. Sie sind effektiver als Gentamicin und zeigen weniger unerwünschte Wirkungen (Brendel et al. 2011). In Folgeuntersuchungen sollten daher die hier gemachten Beobachtungen für andere Readthrough-induzierende Substrate, die therapeutisch eingesetzt werden könnten (z. B. NB54 und NB84), bestätigt werden.

Zusammenfassend kann festgestellt werden, dass die häufigsten Nonsense-Mutationen des Rett-Syndroms unterschiedlich gut durch induzierten translationalen Readthrough therapiert werden können. Aufgrund der gravierenden Nebenwirkungen der Readthroughinduzierenden Medikamente ist es sinnvoll, die Medikamente zielgerichtet einzusetzen. Es wäre interessant ähnliche Messungen für weitere durch Nonsense-Mutation verursachte Erkrankungen durchzuführen. 


\section{$5 \quad$ Zusammenfassung}

In der vorliegenden Arbeit wurden verschiedene Aspekte zum translationen ReadthroughPhänomen bearbeitet. Die Termination der Translation, ein Teilprozess der Proteinbiosynthese, wird durch das Basentriplett eines Stopcodons markiert. Wird das Stopcodon anders interpretiert und in eine Aminosäure übersetzt, spricht man von translationalem Readthrough. Zum einen kann translationaler Readthrough endogen sein und zu der Entstehung neuer Protein-Isoformen führen. Zum anderen kann translationaler Readthrough mit Medikamenten induziert werden und stellt einen Behandlungsansatz bei durch Nonsense-Mutation verursachten Erkrankungen dar.

Im ersten Teil der Arbeit wurde die Methode der Durchflusszytometrie zur quantitativen Messung des endogenen sowie des induzierten translationalen Readthrough erfolgreich etabliert. Es wurden humane HeLa-Zellen und embryonale Huhnzellen (chicken embryo fibroblasts, CEF) mit fluoreszierenden Vektorkonstrukten transfiziert. In die Vektorkonstrukte wurde die DNA des rot fluoreszierenden Proteins (RFP), des StopcodonKontexts und des grün fluoreszierenden Proteins (GFP) integriert. Der Stopcodon-Kontext beinhaltete die DNA des Stopcodons und jeweils zehn Nukleotide vor und nach dem Stopcodon des zu messenden Proteins. Die Signale wurden durchflusszytometrisch gemessen. RFP stellte die Kontrolle der Enzymsynthese dar, während GFP translationalen Readthrough signalisierte.

Die Durchflusszytometrie stellte sich als eine effiziente und gute Alternative zu anderen Methoden zur Messung des translationalen Readthrough dar und könnte in Zukunft Forschungen zum translationalen Readthrough-Phänomen erleichtern.

Im zweiten Teil wurden peroxisomale Enzyme (Malatdehydrogenase 1 und Laktatdehydrogenase B), die einen besonders hohen endogenen Readthrough-Anteil zeigen, in Modellzellen von Nichtsäugetierzellen näher charakterisiert: Die peroxisomale MDH1x und LDHBx werden über ein in den Readthrough-Erweiterungen verstecktes Zielsignal (peroxisomal targeting Signal, PTS) in das Peroxisom transportiert. In der ReadthroughErweiterung der LDHBx ist bei Nichtsäugetieren bekanntermaßen kein PTS konserviert. In der vorliegenden Arbeit konnte mittels Immunfluoreszenzmikroskopie gezeigt werden, dass die LDHBx tatsächlich nur in $20 \%$ bis $33 \%$ der Fälle in Zellen von Nichtsäugetieren im Peroxisom lokalisiert ist. Da sich die LDHBx und die MDH1x in Funktion und Struktur sehr ähneln, könnte die evolutionär ältere MDH1x hypothetisch im Peroxisom der Nichtsäugetiere Funktionen übernehmen, die im Peroxisom der Säugetiere von der LDHBx zusammen mit der MDH1x übernommen werden. Basierend auf zuvor erhobenen Daten 
der Göttinger neuropädiatrischen Arbeitsgruppe konnte zusätzlich festgestellt werden, dass die MDH1(x) in CEF-Zellen im Vergleich zur MDH1(x) in humanen HeLa-Zellen keinen signifikanten Unterschied bezüglich der Quantität des Readthrough zeigt.

Im dritten Teil wurde der Einfluss der Nukleotide, die um das Stopcodon lokalisiert sind, auf den translationalen Readthrough analysiert. In-silico-Modellierungen sprachen für einen signifikanten Einfluss der Base sechs Positionen proximal des Stopcodons. Die Frage nach dem Einfluss der proximalen Basen auf den translationalen Readthrough wurde in der vorliegenden Arbeit in vitro mit einem neu etablierten dual reporter assay untersucht. Der Assay ermöglichte es, Readthrough-Werte der DNA-Sequenzen zwei verschiedener Proteine mit Mutationen zwei Trinukleotidsequenzen proximal des Stopcodons (Position minus sechs) zu vergleichen. Mutationen sechs Positionen proximal des Stopcodons reduzierten den endogenen translationalen Readthrough signifikant. Die In-silico-Daten zum maßgeblichen Einfluss der Base sechs Positionen proximal des Stopcodons konnten erstmals in vivo im Experiment mit lebenden Zellen bestätigt werden. Zusätzlich konnte gezeigt werden, welche Base für welches Enzym besonders viel oder wenig Readthrough auslöst.

Um die Bedeutung der proximalen Nukleotide für den translationalen Readthrough herauszustellen, wurde der endogene translationale Readthrough eines Konstrukts bestehend aus RFP, dem Stopcodon des Gens VEGF-Ax mit den darauffolgenden 63 Nukleotiden und GFP durchflusszytometrisch gemessen. In dieser Versuchsreihe konnte kein signifikanter endogener translationaler Readthrough beobachtet werden. Eine frühere Studie wies darauf hin, dass für das Protein VEGF-Ax die 63 Nukleotide distal des Stopcodons entscheidend für den translationalen Readthrough sein könnten. Dies konnte hier nicht bestätigt werden. Entweder erlaubt das Gen $V E G F-A x$ daher keinen endogenen translationalen Readthrough oder der endogene translationale Readthrough ist von dem gesamten Stopcodon-Kontext (einschließlich proximaler und distaler Nukleotide) abhängig.

Im vierten Teil der Arbeit wurde der induzierte translationale Readthrough der NonsenseMutationen des Rett-Syndroms untersucht. Es wurde die Effizienz der ReadthroughInduktion durch das Aminoglykosid Geneticin bei den elf häufigsten Nonsense-Mutationen des Rett-Syndroms einzeln evaluiert. Dazu wurden HeLa-Zellen mit einem Vektorkonstrukt (bestehend aus RFP, Stopcodon-Kontext der zu messenden Nonsense-Mutation, GFP) transfiziert und mit Geneticin behandelt. Es konnte ein deutlich signifikanter Unterschied in der Effizienz der Readthrough-Induzierbarkeit zwischen den Nonsense-Mutationen festgestellt werden. Für einige Mutationen ließ sich translationaler Readthrough sehr gut 
induzieren (z. B. RettpR270X), während andere, darunter auch die häufigste Mutation des Rett-Syndroms in Deutschland (RettpR168X), keinen induzierbaren Readthrough zeigten. Dies könnte klinisch relevant werden, weil auf der Basis dieser Ergebnisse Readthroughinduzierende und möglicherweise nebenwirkungsreiche Medikamente zielgerichtet eingesetzt werden könnten. 


\section{$6 \quad$ Literaturverzeichnis}

Abe Y, Honsho M, Nakanishi H, Taguchi R, Fujiki Y (2014): Very-long-chain polyunsaturated fatty acids accumulate in phosphatidylcholine of fibroblasts from patients with Zellweger syndrome and Acyl-CoA oxidase1 deficiency. Biochim Biophys Acta 1841, 610-619

Amir RE, Van den Veyver IB, Wan M, Tran CQ, Francke U, Zoghbi HY (1999): Rett syndrome is caused by mutations in X-linked MECP2, encoding methyl-CpG-binding protein 2. Nat Genet $\underline{23}$, 185-188

Aslam AA, Higgins C, Sinha IP, Southern KW (2017): Ataluren and similar compounds (specific therapies for premature termination codon class I mutations) for cystic fibrosis. Cochrane Database Syst Rev $\underline{1}$, CD012040

Auld DS, Thorne N, Maguire WF, Inglese J (2009): Mechanism of PTC124 activity in cell-based luciferase assays of nonsense codon suppression. Proc Natl Acad Sci USA 106, 3585-3590

Auld DS, Lovell S, Thorne N, Lea WA, Maloney DJ, Shen M, Rai G, Battaile KP, Thomas CJ, Simeonov A, et al. (2010): Molecular basis for the high-affinity binding and stabilization of firefly luciferase by PTC124. Proc Natl Acad Sci USA 107, 4878-4883

Baranov PV, Gesteland RF, Atkins JF (2002): Recoding: translational bifurcations in gene expression. Gene 286, 187-201

Beier H, Grimm M (2001): Misreading of termination codons in eukaryotes by natural nonsense suppressor tRNAs. Nucleic Acids Res 29, 4767-4782

Bertram G, Innes S, Minella O, Richardson JP, Stansfield I (2001): Endless possibilities: translation termination and stop codon recognition. Microbiology 147, 255-269

Beznosková P, Wagner S, Jansen ME, von der Haar T, Valášek LS (2015): Translation initiation factor eIF3 promotes programmed stop codon readthrough. Nucleic Acids Res $\underline{43}, 5099-5111$

Bidou L, Allamand V, Rousset J-P, Namy O (2012): Sense from nonsense: therapies for premature stop codon diseases. Trends Mol Med 18, 679-688

Boyle MP, De Boeck K (2013): A new era in the treatment of cystic fibrosis: correction of the underlying CFTR defect. Lancet Respir Med 1, 158-163

Braverman NE, Moser AB, Steinberg SJ: Rhizomelic Chondrodysplasia Punctata Type 1. In: Adam MP, Ardinger HH, Pagon RA, Wallace SE, Bean LJ, Stephens K, Amemiya A(Hrsg.):

GeneReviews, University of Washington, Seattle 1993-2020

Brendel C, Klahold E, Gärtner J, Huppke P (2009): Suppression of nonsense mutations in Rett syndrome by aminoglycoside antibiotics. Pediatr Res $\underline{65}, 520-523$

Brendel C, Belakhov V, Werner H, Wegener E, Gärtner J, Nudelman I, Baasov T, Huppke P (2011): Readthrough of nonsense mutations in Rett syndrome: evaluation of novel aminoglycosides

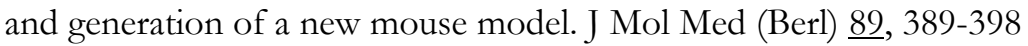

Bushby K, Finkel R, Wong B, Barohn R, Campbell C, Comi GP, Connolly AM, Day JW, Flanigan KM, Goemans N, et al. (2014): Ataluren treatment of patients with nonsense mutation dystrophinopathy. Muscle Nerve $\underline{50}, 477-487$ 
Cendrin F, Chroboczek J, Zaccai G, Eisenberg H, Mevarech M (1993): Cloning, sequencing, and expression in Escherichia coli of the gene coding for malate dehydrogenase of the extremely halophilic archaebacterium Haloarcula marismortui. Biochemistry $\underline{32}$, 4308-4313

Chahrour M, Zoghbi HY (2007): The story of Rett syndrome: from clinic to neurobiology. Neuron $\underline{56}, 422-437$

Di Cara F, Rachubinski RA, Simmonds AJ (2019): Distinct Roles for Peroxisomal Targeting Signal Receptors Pex5 and Pex7 in Drosophila. Genetics 211, 141-149

Dranchak PK, Di Pietro E, Snowden A, Oesch N, Braverman NE, Steinberg SJ, Hacia JG (2011): Nonsense suppressor therapies rescue peroxisome lipid metabolism and assembly in cells from patients with specific PEX gene mutations. J Cell Biochem 112, 1250-1258

Dunn JG, Foo CK, Belletier NG, Gavis ER, Weissman JS (2013): Ribosome profiling reveals pervasive and regulated stop codon readthrough in Drosophila melanogaster. eLife $\underline{2}$, e01179

Ebrahimi-Fakhari D, Dillmann U, Flotats-Bastardas M, Poryo M, Abdul-Khaliq H, Shamdeen MG, Mischo B, Zemlin M, Meyer S (2018): Off-Label Use of Ataluren in Four Non-ambulatory Patients With Nonsense Mutation Duchenne Muscular Dystrophy: Effects on Cardiac and Pulmonary Function and Muscle Strength. Front Pediatr $\underline{6}, 316$

Engelberg-Kulka H, Dekel L, Israeli-Reches M, Belfort M (1979): The requirement of nonsense suppression for the development of several phages. Mol Gen Genet 170, 155-159

Eswarappa SM, Potdar AA, Koch WJ, Fan Y, Vasu K, Lindner D, Willard B, Graham LM, DiCorleto PE, Fox PL (2014): Programmed translational readthrough generates antiangiogenic VEGF-Ax. Cell 157, 1605-1618

Farré JC, Mahalingam SS, Proietto M, Subramani S (2019): Peroxisome biogenesis, membrane contact sites, and quality control. EMBO Rep $\underline{20}$, e46864

Firth AE, Brierley I (2012): Non-canonical translation in RNA viruses. J Gen Virol 93, 1385-1409

Firth AE, Wills NM, Gesteland RF, Atkins JF (2011): Stimulation of stop codon readthrough: frequent presence of an extended 3' RNA structural element. Nucleic Acids Res $\underline{39}$, 6679-6691

Floquet C, Hatin I, Rousset JP, Bidou L (2012): Statistical Analysis of Readthrough Levels for Nonsense Mutations in Mammalian Cells Reveals a Major Determinant of Response to Gentamicin. PLOS Genet $\underline{8}$, e1002608

François B, Russell RJM, Murray JB, Aboul-ela F, Masquida B, Vicens Q, Westhof E (2005):

Crystal structures of complexes between aminoglycosides and decoding A site oligonucleotides: role of the number of rings and positive charges in the specific binding leading to miscoding. Nucleic Acids Res $\underline{33}, 5677-5690$

Freitag J, Ast J, Bölker M (2012): Cryptic peroxisomal targeting via alternative splicing and stop codon read-through in fungi. Nature $\underline{485}, 522-525$

Geller AI, Rich A (1980): A UGA termination suppression tRNATrp active in rabbit reticulocytes. Nature 283, 41-46 
Goldmann T, Overlack N, Möller F, Belakhov V, van Wyk M, Baasov T, Wolfrum U, NagelWolfrum K (2012): A comparative evaluation of NB30, NB54 and PTC124 in translational readthrough efficacy for treatment of an USH1C nonsense mutation. EMBO Mol Med $\underline{4}$, 1186-1199 Gould SJ, Keller GA, Subramani S (1987): Identification of a peroxisomal targeting signal at the carboxy terminus of firefly luciferase. J Cell Biol 105, 2923-2931

Gould SJ, Keller GA, Hosken N, Wilkinson J, Subramani S (1989): A conserved tripeptide sorts proteins to peroxisomes. J Cell Biol 108, 1657-1664

Goward CR, Nicholls DJ (1994): Malate dehydrogenase: a model for structure, evolution, and catalysis. Protein Sci $\underline{3}, 1883-1888$

Hagberg B (1995): Rett syndrome: clinical peculiarities and biological mysteries. Acta Paediatr 1992 84, 971-976

Hentze MW, Kulozik AE (1999): A Perfect Message: RNA Surveillance and Nonsense-Mediated Decay. Cell 96, 307-310

Hofhuis J, Schueren F, Nötzel C, Lingner T, Gärtner J, Jahn O, Thoms S (2016): The functional readthrough extension of malate dehydrogenase reveals a modification of the genetic code. Open Biol $\underline{6}, 160246$

Hofhuis J, Dieterle S, George R, Schueren F, Thoms S (2017): Dual Reporter Systems for the Analysis of Translational Readthrough in Mammals. Methods Mol Biol Clifton NJ 1595, 81-92 Hofstetter H, Monstein HJ, Weissmann C (1974): The readthrough protein A1 is essential for the formation of viable Q beta particles. Biochim Biophys Acta $\underline{374}$, 238-251

Howard MT, Shirts BH, Petros LM, Flanigan KM, Gesteland RF, Atkins JF (2000): Sequence specificity of aminoglycoside-induced stop condon readthrough: potential implications for treatment of Duchenne muscular dystrophy. Ann Neurol 48, 164-169

Huppke P, Held M, Laccone F, Hanefeld F (2003): The spectrum of phenotypes in females with Rett Syndrome. Brain Dev 25, 346-351

Ip JPK, Mellios N, Sur M (2018): Rett syndrome: insights into genetic, molecular and circuit mechanisms. Nat Rev Neurosci 19, 368-382

Keeling KM, Xue X, Gunn G, Bedwell DM (2014): Therapeutics based on stop codon readthrough. Annu Rev Genomics Hum Genet 15, 371-394

Kellermayer R (2006): Translational readthrough induction of pathogenic nonsense mutations. Eur J Med Genet $\underline{49}$, 445-450

Kerem E, Konstan MW, De Boeck K, Accurso FJ, Sermet-Gaudelus I, Wilschanski M, Elborn JS, Melotti P, Bronsveld I, Fajac I, et al. (2014): A randomized placebo-controlled trial of ataluren for the treatment of nonsense mutation cystic fibrosis. Lancet Respir Med 2, 539-547

Landfeldt E, Sejersen T, Tulinius M (2019): A mini-review and implementation model for using ataluren to treat nonsense mutation Duchenne muscular dystrophy. Acta Paediatr 108, 224-230 
Leigh F, Ferlini A, Biggar D, Bushby K, Finkel R, Morgenroth LP, Wagner KR (2018): Neurology Care, Diagnostics, and Emerging Therapies of the Patient With Duchenne Muscular Dystrophy. Pediatrics $\underline{142}, 5-16$

Mantero M, Gramegna A, Pizzamiglio G, D’Adda A, Tarsia P, Blasi F (2017): Once daily aerosolised tobramycin in adult patients with cystic fibrosis in the management of Pseudomonas aeruginosa chronic infection. Multidiscip Respir Med 12, 2

McDonald CM, Campbell C, Torricelli RE, Finkel RS, Flanigan KM, Goemans N, Heydemann P, Kaminska A, Kirschner J, Muntoni F, et al. (2017): Ataluren in patients with nonsense mutation Duchenne muscular dystrophy (ACT DMD): a multicentre, randomised, double-blind, placebocontrolled, phase 3 trial. Lancet $\underline{390}$, 1489-1498

McElroy SP, Nomura T, Torrie LS, Warbrick E, Gartner U, Wood G, McLean WHI (2013): A lack of premature termination codon read-through efficacy of PTC124 (Ataluren) in a diverse array of reporter assays. PLOS Biol 11, e1001593

Mort M, Ivanov D, Cooper DN, Chuzhanova NA (2008): A meta-analysis of nonsense mutations causing human genetic disease. Hum Mutat 29, 1037-1047

Percy AK, Lane JB, Childers J, Skinner S, Annese F, Barrish J, Caeg E, Glaze DG, MacLeod P (2007): Rett syndrome: North American database. J Child Neurol 22, 1338-1341

Popescu AC, Sidorova E, Zhang G, Eubanks JH (2010): Aminoglycoside-mediated partial suppression of MECP2 nonsense mutations responsible for Rett syndrome in vitro. J Neurosci Res $\underline{88}, 2316-2324$

PTC Therapeutics (South Plainfield, NJ) (Hrsg.): Herstellerangaben siehe https://www.ptcbio.com/therapeutic-focus/approach/nonsense-Readthrough/; abgerufen am 22.8.2019

Schueren F, Thoms S (2016): Functional Translational Readthrough: A Systems Biology Perspective. PLOS Genet $\underline{12}$, e1006196

Schueren F, Lingner T, George R, Hofhuis J, Dickel C, Gärtner J, Thoms S (2014): Peroxisomal lactate dehydrogenase is generated by translational readthrough in mammals. eLife $\underline{3}$, e03640

Steinberg SJ, Raymond GV, Braverman NE, Moser AB: Zellweger Spectrum Disorder. In: Adam MP, Ardinger HH, Pagon RA, Wallace SE, Bean LJ, Stephens K, Amemiya A (Hrsg.):

GeneReviews, University of Washington, Seattle 1993-2020

Thoms S (2015): Import of proteins into peroxisomes: piggybacking to a new home away from home. Open Biol $\underline{5}, 150148$

Torabi N, Kruglyak L (2012): Genetic basis of hidden phenotypic variation revealed by increased translational readthrough in yeast. PLOS Genet $\underline{8}$, e1002546

Van Esch H, Bauters M, Ignatius J, Jansen M, Raynaud M, Hollanders K, Lugtenberg D, Bienvenu T, Jensen LR, Gecz J, et al. (2005): Duplication of the MECP2 region is a frequent cause of severe mental retardation and progressive neurological symptoms in males. Am J Hum Genet $\underline{77}$, 442-453 
Van Roermund CW, Elgersma Y, Singh N, Wanders RJ, Tabak HF (1995): The membrane of peroxisomes in Saccharomyces cerevisiae is impermeable to $\mathrm{NAD}(\mathrm{H})$ and acetyl-CoA under in vivo conditions. EMBO J 14, 3480-3486

Welch EM, Barton ER, Zhuo J, Tomizawa Y, Friesen WJ, Trifillis P, Paushkin S, Patel M, Trotta CR, Hwang S, et al. (2007): PTC124 targets genetic disorders caused by nonsense mutations. Nature 4 477, 87-91

Woodley DT, Cogan J, Hou Y, Lyu C, Marinkovich MP, Keene D, Chen M (2017): Gentamicin induces functional type VII collagen in recessive dystrophic epidermolysis bullosa patients. J Clin Invest $\underline{127}, 3028-3038$

Yamaguchi Y, Hayashi A, Campagnoni CW, Kimura A, Inuzuka T, Baba H (2012): L-MPZ, a novel isoform of myelin P0, is produced by stop codon readthrough. J Biol Chem $\underline{287}, 17765-17776$

Zainal Abidin N, Haq IJ, Gardner AI, Brodlie M (2017): Ataluren in cystic fibrosis: development, clinical studies and where are we now? Expert Opin Pharmacother 18, 1363-1371 


\section{Danksagung}

An dieser Stelle möchte ich mich bei all denjenigen bedanken, die mich während der Anfertigung dieser Doktorarbeit unterstützt haben. Mein besonderer Dank gilt meinem Doktorvater, Herrn PD Dr. rer. nat. S. Thoms, für die Möglichkeit diese Arbeit in seiner Arbeitsgruppe durchzuführen. Insbesondere der konstruktive Austausch in zahlreichen Gesprächen und das Korrekturlesen waren eine große Hilfe für mich. Ich danke auch besonders meiner Betreuerin, Frau Dr. rer. nat. J. Hofhuis, die mich täglich bei der Versuchsplanung und der Versuchsdurchführung unterstützte, stets ein offenes Ohr für meine Fragen hatte, mich immer ermutigte und mir insgesamt beim Verfassen dieser Arbeit eine große Unterstützung war. Bei Frau Prof. Dr. med. J. Gärtner möchte ich mich dafür bedanken, dass ich in ihrer Abteilung promovieren durfte. Mein Dank für die Einweisung und Bereitstellung des FACS-Geräts geht an die Mitarbeiterinnen und Mitarbeiter der pharmakologischen Abteilung der Universitätsmedizin Göttingen. Schließlich bedanke ich mich bei den medizinisch-technischen Assistentinnen und Assistenten des Stoffwechsel- und DNA-Labors für die technische Unterstützung in der Durchführung meiner Experimente. 